\title{
1 The Formation of Gullies on Mars Today
}

3 Colin M. Dundas ${ }^{\mathrm{a}}$ *

$4 \quad$ Alfred S. McEwen ${ }^{\mathrm{b}}$

5 Serina Diniega ${ }^{c}$

6 Candice J. Hansen ${ }^{\mathrm{d}}$

$7 \quad$ Shane Byrne

$8 \operatorname{Jim}$ N. McElwaine ${ }^{e, f}$

9

10

$11{ }^{a}$ Astrogeology Science Center, U.S. Geological Survey, 2255 N. Gemini Dr., Flagstaff,

12 AZ 86001, USA (cdundas@usgs.gov).

13 bunar and Planetary Laboratory, The University of Arizona, Tucson, AZ 85721, USA.

14 'Jet Propulsion Laboratory, California Institute of Technology, Pasadena, CA 91109,

15 USA.

16 dPlanetary Science Institute, St. George, UT 84770, USA.

17 ePlanetary Science Institute, 1700 E. Fort Lowell, Tucson, AZ 85719, USA.

18 fDurham University, Department of Earth Sciences, Durham, UK.

19

20

$21 *$ Corresponding author.

22 


\section{Abstract}

25 A decade of high-resolution monitoring has revealed extensive activity in fresh

26 Martian gullies. Flows within the gullies are diverse: they can be relatively light, neutral,

27 or dark, colorful or bland, and range from superficial deposits to 10 -meter-scale

28 topographic changes. We observed erosion and transport of material within gullies, new

29 terraces, freshly eroded channel segments, migrating sinuous curves, channel

30 abandonment, and lobate deposits. We also observed early stages of gully initiation,

31 demonstrating that these processes are not merely modifying pre-existing landforms. The

32 timing of activity closely correlates with the presence of seasonal $\mathrm{CO}_{2}$ frost, so the

33 current changes must be part of ongoing gully formation that is driven largely by its

34 presence. We suggest that the cumulative effect of many flows erodes alcoves and

35 channels and builds lobate aprons, with no involvement of liquid water. Instead, flows

36 may be fluidized by sublimation of entrained $\mathrm{CO}_{2}$ ice or other mechanisms. The frequent

37 activity has likely erased any features dating from high-obliquity periods, so fresh gully

38 geomorphology at middle and high latitudes is not evidence for past liquid water. $\mathrm{CO}_{2}$

39 ice-driven processes may have been important throughout Martian geologic history, and

40 their deposits could exist in the rock record, perhaps resembling debris-flow sediments. 
42 Gully landforms on Mars resemble water-formed features on Earth, with channels

43 transporting material from an alcove to a depositional apron. From their discovery (Malin

44 and Edgett, 2000), they have generally been interpreted as evidence for wet debris flows

45 or flowing liquid water (e.g., Carr, 2006). Such liquid would have major implications for

46 Martian climate, geology, the possibility of life, and the definition of Special Regions for

47 planetary protection (Rummel et al., 2014). Understanding the formation of gullies has

48 thus been a major focus of recent Mars science, as shown by the work in this volume.

49 Numerous hypotheses for gully formation have been considered. Martian surface

50 conditions are not favorable for the existence of liquid water, so initial models focused on

51 release of groundwater from shallow or deep aquifers (Malin and Edgett, 2000; Mellon

52 and Phillips, 2001; Gaidos, 2001), possibly aided by geothermal heating melting

53 permafrost (Hartmann, 2001; Hartmann et al., 2003) or the occurrence of brines (Knauth

54 and Burt, 2002). However, the occurrence of gullies on sand dunes and isolated peaks

55 argued against significant input from aquifers, and led to the development of models

56 based on insolation-driven melting of snow or shallow permafrost at times when the

57 obliquity of Mars was high (Lee et al., 2001; Costard et al., 2002; Gilmore and Phillips,

58 2002; Hecht, 2002; Christensen, 2003; Hartmann et al., 2003; Williams et al., 2009).

59 Alternative processes were considered, such as release of liquid $\mathrm{CO}_{2}$ from the subsurface

60 (Musselwhite et al., 2001), various $\mathrm{CO}_{2}$ frost-based hypotheses (e.g., Hoffman, 2002;

61 Ishii and Sasaki, 2004; Ishii et al., 2006), or purely dry flow with no volatile involved

62 (Treiman, 2003; Shinbrot et al., 2004), but were generally considered unlikely due to the

63 morphologic similarity between Martian gullies and water-formed terrestrial features. 
64 New flows were discovered in gullies by the Mars Orbiter Camera (MOC) on the 65 Mars Global Surveyor mission (Malin et al., 2006). Later observations showed that the 66 activity is seasonal (Harrison et al., 2009; Dundas et al., 2010), and at several locations 67 changes in gullies have been tightly constrained to occur around the time that seasonal 68 frost is present, indicating that they are driven by the frost (Reiss et al., 2010; Diniega et 69 al., 2010; Dundas et al., 2012; 2015b; Raack et al., 2015). Although seasonal melting of $70 \mathrm{H}_{2} \mathrm{O}$ frost was noted as a possible cause of activity (Reiss et al., 2010), $\mathrm{CO}_{2}$ frost is much

71 more abundant on Mars (e.g., Leighton and Murray, 1966). In combination with the

72 occurrence of assorted defrosting features in some gullies, this led Diniega et al. (2010)

73 and Dundas et al. $(2010 ; 2012 ; 2015 b)$ to suggest that $\mathrm{CO}_{2}$-driven processes were

74 responsible for the current activity, a possibility foreshadowed by early reports of $\mathrm{CO}_{2}$

75 defrosting and possible flow features in gullies (Bridges et al., 2001; Hoffman, 2002;

76 Hansen et al., 2007; Mangold et al., 2008). In a captioned image release, Malin and

77 Edgett (2005) also suggested that $\mathrm{CO}_{2}$ frost could be involved in an early example of

78 dune gully activity. Diniega et al. (2010) and Dundas et al. (2012; 2015b) argued that the

79 current activity could be actively forming dune gullies and "classic" Martian gullies, and 80 not merely modifying older water-formed features.

81 Seasonal frost deposits are prominent at middle and high latitudes on Mars. The

$82 \mathrm{CO}_{2}$ caps extend only to around $\pm 50^{\circ}$ latitude (e.g., Piqueux et al., 2015), poleward of

83 many gullies. However, localized frost on slopes occurs closer to the equator, at latitudes

84 where gullies are common. Recent mid-latitude surveys include examinations of Mars

85 Orbiter Camera (MOC) images by Schorghofer and Edgett (2006), and of near-IR

86 spectral data by Vincendon et al. (2010a, 2010b). Schorghofer and Edgett (2006) 
87 observed frost at latitudes as low as $24^{\circ} \mathrm{S}$, which they interpreted as $\mathrm{CO}_{2}$, although

88 visible-wavelength images cannot distinguish composition. Vincendon et al. (2010a,

$892010 \mathrm{~b}$ ) reported detections of $\mathrm{CO}_{2}$ frost at latitudes as low as $34^{\circ} \mathrm{S}$, and water frost

90 reaching $13^{\circ} \mathrm{S}$ and $32^{\circ} \mathrm{N}$. This hemispheric asymmetry in the occurrence of low-latitude

91 frost, also observed by Schorghofer and Edgett (2006), is caused by the occurrence of

92 southern winter solstice near aphelion, which makes the winter longer and colder. Dundas

93 et al. (2015b) reported a similar asymmetry in gully activity. Vincendon (2015) examined

94 near-infrared spectra of active gullies, and found that most were consistent with the

95 presence of $\mathrm{CO}_{2}$ frost at the time of gully activity. However, the relatively-bright gully

96 deposits were reported to form at times and places where $\mathrm{H}_{2} \mathrm{O}$ ice was expected but $\mathrm{CO}_{2}$

97 was less probable.

98 A variety of frost-driven hypotheses have been proposed to explain gully

99 formation or activity. Hecht (2002) suggested that abrupt heating of water frost could

100 enable it to melt before sublimating, providing a source of liquid. Kossacki and

101 Markiewicz (2004) modeled this process and proposed that melting could occur at a

102 given location on a single day of each Mars year, but only in trace amounts. $\mathrm{CO}_{2}$-driven

103 hypotheses have also been considered. Hoffman (2002) argued that basal sublimation

104 beneath $\mathrm{CO}_{2}$ could trigger mass movements, by avalanching and/or gas-lubricated flows.

105 Ishii and Sasaki (2004) and Ishii et al. (2006) also proposed that $\mathrm{CO}_{2}$ frost could

106 avalanche, eroding the surface and forming gullies. They suggested that this was

107 consistent with the orientations and global distribution of recent gullies, which closely

108 matched models for seasonal $\mathrm{CO}_{2}$ condensation. Hugenholtz (2008) suggested frosted

109 granular flow, whereby a small amount of surface frost reduces friction and enables 
110 granular flows. Cedillo-Flores et al. (2011) argued that sublimating $\mathrm{CO}_{2}$ could fluidize

111 overlying material, although they did not address the initial burial of the ice. Diniega et

112 al. (2013) suggested a model of sliding $\mathrm{CO}_{2}$ blocks for "linear" gullies on sandy slopes.

113 Pilorget and Forget (2016) modeled $\mathrm{CO}_{2}$ ice on gully slopes, and suggested that the

114 pressure rise from basal sublimation was capable of fracturing the ice and triggering mass

115 movements.

116 We analyzed the distribution of seasonal frost in the mid-latitudes in high-

117 resolution color images. This enables a meter-scale understanding of the behavior of the

118 frost and its association with landforms. We compare these frost data with observations

119 of gully activity and its morphological effects, expanding the survey of Dundas et al.

120 (2015b). Finally, we discuss the implications of this work for the formation and evolution

121 of gullies on Mars.

122 Following common practice, we use the term gully or gully landform for the

123 alcove-channel-apron assemblages on Mars reported by Malin and Edgett (2000),

124 although under terrestrial definitions (e.g., Neuendorf et al., 2005) "gulch" or "ravine"

125 would be more accurate for many of these kilometer-scale features. Additionally,

126 although terrestrial "debris flows" are commonly defined as wet flows with a wide range

127 of grain sizes (e.g., Iverson, 1997; Turnbull et al., 2015), this usage is not always

128 followed in planetary science, so we refer to "wet" or "aqueous" debris flows to

129 emphasize this aspect. We use the Mars Year calendar defined by Clancy et al. (2000).

130 Seasons are referred to by the areocentric longitude of the sun $\left(L_{S}\right)$, where $L_{S}=0^{\circ}$ is the

131 northern vernal equinox. Mars Year 0 (MY 0) began at $\mathrm{L}_{\mathrm{S}}=0^{\circ}$ on May 24, 1953. 


\section{Data and Methods}

134 Data

135 The primary data set for this work was images acquired by the High Resolution

136 Imaging Science Experiment (HiRISE; McEwen et al., 2007) on board the Mars

137 Reconnaissance Orbiter (MRO) spacecraft (Zurek and Smrekar, 2007). HiRISE images

138 are typically 5-6 km wide, with a central swath in three colors (red, blue-green (BG), and

139 near-infrared) in the central $20 \%$ of the image, and a pixel scale of $25-60 \mathrm{~cm}$. Delamere

140 et al. (2010) provide more information about HiRISE color imaging. The Reduced Data

141 Records (RDRs) used in this study are map-projected at a scale of 25 or $50 \mathrm{~cm} /$ pixel (or

142 rarely $1 \mathrm{~m} /$ pixel). The Sun-synchronous MRO orbit constrains the local time for mid-

143 latitude images to be near 3 PM. Incidence angles vary primarily with season.

144

145 Frost Survey

146 In order to survey mid-latitude frost, we selected a data set from HiRISE images

147 acquired before $\mathrm{LS}_{\mathrm{S}}=0^{\circ}$ of MY 33, roughly 4.5 MY after the start of the MRO mission.

148 (Transition Orbit imaging occurred between $\mathrm{L}_{\mathrm{S}}=114-116^{\circ}$ of MY 28, and Primary

149 Science Phase began at $\mathrm{L}_{S}=132^{\circ}$.) The images were chosen from the HiRISE "science

150 themes" of Seasonal, Mass Wasting, Fluvial, and Impact Processes (McEwen et al.,

151 2007). These themes were selected because they specifically target gullied locations and

152 other steep slopes such as fresh craters with repeat coverage. Some gullies or steep slopes

153 occur in other themes, but these constitute a sufficient sample. Images with significant

154 atmospheric haze were discarded. We chose data from an envelope of latitude and $\mathrm{L}_{\mathrm{s}}$ that

155 encompasses the infrared observations of water frost by Vincendon et al. (2010a) for 
156 latitudes $25^{\circ}-60^{\circ}$ in each hemisphere. This encompasses the range of most "classic"

157 gullies, including those with well-studied activity. Water frost is also observed at lower

158 southern latitudes (Vincendon et al., 2010a), and some equatorial gullies have been

159 documented (e.g., McEwen et al., 2014; Auld and Dixon, 2016), but their activity has not

160 been well studied. We focused on the mid-latitudes for the present study, and discuss the

161 implications for equatorial gullies below. Frost is especially abundant in polar gullies.

162 We used only the color RDR observations, because frost can be indistinct in the

163 red filter-only portion of the image (i.e., although it is often possible to determine that

164 frost is present in the red-filter images, it is difficult to be confident that it is not present

165 when not observed). With only three color bands, it is difficult to conduct an automated

166 search for spectral features of $\mathrm{H}_{2} \mathrm{O}$ or $\mathrm{CO}_{2}$ frost in HiRISE data. Color ratios and

167 brightnesses characteristic of frost in the BG bandpass may not be sufficiently unique for

168 confident identification, especially in shadows or for small frost patches, which are some

169 of the cases of most interest here. (An automated frost-detection algorithm developed by

170 the HiRISE team for use in color adjustments is generally successful but commonly

171 misses small frost patches or those in shadow.) The large size of the images also makes it

172 impractical to manually search the entirety of every image at full resolution, even in our

173 limited data set. Instead, we focused on the upper parts of steep slopes, particularly those

174 with gullies as well as non-gullied slopes of a similar size and (apparent) steepness.

175 Images lacking such slopes were ignored. We also excluded sites with excessively

176 complex topography (such as certain rugged crater central peaks), because those sites are

177 time-consuming to search, have ambiguous slope orientations when stereo data are not

178 available, and may have unusual thermal environments due to complex slope interactions. 
179 These considerations also led to the exclusion of dune field slopes. Impact craters less

180 than $1 \mathrm{~km}$ in diameter were also omitted; frost and gullies do occur in such craters and on

181 dunes, but this provided an objective cutoff and limited the data set to a manageable size.

182 The resulting data set is dominated by impact crater slopes, with a few other significant

183 scarps included.

184 Once these constraints were applied, we examined the remaining steep slope 185 segments at the full RDR resolution to look for frost. Images were locally stretched as

186 needed to enhance the color contrast, including in shadows. Although many cases are

187 obvious, small patches of trace frost require some interpretation to rule out the presence

188 of relatively-bright, relatively-blue lithic material. We interpreted as frost any surface

189 material that appears distinctly "white" or bright "blue" in a stretched three-color HiRISE

190 image (i.e., bright in all three bands or in the blue-green band), and that does not appear

191 to be rock, sand, etc., based on morphology and geologic setting. (For instance,

192 relatively-blue material dominating an equator-facing slope is unlikely to be frost except

193 in cases where frost is ubiquitous. Sand deposits are likely to be rippled and relatively

194 dark.) Frost commonly has very strong associations with small-scale topography, so

195 bright material fringing topographic features or occupying particular slope facets is likely

196 to be frost. For some uncertain cases where summer images were available, we compared

197 the two. Features that persisted in summer images were assumed to be relatively-blue

198 lithic material, although it is possible that in rare instances perennial ground ice could be

199 exposed. Distinguishing diffuse frost from atmospheric haze can also be problematic, but

200 the latter is indifferent to surface topography. In some cases, we interpret other coloration

201 as frost based on context. The most common of these was in times and places where frost 
202 is very widespread, and may be translucent and/or dirty in the area of interest. In

203 combination with a lack of defrosted surfaces for contrast, this can make frost coloration

204 less distinctive. With only three broad color channels, it was not possible to distinguish

205 between $\mathrm{H}_{2} \mathrm{O}$ and $\mathrm{CO}_{2}$ frost.

206 Slopes were divided into eight $45^{\circ}$ octants and we recorded the presence or

207 absence of frost on slopes in each octant in each image. We subdivided these

208 observations into alcove and non-alcove slopes, where alcove slopes are the interiors of

209 moderately- to well-developed gully or gully-like alcoves. Shallow alcoves and other

210 slope irregularities were grouped with non-alcove slopes. Since high-resolution

211 topography is only available for a small fraction of sites, slope direction was estimated

212 from the RDR images. In cases where a slope was predominantly facing direction $\mathrm{X}$ but

213 just barely curved into the next octant, only direction $\mathrm{X}$ was recorded. This ensured that

214 those small slivers, which do not fully capture the frost conditions for their nominal slope

215 orientation, would not be an excessive fraction of the data. The relevant direction is the

216 downhill orientation of the slope on the scale at which gullies develop, because we are

217 interested in the geomorphic evolution of gullies. For instance, a hollow with frost on a

218 small southward slope facet of a generally east-facing slope was recorded as east-facing

219 frost, because such frost could contribute to the formation of east-facing gullies. We also

220 noted the presence of spots or flows superposing the frost, associated with active

221 defrosting (cf. Kieffer, 2007; Hansen et al., 2010; Thomas et al., 2010).

222 Some of the seasonal ice that we classified as frost may actually have been

223 deposited by precipitation, as snow. Snowfall contributes an estimated $3-20 \%$ of the

224 mass of the $\mathrm{CO}_{2}$ cap at $70-90^{\circ} \mathrm{S}$ latitude (Hayne et al., 2014). We have no reliable way to 
225 distinguish the two in HiRISE data, and refer to all seasonal ice as frost in order to

226 distinguish it from ground ice, which is also likely present in the subsurface near many

227 gullies.

228 Some frost was likely missed by this survey, for several reasons. Small frost

229 patches or diffuse thin frosts might not produce distinct color and albedo changes, and

230 dust could also reduce the contrast. Frost can also be transparent or translucent at visible

231 wavelengths under some conditions. Additionally, frost in shadow can be more difficult

232 to recognize due to illumination by scattered light only. We recorded frost as possible in

233 cases where there were candidate patches but we were not confident of the interpretation.

234 This most commonly occurred in shadows or small diffuse patches. If the image quality

235 in shadow was too poor for any useful interpretation, the shadowed slope was excluded.

237 Gully Activity Survey

238 We updated the gully activity survey of Dundas et al. (2015b) with 1.5 Mars years

239 of additional data, through MRO orbit 48999 . This both added many new monitoring

240 sites and extended the time record for many individual gullies. In a handful of cases, we

241 have not used the most recent available image, generally because it was poorly

242 illuminated. The methods follow those in Dundas et al. (2015b). Briefly, HiRISE images

243 of the aprons and lower channels at a reduced resolution of $1 \mathrm{~m} /$ pixel were blink-

244 compared to look for changes. Monitoring sites are those gully sites poleward of $25^{\circ}$

245 latitude in each hemisphere with HiRISE image coverage separated by at least 4000

246 MRO orbits (roughly ten months). Images from each site were compared against the most

247 similar older images to produce optimal comparisons spanning the full time interval for 
248 each site. Although in some instances the lighting and image geometry were significantly

249 different, it is possible to detect changes even in non-ideal cases. However, some number

250 of changes are missed. This is emphasized by the occasional observation of changes that

251 can be dated with older images, but only after they are detected in more recent data with

252 better conditions for comparison. This is an inherent limitation of the data and implies

253 that the activity rates here are a lower bound. Thin, transient albedo changes with no

254 meter-scale topographic effects are particularly likely to be missed, but more substantial

255 changes may be unseen (or not considered confirmed) when the available images have

256 dissimilar lighting or viewing geometry.

257 Martian gullies (Fig. 1) are often divided into dune gullies and non-dune gully

258 landforms. Dune gullies have often been neglected in efforts to understand the formation

259 of "classic" gullies (alcove-channel-apron morphology) on crater walls and other steep

260 slopes. "Linear dune gullies" like those in Russell crater (Mangold et al., 2003; Reiss and

261 Jaumann, 2003) do have a distinctive appearance in that they lack aprons and often have

262 terminal pits (Fig. 1e), but many dune gullies have the classic alcove-channel-apron

263 morphology (Fig. 1f). Additionally, dune and non-dune gullies are more gradational than

264 commonly appreciated (Fig. 1b-d). Here we have included the gradational forms with the

265 main survey. Both types of dune gully are commonly active, and due to the number of

266 changes we did not attempt to catalog all events on the dunes. However, dune gullies

267 with classic morphology likely form by the same processes as similar crater-wall gullies,

268 so we document several examples with prominent morphologic changes.

\section{Observations}


272 The southern-hemisphere seasonal frost distribution in HiRISE data (Fig. 2) is

273 broadly consistent with the observations of water frost by Vincendon et al. (2010a).

274 Those water frost observations approximately define the occurrence envelope of seasonal

275 frost on Mars, because water ice has a broader spatial and temporal distribution

276 (Schorghofer and Edgett, 2006; Vincendon et al., 2010a, b). However, $\mathrm{CO}_{2}$ dominates the 277 mass percentage of the frost except at the very fringes of $\mathrm{CO}_{2}$ deposition (e.g., Leighton 278 and Murray, 1966; Vincendon, 2015), as the minor atmospheric species $\mathrm{H}_{2} \mathrm{O}$ forms only

279 very thin deposits at any latitude. Some seasonal water frost occurs at lower latitudes than 280 the $25^{\circ} \mathrm{S}$ cutoff in this study (Vincendon et al., 2010a). The relationship between frost

281 and slope orientation is as expected: frost was most commonly observed on pole-facing 282 slopes, and the spatial and temporal occurrence expands at higher latitudes. Frost is 283 strongly affected by topography even at very small scales, occurring in the most-sheltered 284 slope facets. Such local effects enable frost to occur even on broadly equator-facing 285 slopes (Fig. 3).

286 We did not include the highest-latitude gullies in this survey because images are 287 concentrated at only a few locations. However, those locations have been imaged 288 frequently and demonstrate widespread defrosting spots and flows (Fig. 4; see also 289 Dundas et al., 2012). Sublimation activity at particular locations is similar from year to 290 year, but does not repeat exactly.

291 Defrosting spots and flows occur in the latter part of the frost season, as the frost 292 is being removed. These sublimation features were most commonly observed at higher 
293 latitudes, and are rare equatorward of $\sim 40^{\circ} \mathrm{S}$. Defrosting spots and flows commonly show 294 a strong concentration within alcoves and channels.

295 Data in the northern hemisphere were sparse due to the lower abundance of 296 gullies and steep slopes on the northern plains. Frost was only observed poleward of $297 \sim 35^{\circ} \mathrm{N}$, consistent with near-infrared spectral observations of water frost by Vincendon et 298 al. (2010a). Defrosting spots and flows are also rare.

\section{Gully Change Survey}

301 The extended change survey (Fig. 5) reveals that gully activity is common, 302 particularly in gullies in the southern highlands. Over the full monitoring survey, $20 \%$ of 303 gully sites south of $25^{\circ} \mathrm{S}$ have shown activity with before-and-after HiRISE coverage, 304 compared with $5 \%$ north of $25^{\circ} \mathrm{N}$, and multiple events at particular sites are more 305 common in the south as well. The number of winter solstices spanned by HiRISE 306 observations was 2.9 per site in the southern hemisphere, compared with 2.5 in the north, 307 so northern activity may be slightly underrepresented but not by enough to explain this 308 difference. These figures include gullies on sand-covered non-dune slopes, but not dune 309 gullies. Monitoring sites are preferentially those with fresh gullies and steep slopes,

310 which are likely to be the most active, but do include less pristine gullies as well.

311 (Possible biases are discussed extensively in Dundas et al. (2015b); the expanded data set 312 herein has the same general characteristics.) In addition to being more frequent, activity 313 in the south is more geomorphically effective, as most of the observed changes in the 314 north are superficial (little or no topographic change resolvable by HiRISE). Several sites 315 and even individual gullies have experienced multiple flows (at least sixteen mass 
316 movements have occurred in Gasa crater over five Mars years), but the overall level of

317 activity suggests that recurrence intervals in individual gullies are on the order of

318 centuries. Dune gullies are particularly active, with annual changes in some cases, but

319 numerous non-dune gully sites have also seen repeated changes. The timing of some

320 flows can be constrained to within a few weeks, while other intervals span a Mars year or

321 more. When well-constrained, gully activity is closely correlated with seasonal frost,

322 particularly the latter part of the frosted season (Fig. 6).

323 The features of the various gully changes are diverse. The mass movements range

324 from barely resolved to kilometers long, from superficial albedo changes to major erosion

325 and deposition, and can be bright, dark, colorful, or neutral in tone. Here we describe

326 flows from source to sink and the various morphological effects that occur, with the

327 understanding that there are exceptions to most general statements. Additional examples

328 of changes are shown in the following section.

329 The detectable sources of individual events are usually small and indistinct. We

330 search for changes by making comparisons of the aprons and channels, where they are

331 most visible. When events were traced up towards the source, the effects typically

332 become more subtle, and may appear disconnected, although it is likely that there are

333 simply unresolved changes uniting the flow, or the flow passed through with little effect.

334 The typical plan form is best seen by examining flows that have covered or disturbed

335 seasonal frost, which makes the entire shape of the flow distinct even where erosion and

336 deposition are superficial (Fig. 7). These flows were virtually point-source features,

337 which descended down channels before producing much larger terminal effects. Some 
338 flows do have larger, distributed source areas, although this could represent collapse

339 propagating from a smaller initial failure.

340 Lower in the flow path, the morphological effects become more prominent.

341 Changes in the channels are common. Some of these are obviously erosive or

342 depositional, although in other cases there are distributed changes that have clearly

343 altered the morphology but where the net local effect is not clear at HiRISE resolution.

344 However, the formation of terminal deposits requires that material be eroded further up

345 the slope, so the overall effect is to erode material from the alcoves and/or channels,

346 resulting in net transport down the channel bed to the apron. Transport and deposition of

347 meter-scale boulders is common in the larger events.

348 Deposition occurs in the lower reaches of the flows. Sometimes deposits end

349 within existing channels; others reach beyond and onto the apron. The deposits are highly

350 variable: some form thick lobate deposits, while others appear superficial at HiRISE

351 resolution. The flows can deposit boulders or bury existing rocks in finer material, so

352 boulder density is not necessarily an indicator of freshness or rock breakdown (as

353 proposed by de Haas et al., 2013). Lobate features are not necessarily at the farthest point

354 of the deposit, and disturbances and changes can reach beyond obvious lobate flows. The

355 deposits can be brighter or darker than their surroundings, but can also be near-neutral in

356 HiRISE red-filter images. Likewise, some deposits are distinct in color while others

357 closely match the existing surface. Deposits that appear relatively-blue in HiRISE

358 enhanced color are almost always darker than their surroundings in the red-filter images,

359 while those that appear yellow are brighter. 
Flows retain distinct color or albedo for varying lengths of time. For instance, the

361 two bright deposits reported by Malin et al. (2006) formed no later than MY 27 and

362 remained obvious in HiRISE images from MY 33. Other flows mostly fade within a Mars

363 year, reflecting more effective local resurfacing, likely dust deposition. Some flows are

364 only distinct while shadowed (Dundas et al., 2012; 2015b). These are demonstrably

365 active events because the patterns change from year to year at individual sites, despite

366 similar lighting. However, they have unresolvable effects on the color and relief of the

367 surface. Other, similar flows are most distinct in winter shadow but produce very minor

368 changes in well-lit images, demonstrating a gradation with more typical activity. Such

369 flows may be minor activity that was distinct because of contrast with traces of frost,

370 analogous to the more obvious flows over frost observed elsewhere (Fig. 7), but produce

371 changes that are minimal at HiRISE resolution in well-illuminated images. Alternatively,

372 they could be extremely thin flows that produced only short-term albedo differences.

373 They may be under-reported because we have not searched for them in all shadowed

374 images, as well as the inherent difficulty of observing features in deep shadow.

375 Although most of the changes occurred within defined gullies, some appear to be

376 the initial stages of gully formation. A pair of flows in Raga crater followed a crease in

377 the topography, which was so ill-defined in the earliest images of the site that it would

378 likely have been omitted by gully surveys. After two events, the channel became notably

379 more visible and connected (Fig. 8), progressing towards the appearance of better-defined

380 gullies a short distance away. Both of these changes occurred in fall or winter, making

381 them quite distinct from the Recurring Slope Lineae (RSL) found in the same crater in

382 the warm seasons on more equator-facing slopes (McEwen et al., 2011). 
384 (Diniega et al., 2010). For example, a single large dune gully in Matara crater (Fig. 1f)

385 has experienced major mass movements in every winter since the start of HiRISE

386 observation. Such gullies can be fundamentally reworked within a few years. Fig. 9

387 shows a gully on a large dune west of the Argyre basin. Over three Mars years, the

388 system transitioned from a degraded alcove and infilled channel to a sharp, fresh alcove 389 feeding a 500-m-long, 20-m-wide, terraced channel.

\section{Interpretation}

\section{Processes Causing Current Activity}

393 The timing of numerous well-constrained gully events points to seasonal frost as

394 the cause or trigger for current flows in gullies. Other possible seasonally-controlled

395 drivers are inconsistent with the observed temporal behavior. Groundwater release could 396 be seasonal, but should favor summer (Goldspiel and Squyres, 2011) and is extremely

397 unlikely on sand dunes or isolated peaks. Aeolian processes are most active at maximum 398 atmospheric pressure, during southern summer (Ayoub et al., 2014). RSL are most active 399 in the warmest seasons (McEwen et al., 2011; 2014). These options are out of phase with 400 the season of most observed gully flows. In contrast, the observed timing of activity is 401 highly correlated with the presence of seasonal frost.

402 Fine details of the distribution of visible frost further support seasonal frost as the 403 trigger for activity. Penticton crater has frost on a broadly equator-facing slope at an 404 unusually low latitude $\left(38.4^{\circ} \mathrm{S}\right)$, and a rare example of an equator-facing new gully 405 deposit at that latitude (Fig. 3). This coincidence suggests that the frost could have been 
406 the trigger for the Penticton flow. The steep slopes and morphology of the deposit are

407 considered consistent with dry flow (Pelletier et al., 2008), so a trigger by this small

408 amount of frost is possible. If this is the case, the minimum frost amount required to

409 trigger mass movements may be very low, but with only one example we cannot establish

410 whether this flow was caused by frost or was simply a random volatile-free event.

411 Volatile-free mass wasting must occur on Mars and a few likely examples have been

412 observed outside of gullies, but the frequency is unknown.

413 Liquid flow due to melting water frost is excluded as the cause of current

414 changes, for several reasons. First, melting is extremely difficult on present-day Mars.

415 Ingersoll (1970) pointed out that the latent heat losses to sublimation are so high that

416 insolation at the orbit of Mars is insufficient to melt ice. Even at temperatures below 273

$417 \mathrm{~K}$, the evaporative cooling removes more heat than can possibly be supplied by the Sun,

418 precluding warming to the melting point. Hecht (2002) suggested that under certain

419 circumstances (rapid heating, a lowered melting point, and low effective emissivity due

420 to heat input from alcove walls), water ice could be melted. Kossacki and Markiewicz

421 (2004) modeled such a scenario and suggested brief melting episodes during defrosting,

422 producing $<1 \mathrm{~kg} / \mathrm{m}^{2}$ of melt. However, their model significantly underestimates

423 evaporative cooling since it included only forced-convection (wind-driven) sublimation.

424 For the assumed wind speed of $5 \mathrm{~m} / \mathrm{s}$, free convection is a factor of 2-4 stronger at 270

$425 \mathrm{~K}$, depending on the atmospheric pressure (cf. Dundas and Byrne, 2010). This is likely to

426 prevent even this limited melting. Second, the atmospheric pressure at many of the active

427 locations is below the triple point pressure. Finally, the expected thickness of $\mathrm{H}_{2} \mathrm{O}$ frost

428 deposits is small, likely no more than a fraction of a millimeter (Vincendon et al., 2010b; 
429 Vincendon, 2015). Such negligible amounts would not flow through or over a porous

430 medium even if they melt somehow.

431 Boiling of small volumes of brine in the shallow subsurface (Massé et al., 2016) is

432 possible, if the brine is present and does not evaporate. (Melting and boiling pure

433 subsurface ice suffers from the same difficulties as surface frost.) Conditions for

434 deliquescence to produce such brine occur on Mars (e.g., Gough et al., 2011), but if such

435 brines form from deliquescence, the available volumes would be extremely limited

436 because the Martian atmosphere is very dry, and in the winter $\mathrm{H}_{2} \mathrm{O}$ will be cold-trapped at

437 the surface rather than in the subsurface. If such a process occurs on Mars, it is likely to

438 involve much less water than the flows generated in the laboratory by Massé et al.

439 (2016), but could serve as a trigger for dry flows. However, it should not occur when $\mathrm{CO}_{2}$

440 ice is present on the surface, which buffers the local temperature to the frost point; $\mathrm{CO}_{2}$

441 was definitely present for some of the observed activity with the best time constraints. In

442 sum, the strength of the deliquesced brine for realistic Martian conditions is unknown,

443 and the seasonal timing of activity does not support this process in gullies. Instead, it is

444 likely that activity is caused by processes with no melting or liquid present.

445 Pilorget and Forget (2016) modeled the possibility that basal sublimation and

446 rising pressure beneath $\mathrm{CO}_{2}$ ice trigger gully activity, developing an idea considered by

447 Hoffman (2002) and Ishii et al. (2006); this is essentially the "Kieffer model" that

448 produces high-latitude defrosting spots (e.g., Kieffer, 2000; 2007; Piqueux et al., 2003;

449 Hansen et al., 2010; Thomas et al., 2010). However, gully activity is common between

$45030-40^{\circ} \mathrm{S}$, where we rarely observed defrosting spots or flows. Does this contradict the

451 basal sublimation model? It is possible that at lower latitudes, spots are small or short- 
452 lived and difficult to observe, particularly in the shadowed, rugged topography of gullies.

453 It is also possible that gas ejection in gullies rarely moves silicate material—steep alcoves

454 may have smaller amounts of loose fine material than the polar regions. In this case, gas

455 ejection might have no tangible effect except when it triggers rare, stochastic, larger-scale

456 failures leading to the observed mass movements. The model is supported in higher-

457 latitude gullies, where spots and flows are common and recur every Mars year (Fig. 4;

458 see also Dundas et al. (2012)). These flows can be considered bedload transport along a

459 channel, albeit in unfamiliar form. The volumes transported annually may be small (the

460 flows have no visible relief in HiRISE images), but the high frequency could make this a

461 significant process in gully evolution where it occurs.

462 Although the basal sublimation model is consistent with activity in high-latitude

463 gullies and can potentially cause lower-latitude activity, it is probably not the only

464 significant frost process. The small abundances and patchy distribution of the lower-

465 latitude frost are not conducive to gas trapping, and may prevent the $\mathrm{CO}_{2}$ pressurization

466 process from being as efficient as modeled. Additionally, Vincendon (2015) reported that

467 some gullies with activity, particularly those with bright deposits, have $\mathrm{H}_{2} \mathrm{O}$ frost but no

468 detectable $\mathrm{CO}_{2}$. $\mathrm{CO}_{2}$ may yet be detected by future observations of those sites, occur at

469 night (cf. Piqueux et al., 2016) or in unresolved patches, or be concealed by coatings of

470 water frost. However, the occurrence of gully activity at locations where frost abundances

471 are low suggests that other trigger mechanisms contribute to activity; these are not

472 mutually exclusive. The point-source initiation of some flows that disturb frost (Fig. 7)

473 suggests avalanching (cf. Hoffman, 2002; Ishii and Sasaki, 2004; Ishii et al., 2006). This

474 could occur within granular frost without any gas pressure, although gas pressure would 
475 be an effective way to trigger avalanches (Hoffman, 2002; Ishii et al., 2006). Another

476 possibility is frosted granular flow (Hugenholtz, 2008), although the morphology of

477 terrestrial examples is a poor match for Martian gullies (Harrison, 2016). Slope failures

478 might also be triggered by deposition and sublimation of small amounts of frost on steep

479 alcove slopes, picking up material as they descend. Such a process would be more

480 effective if any frost is deposited between the grains, so that sublimation can dislodge

481 material (cf. Sylvest et al., 2016), and might be most effective in early or late winter

482 when frost is patchy and has uneven effects on the surface.

483 Why do $\mathrm{CO}_{2}$-triggered gully flows produce morphologies distinct from typical

484 terrestrial mass wasting? One possibility is that terrestrial geomorphologies are

485 dominated or overprinted by other processes. Another possibility is that gas fluidization

486 from frost makes the flows more mobile than simple granular flow, as suggested by

487 Hoffman (2002). Cedillo-Flores et al. (2011) showed that sand or dust superposed on top

488 of $\mathrm{CO}_{2}$ frost on Mars could be fluidized by sublimation driven by heat fluxes of tens of

$489 \mathrm{~W} / \mathrm{m}^{2}$, at which point the upward gas flow overcomes the weight of the particles.

490 However, their model proposed that the mobilized material was aeolian sediment

491 superposed on the frost and heated by the Sun. This resembles the behavior of defrosting

492 flows creeping within some gullies (Fig. 4), but is unlike the observed point-source flows

493 modifying bare frost (Fig. 7) and has no mechanism for erosion of the surface. To date,

494 we have not observed any indication that aeolian processes are an important precursor to

495 gully mass movements in general (as proposed by Treiman (2003)), although sand

496 movement certainly affects dune gullies. Some flows clearly mobilize boulders, not just

497 aeolian materials. Pilorget and Forget (2016) suggested that the gas generated by basal 
498 sublimation underneath frost could also serve to fluidize the flows, but there are few

499 defrosting spots in the lower-latitude active gullies. Additionally, some activity occurs in

500 early winter while $\mathrm{CO}_{2}$ is condensing and gas pressure should be low.

501 We suggest a related alternative, in which gas generation occurs via two effects

502 within a mix of sediment and $\mathrm{CO}_{2}$ ice tumbling down a gully. First, the potential energy

503 of falling material is initially converted to kinetic energy but must ultimately dissipate as

504 heat (Iverson, 1997), or latent heat loss (sublimation) if buffered at the $\mathrm{CO}_{2}$ frost point

505 temperature. The available energy is $3.7 \mathrm{~J} / \mathrm{kg}$ per meter of descent, for Martian gravity.

506 For a typical vertical fall of $300 \mathrm{~m}$, this amounts to $1100 \mathrm{~J} / \mathrm{kg}$. Second, eroded sediment

507 from the shallow subsurface will be at least slightly warmer than the ice (especially if gas

508 pressure has risen, causing a higher frost point), and could cause additional sublimation

509 (Hoffman, 2002). Warmer material can also be entrained when flows pass into unfrosted

510 areas. Mixing within the falling material will allow this heat to be transferred to the $\mathrm{CO}_{2}$

511 frost, causing sublimation. Lithic material at only a few $\mathrm{K}$ above the frost point

512 temperature could make several thousand $\mathrm{J} / \mathrm{kg}$ available, and defrosted areas could be

513 tens of degrees warmer. Hence, this is potentially even more important than the kinetic

514 energy effect, and dramatically so in conditions where the flow is able to incorporate

515 much warmer materials, although not all of the heat transfer need occur while the

516 material is flowing. Thus, there is likely at least $\sim 10^{3} \mathrm{~J} / \mathrm{kg}$ of energy to be dissipated in

517 typical gully flows, or $\sim 10^{6} \mathrm{~J} / \mathrm{m}^{3}$ for a porous mixture of frost and lithic material. If the

518 flow distance is $1 \mathrm{~km}$ at a velocity of $10 \mathrm{~m} / \mathrm{s}$ (plausible values for gullies in Hale crater

519 (Kolb et al., 2010a), which are now known to be active) then the heat used in gas

520 generation could be up to $10^{4} \mathrm{~W} / \mathrm{m}^{3}$, producing a vapor flux equivalent to $10^{4} \mathrm{~W} / \mathrm{m}^{2}$ for a 
521 1-m-thick flow if all spent on sublimation. This is a highly transient phenomenon, so this

522 power is only generated briefly. The high energy dissipation in the gully flows is possible

523 because it is distributed through the entire volume of the flow, and is not a radiant heat

524 flux, but it is converted to per-area units here for comparison with the values from

525 Cedillo-Flores et al. (2011). Since we are estimating the energy directed into sublimation,

526 equal energy fluxes imply identical gas fluxes. If no $\mathrm{CO}_{2}$ were present and this energy

527 was expended on warming lithic material rather than sublimating frost, the temperature

528 rise during the flow would be $<2 \mathrm{~K}$. Sublimation could occur within the flow, or at the

529 base if it runs over frost. There is undoubtedly some efficiency factor since not all energy

530 will be expended on sublimation: some energy will be lost to the surroundings, and some

531 kinetic energy could warm the lithic component of the gully flow out of equilibrium with

532 the $\mathrm{CO}_{2}$ ice. (However, acting in the other direction, addition of energy from warmer

533 rocks and sediment could increase the gas generation by an order of magnitude or more

534 over these estimates.) Moreover, the values suggested by Cedillo-Flores et al. (2011) are

535 lower bounds on the flux needed in this scenario, since some of the gas is generated

536 within the flow, which would cause a range in fluidity with height. However, if even a

537 few percent of this energy goes into frost sublimation, the fluxes indicated by Cedillo-

538 Flores et al. (2011) are easily exceeded, so some amount of fluidization is likely.

539 Complete fluidization is not necessary to explain the Martian gully flows. The fan

540 deposits of gullies are moderately steep and sometimes consistent with no gas fluidization

541 (Kolb et al., 2010b), and it is likely that a spectrum of behaviors occurs even within

542 individual gullies. 
544 terrestrial mass movements, although they resemble processes that occur in ignimbrites

545 and pyroclastic flows (cf. Branney and Kokelaar, 2002). We predict that, all else being

546 equal, greater fluidization will correlate with thicker flows (greater gas flux per unit area,

547 and gas escape timescales will follow the square of flow thickness per Darcy's Law),

548 finer grain size (more effective transfer of heat from sediment to frost, greater ease of

549 mobilization, and slower gas escape due to reduced permeability), flows that incorporate

550 warm sediment well above the frost point (more likely later in the season), and flows with

551 a greater vertical fall distance (more available energy per unit mass). Cohesion of dust

552 and rapid cooling of small grains may reduce the effect of very fine grains (Cedillo-

553 Flores et al., 2011). There may also be a correlation with a higher proportion of frost

554 within the falling material, although if heat extraction from eroded material is important

555 there might be an optimal ratio rather than a monotonic increase. High frost fractions

556 could result in rapid (almost explosive) sublimation and high mobility similar to a

557 suspension current, but might also result in swift gas loss causing the flow to stop. The

558 frost/lithic ratio is not measurable with current data, but could correlate with latitude and

559 season. Notably, of five gully sites studied by Kolb et al. (2010b), the highest-latitude site

560 (at $46^{\circ} \mathrm{S}$ ) had some of the most fluidized deposits. The efficiency factor is unknown and

561 probably variable, depending on factors such as the grain sizes (also an important factor

562 in the flux needed to cause fluidization) and the ratio of frost to lithic material.

563 Experimental work is needed to determine how effective these processes would be under

564 Martian conditions. Active fluidization during flow would have been difficult to observe

565 in previous experiments on $\mathrm{CO}_{2}$ frost flows (e.g., Sylvest et al., 2016), but those small- 
566 scale experiments demonstrate that sublimation of $\mathrm{CO}_{2}$ within sand can trigger flows on 567 slopes well below the dynamic angle of repose.

568 In light of these observations, we propose the following model for the relationship

569 between frost and gully activity. Gully mass movements are initiated by seasonal frost

570 through several mechanisms. Of these, the defrosting-pressurization model suggested by

571 Hoffman (2002) and Pilorget and Forget (2016) is directly supported in higher-latitude

572 gullies, but other mechanisms are probably also involved at lower latitudes. Point-source

573 flows resemble the initiation of avalanches, and small amounts of frost may be enough to

574 trigger some activity simply by dislodging grains. Frost blocks and dark halos observed

575 in linear gullies (Pasquon et al., 2016) (Fig. 10) suggest that that distinctive morphology

576 is produced by sliding slabs of ice (Diniega et al., 2013). In other gullies, the relative

577 importance of the various processes is probably variable, particularly as a function of

578 latitude and other local conditions that affect frost condensation, such as alcove

579 topography. These processes result in flows with varying mixtures of frost and entrained

580 regolith descending down a channel, eroding and depositing in accordance with the flow

581 velocity and interactions with local topography and overall slope. If small amounts of

582 frost are capable of triggering mass movements, $\mathrm{H}_{2} \mathrm{O}$ frost may initiate flows in some

583 cases, although not by melting. However, it would not be able to fluidize flows in the

584 manner proposed for $\mathrm{CO}_{2}$, so such flows would behave like volatile-free mass

585 movements. The correlation between $\mathrm{CO}_{2}$ frost and prominent gullies suggests that $\mathrm{CO}_{2}$

586 is much more important. This is unsurprising, since $\mathrm{CO}_{2}$ frost is typically several orders

587 of magnitude more abundant than $\mathrm{H}_{2} \mathrm{O}$. Equatorial water frost does occur, as do

588 equatorial gullies, but the latter are typically poorly developed and were not reported in a 
589 global survey of $6 \mathrm{~m} /$ pixel Context Camera images (Harrison et al., 2015). The

590 concentration of prominent gullies on mid-latitude pole-facing slopes is consistent with

$591 \mathrm{CO}_{2}$ as the major driver of erosion and cause of fluidized gully flows.

592 One northern-hemisphere gully alcove (Fig. 11) showed a pattern of spots with

593 brightness and color suggestive of frost or ice, sufficiently late in the spring that frost is

594 unlikely. The pattern of spots varies somewhat from year to year and the spots become

595 less distinct over the spring. The alcove is cut into mid-latitude mantle material

596 interpreted to be ice-rich (Conway and Balme, 2014), so it is likely that these exposures

597 are subsurface $\mathrm{H}_{2} \mathrm{O}$ ice that is subsequently covered by a sublimation lag. This suggests

598 that sublimation is an important secondary process in modifying some gully alcoves and

599 liberating material for transport, as suggested by Forget et al. (2016). In such a process, a

600 feedback between sublimation and $\mathrm{CO}_{2}$-driven transport could occur: frost-driven flows

601 strip dry lag material above the ground ice, which subsequently sublimates until another

602 lag develops. Gully locations cut into such ice-rich mantle deposits would thus be a form

603 of sublimation-thermokarst, related to scalloped depressions (cf. Dundas et al., 2015a).

604

605 Morphological Effects of Current Activity

606 Numerous morphologies observed in Martian gullies have been proposed to

607 indicate that they are ultimately liquid water-formed features, regardless of the causes of

608 current activity. These include sinuous, incised channels (Malin and Edgett, 2000;

609 Mangold et al., 2010), braided or anastomosing channels (Malin and Edgett, 2000;

610 Gallagher et al., 2011), terraces and longitudinal bars (Schon and Head, 2009), leveed

611 lobate flows (Levy et al., 2010; Lanza et al., 2010; Johnsson et al., 2014; de Haas et al., 
612 2015b), longitudinal profile characteristics (Conway et al., 2015), and statistical

613 parameterization of three-dimensional topography (Conway and Balme, 2016). However,

614 the purported diagnostic nature of all of these features depends on experience with

615 terrestrial analogs. A priori, we do not know what morphologies should be produced by

616 flows triggered or enhanced by $\mathrm{CO}_{2}$ frost, especially at Mars' gravitational acceleration,

617 because the details of the processes are incompletely understood and we have no clear

618 terrestrial analogs. Therefore, it is essential to understand what morphologies can be

619 produced within currently-active features, which must be produced by frost-driven

620 processes. Dundas et al. (2015b) showed new examples of several of these morphologies.

621 Here we describe additional examples of newly formed morphologies in order to show

622 that they can be created via current Martian surface processes.

623 Channel incision commonly occurs, particularly in the form of local erosion and

624 channel extension or widening. It is extremely frequent and large-scale in dune gullies. In

625 non-dune gullies, some clear examples were seen, such as erosion of a 50-m-long

626 breakout from a preexisting channel (Dundas et al., 2015b); more commonly, the erosion

627 is more subtle. Fig. 12a-b shows an example of extension of a pre-existing channel.

628 Flows passing down the channel occasionally destabilize the slope, causing wall collapse

629 and liberating material for future transport (Fig. 12c-d). Channel sinuosity also develops

630 over time. In several cases, sinuous curves were observed to migrate and become more

631 sinuous. The process involves erosion of the down-slope outside bank, suggesting that

632 energetic flows strike the outside of the curve and enhance the curves in the channel as

633 they are deflected. This does not continue indefinitely — we have also observed cutoff of a 
634 sinuous curve (Fig. 13), analogous to the formation of an oxbow lake in a meandering 635 stream.

636 Figure 14 shows an excellent example of current activity capable of producing 637 complex, braided patterns. This location has a system of branching channels (Fig. 14a).

638 These channels had faint bright material in an early HiRISE image (Fig. 14b), but in a

639 later image have distinct bright deposits (Fig. 14c). A visible topographic change

640 demonstrates that this is not simply a photometric effect. Instead, the older bright

641 material represents a previous event following a similar pattern. The flows very likely

642 had one source and branched downslope, although the source was not apparent. Within

643 the lower reaches, the flows followed multiple channels, and broke out and branched in

644 several places, likely due to the interaction of topographic irregularities and flow

645 momentum.

646 Terraces form when channel erosion cuts through previously deposited material.

647 As such, they indicate variations in the locations of erosion and deposition, but need not

648 be caused by fluvial processes. We observed erosion of previous channel floors in several

649 places. A clear example occurred in the large dune gully shown in Fig. 9, which

650 developed a distinct cut-bank terrace as the channel evolved. Smaller examples were seen

651 in non-dune gullies. Bar-like deposits were observed in many of the modified channels

652 (Fig. 15). Like terraces, such bars are not diagnostic of flowing water, but simply indicate

653 localized erosion and deposition by particular flows, with the gross dimensions of the

654 gully likely set by the largest events.

655 Lobate flow deposits occur near the toes of many changes. Figure 16 shows an

656 example formed in Istok crater $\left(45.1^{\circ} \mathrm{S}, 274.2^{\circ} \mathrm{E}\right)$, likely in the winter of MY 33 . The 
657 deposit resembles features in the same crater interpreted by Johnsson et al. (2014) and de

658 Haas et al. (2015b) as aqueous debris flows. Boulder-rich levees also formed along

659 segments of this flow. In general, levees are uncommon (or not resolved) in current

660 flows, but they are also uncommon in gullies as a whole. Large, leveed lobate deposits

661 have also been observed on equatorial sand dunes, so the formation of leveed flows in

662 general is possible at present.

663 Conway et al. (2015) suggested that various measures of concavity of the

664 longitudinal profile of gullies were diagnostic of aqueous processes. We examined the

665 longitudinal profile of the major dune gully in eastern Matara crater (Fig. 17) using a

666 high-resolution Digital Terrain Model. This gully (Fig. 1f) has shown annual large-scale

667 activity sufficient to substantially rework the morphology within a decade, so it is

668 unlikely to preserve morphologies not produced by current processes. This gully falls

669 within the normal range of Martian gullies for several measures of concavity (Fig. 17),

670 demonstrating that those parameters can be produced by current $\mathrm{CO}_{2}$ ice processes.

671 The massive changes observed in some dune gullies (e.g., Fig. 9) demonstrate that

672 gullies with the classic alcove-channel-apron morphology can be swiftly created or

673 modified by current processes. It is not plausible that such gullies preserve morphologies

674 established during a high-obliquity ice age while many thousands of cubic meters of sand

675 are eroded and deposited annually. Although reworking on this scale has so far only been

676 observed in dune gullies, the differences between activity in dune and non-dune gullies

677 appear to be in scale rather than in kind (likely because sand is not very cohesive and

678 easily mobilized). Furthermore, current activity appears capable of initiating gullies (Fig. 
679 8), not merely modifying older features. Thus, our observations show that current

680 processes are capable of creating the classic gully morphology.

681

682 A Dry Frost Model for Gully Formation and Evolution

683 This study of Martian gully activity yields several fundamental results. First,

684 current activity is driven by seasonal frost, which is predominantly $\mathrm{CO}_{2}$, and not by liquid

685 water. Second, this present-day activity is extensive and could be observed in most

686 gullies, given a sufficiently long observation period. Finally, diverse gully morphologies,

687 including those sometimes considered diagnostic of liquid water, are forming today.

688 Anything that does happen, can happen — and therefore, these observations demonstrate

689 that gully formation is active, ongoing, and does not require significant volumes of liquid

690 water. In light of these results, we propose that the fresh Martian gullies are not water-

691 formed features, and that bulk volumes of liquid water were never present in the gullies.

692 Instead, they form through dry, frost-driven processes.

693 In this model, individual gullies begin with events like the erosion seen in Raga

694 crater (Fig. 8), localized by irregularities in the topography like the ill-defined partial

695 channel at that site. Such irregularities also likely form the initiation points for alcoves.

696 The concentration of frost activity in alcoves, combined with the locally steeper slopes,

697 demonstrates that frost-driven processes can be concentrated within gullies in a positive

698 feedback. Micro-topographic control of frost also enables the occurrence of ices on

699 slopes where the overall orientation is not conducive to frost formation. Such topographic

700 effects may control the locations of gullies, and likely explain the miscorrelations

701 between model-predicted $\mathrm{CO}_{2}$ frost and gully locations reported by Conway et al. (2016). 
702 Many of these flows (tens to hundreds) build up a full-scale gully landform. The

703 evolution is erratic, due to the variable size and erosive effects of the flows: channels

704 form, low-energy flows result in local infill and deposition, energetic events break out to

705 form new branches leading to channel abandonment, and sinuous curves develop and are 706 cut off, while the alcove gradually expands. All of these phenomena have been observed

707 and, integrated over many flows, will build the complex morphologies of well-developed

708 gullies. The observed rate of activity in southern-hemisphere gullies implies hundreds of

709 mass movements in individual gullies in a few Ma or less. Given the nature and extent of

710 activity, it appears plausible for the observed gullies to form via current processes, with

711 some variations in location and intensity over time due to climate variations, without

712 melting or runoff. Table 1 summarizes a range of previous observations of gullies and

713 their explanation in the seasonal frost model.

714 There is little to distinguish currently active gullies from most of those not (yet)

715 known to be active. Dundas et al. (2015b) found that northern-hemisphere gullies were

716 less active than those in the south, likely due to the current coincidence of aphelion and

717 southern winter solstice, and this remains true in our larger data set. Dune gullies appear

718 to be more active than those on non-sandy material, which likely reflects the ease of

719 mobilizing loose sand. Degraded-appearing gullies appear less active or inactive (Dundas

720 et al., 2015b), but it is very likely that most other gullies would show activity if

721 monitored for decades or centuries. Certain locations like Gasa crater are particularly

722 active at present, due to locally favorable frost conditions or especially steep or erodible

723 material. 
An important consequence of the frequent current activity is that it has reshaped

725 most gullies and controls their morphology. This is most obvious in the complete

726 reworking of large dune gullies within a decade (Fig. 9). However, there have probably

727 been dozens or hundreds of flows in most fresh-looking gullies since the last high-

728 obliquity period (Dundas et al., 2015b). Single flows can have significant geomorphic

729 impacts, so the cumulative effects of many such events must have obliterated any features

730 unique to high-obliquity conditions. In fact, an important question is why current

731 processes have not degraded mid-latitude craters more thoroughly. There are two likely

732 contributing factors (Dundas et al., 2015b). First, gully erosion may be most effective on

733 steep, fresh slopes, especially at lower latitudes where slopes and shadowing are required

734 for frost to accumulate. This would make it self-limiting as a geomorphic agent (cf. de

735 Haas et al., 2015a). Consistent with this, the very young Gasa crater has already

736 developed prominent gullies. (An important factor in the large Gasa crater gullies may be

737 generation of the initial alcoves by landslides (Okubo et al., 2011), and the target

738 materials may also be unusual (Schon and Head, 2012).) Second, mantling deposits from

739 high-obliquity epochs fill and bury gullies, with gully erosion in many cases confined to

740 the mantle (e.g., Christensen, 2003; Schon and Head, 2011; Aston et al., 2011; Raack et

741 al., 2012; Conway and Balme, 2014; Dickson et al., 2015a), while erosion of bedrock

742 alcoves occurs more slowly. This points to a model where gullies largely develop within

743 unconsolidated material (sand and mantle deposits) and only slowly modify coherent

744 rock. The likely formation timescale of fresh non-dune gullies by current processes is $\sim 1-$

74510 Ma based on rough estimation of mass fluxes (Dundas et al., 2015b). Consistent with

746 this, upper bounds of one to several Ma have been reported for gully ages at several 
747 locations (Malin and Edgett, 2000; Reiss et al., 2004; Schon et al., 2009). Such upper

748 bounds are consistent with ongoing formation and could allow older initiation,

749 subsequently reworked. One possibility is that the current generation of gullies began

750 forming around the transition to lower mean obliquity thought to have occurred at $\sim 5 \mathrm{Ma}$

751 (Levrard et al., 2004); perhaps mid-latitude mantle deposition competed with gully

752 erosion more effectively at higher obliquities (cf. Madeleine et al., 2014). However,

753 current flux estimates are not precise enough to prove such a connection.

754 Climate variations are permitted by this model, and should be expected. Changes

755 in the orbital and axial parameters (Laskar et al., 2004) must affect mid-latitude and polar

756 ices. There is evidence for a substantial mass of $\mathrm{CO}_{2}$ stored in the south polar layered

757 deposits, capable of doubling the surface pressure if it were all added to the atmosphere

758 (Phillips et al., 2011; Bierson et al., 2016). These factors have likely caused variations in

759 humidity (e.g., Mischna and Richardson, 2005), ground ice stability (e.g., Mellon and

760 Jakosky, 1995; Chamberlain and Boynton, 2007; Schorghofer and Forget, 2012), and

761 sublimation of surface ice and deposition of frost and snow (e.g., Levrard et al., 2004;

762 2007; Forget et al., 2006; Madeleine et al., 2009; 2014), among other variables. However,

763 they may not have produced any significant amount of surface liquid water in the gullies.

764 Pilorget and Forget (2016) demonstrated that the spatial distribution of $\mathrm{CO}_{2}$ deposition

765 and activity changes with obliquity. These variations, rather than variations in $\mathrm{H}_{2} \mathrm{O}$ frost

766 and snow, could account for formation of gullies that are currently inactive and cratered

767 (cf. Morgan et al., 2010; Raack et al., 2012).

768 Climate variations could even have produced temperatures and pressures that

769 were commonly above the triple point of water (e.g., Dickson et al., 2015b) without 
770 generating runoff. There are two reasons for this. First, latent heat loss to sublimation

771 makes it difficult for the temperature to ever rise to the melting point if water ice is

772 present, as discussed above. Second, there is a difference between thermodynamic

773 stability and stability against transport. Conditions above the triple point would make

774 liquid water thermodynamically favored if $\mathrm{H}_{2} \mathrm{O}$ were present. However, those same

775 conditions would drive $\mathrm{H}_{2} \mathrm{O}$ away and prevent condensation, because they cause a high

776 mean vapor pressure which makes ice (and water) unstable (e.g., Leighton and Murray,

777 1966). Ice could be left over from cold climate conditions, but any ice transitioning

778 towards conditions where melting temperatures might be possible would have a vapor

779 pressure high enough to sublimate rapidly (Mellon and Phillips, 2001).

780 Counterintuitively, the existence of gullies cut into the ice-rich mid-latitude mantle is a

781 strong argument that it has not melted — if local melting conditions were ever attained, the

782 adjacent areas would have undergone massive losses to sublimation, destroying the

783 mantle. The warm locations capable of exceeding the triple point are the locations where

784 ice would be least likely to exist at all, and where ice exists, latent heat will buffer the

785 temperature and make it difficult to reach the melting point. Some models do suggest that

786 limited amounts of past snowmelt (few mm/year) could have occurred (Williams et al.,

787 2009), but trace runoff typically does not produce large mass movements, while the $\mathrm{CO}_{2}$

788 processes occurring at present clearly do so.

789 How long have such dry conditions prevailed on Mars? A generally dry climate

790 may have prevailed for much of the Amazonian, as the atmospheric pressure has been

791 low throughout (e.g., Lammer et al., 2013). Exceptions could have occurred in

792 association with major transient events like impacts and volcanic eruptions. Richardson 
793 and Mischna (2005) argued that the middle period of Martian history may have been even

794 less favorable to surface liquid than the present. Recurring Slope Lineae, the other

795 leading candidate for current near-surface liquid water flow (McEwen et al., 2011) are

796 not understood and have angle-of-repose slopes consistent with dry granular flow

797 (Dundas et al., 2017). Forget et al. (2013) demonstrated that formation of extensive

798 seasonal $\mathrm{CO}_{2}$ ice is a likely consequence of many ancient climate scenarios with a thicker

799 atmosphere, particularly for an atmospheric pressure $\leq 0.5$ bars, so dry frost processes

800 may have occurred through most of Mars' history. However, the evidence for ancient

801 liquid water is diverse, although the climate remains poorly understood (Wordsworth,

802 2016). On early Mars, $\mathrm{CO}_{2}$-driven processes may have been in competition with or

803 secondary to runoff rather than the dominant process, transitioning as the planet grew

804 colder and drier.

805 These gully processes could be recorded in Martian sediments dating from any

806 location and epoch with a $\mathrm{CO}_{2}$ frost cycle, and this possibility should be considered in

807 interpreting Martian sediments, particularly at middle and high latitudes. The gully mass

808 movements transport material ranging from fine grains (including sand and airfall dust) to

809 meter-scale boulders. The morphological similarities between $\mathrm{CO}_{2}$-driven activity and

810 aqueous debris flows suggest that the deposits may also be similar, and $\mathrm{CO}_{2}$-mobilized

811 flows could have fluidization similar to wet debris flows, so such deposits on Mars

812 should not be regarded as proof of liquid water. Diagnostic differences could exist, but

813 none of the new Martian flows has yet been inspected in situ for comparison. (At the time

814 of writing, the Opportunity rover is preparing to investigate a degraded gully-like feature

815 in Meridiani Planum (Parker et al., 2017). The feature is poorly developed compared 
816 with many mid-latitude gullies, and the equatorial latitude $\left(2.3^{\circ} \mathrm{S}\right)$ is less favorable for

817 past $\mathrm{CO}_{2}$ processes, but $\mathrm{CO}_{2}$-driven formation should be considered a possible working

818 hypothesis.) The most likely difference between aqueous and $\mathrm{CO}_{2}$-driven mass

819 movements is possible evidence for loss of ice that was mixed into the final deposit and

820 later sublimated, which could manifest as voids or larger collapse or fluidization features,

821 but the absence of such features would not necessarily rule out $\mathrm{CO}_{2}$ frost. Sediments with

822 evidence for sustained flow and deposition, such as bedform migration, are much more

823 likely to be fluvial (or aeolian), although the deposition style of slowly creeping

824 defrosting flows is unknown. Dune gully flows, if preserved in ancient sandstone, are

825 presumably entirely sand, and linear-gully pits formed by sublimating blocks (Diniega et

826 al., 2013) would disrupt existing bedding.

827 We emphasize several key points for further assessment of this hypothesis.

828 Current Martian processes are carving sinuous channels, creating lobate flows, and

829 producing other morphologies resembling water-formed terrestrial features. Arguments

830 that particular liquid-free processes on Earth do not produce these morphologies are not

831 convincing tests. Unless large volumes of liquid water are being regularly generated in

832 individual gullies by some unknown mechanism and preferentially released in winter,

833 some non-aqueous process is capable of making these features under Martian conditions.

834 As we do not have terrestrial analogs for gullies formed by $\mathrm{CO}_{2}$ frost, we do not know

835 what their morphology and morphometry "should" be. The current formation of aqueous-

836 like landforms on Mars suggests that they would resemble water-formed terrestrial

837 features. It is difficult to categorically prove that runoff during some past high-obliquity

838 climate did not contribute to gully formation, and we do not rule out the possibility of 
839 some surface liquid water in the geologically recent past. However, the essential

840 argument for liquid water carving gullies is that their morphology is uniquely water-

841 formed and has survived since the last period of high axial tilt. The nature and frequency

842 of current activity in fresh gullies make that interpretation difficult to sustain.

843

\section{Conclusions}

845 Extensive activity is occurring in Martian gullies today, including formation of a

846 host of geomorphic features often associated with water. However, the timing of activity,

847 and the dry Martian climate, indicate that seasonal $\mathrm{CO}_{2}$ frost is the cause. The flows seen

848 within Martian gullies may resemble those produced by aqueous processes because they

849 are fluidized to some extent, likely by gas generated from entrained $\mathrm{CO}_{2}$ frost. Changes

850 in gullies have significant geomorphic effects on all parts of the gully system. The

851 extensive changes observed have likely erased and reworked any morphologies within

852 these same gullies that formed during the last high-obliquity period, so gully

853 geomorphology cannot be diagnostic of liquid water occurring only in a past climate.

854 HiRISE observations indicate that Martian gullies are forming today. Liquid water is not 855 necessary for the gullies, and may never have been involved in their formation. Such a

856 dry scenario would mean that gullies need not be treated as potential naturally-occurring

857 Special Regions, although the likely presence of shallow water ice on pole-facing slopes

858 in the mid-latitudes would still make them potential induced Special Regions. $\mathrm{CO}_{2}$ frost

859 processes have likely been active for much of Mars' geologic history, with geomorphic

860 and sedimentary consequences that are not yet understood. 


\section{Acknowledgments}

863 This work was funded by Mars Data Analysis Program grant NNH13AV85I and

864 the Mars Reconnaissance Orbiter HiRISE project. SD's work was carried out at the Jet

865 Propulsion Laboratory, California Institute of Technology, under a contrast with the

866 National Aeronautics and Space Administration (NASA). We thank the HiRISE

867 operations team for acquiring and processing the data, the MRO CTX team for

868 suggesting some locations of possible activity for HiRISE imaging, and NASA for

869 supporting the extended missions necessary to collect long-term monitoring observations.

870 Two reviewers provided helpful comments. All HiRISE images used in this study are

871 available via the Planetary Data System. Any use of trade, firm, or product names is for

872 descriptive purposes only and does not imply endorsement by the U.S. Government.

873

\section{Supplementary Materials}

875 Supporting materials for this article include a description and captions for the

876 supplementary materials, Supplementary Figures 1-6, Supplementary Animations 1-3 (as

877 separate files), and Supplementary Tables 1-2 (as separate files).

878

\section{References}

880 Aston, A. H., Conway, S. J., Balme, M. R., 2011. Identifying Martian gully evolution. In

881 Martian Geomorphology (Balme, M. R., Bargery, A. S., Gallagher, C. J., \& Gupta, S., 882 eds.), Geological Society, London, Special Publication 356, 151-169,

883 doi:10.1144/SP356.9. 
884 Auld, K. S., Dixon, J. C., 2016. A classification of Martian gullies from HiRISE imagery.

885 Planet. Space Sci., 131, 88-101, doi:10.1016/j.pss.2016.08.002.

886 Ayoub, F., Avouac, J.-P., Newman, C. E., Richardson, M. I., Lucas, A., Leprince, S.,

887 Bridges, N. T., 2014. Threshold for sand mobility on Mars calibrated from seasonal

888 variations of sand flux. Nature Commun., 5:5096, doi:10.1038/ncomms6096.

889 Balme, M., Mangold, N., Baratoux, D., Costard, F., Gosselin, F., Masson, P., Pinet, P.,

890 Neukum, G., 2006. Orientation and distribution of recent gullies in the southern

891 hemisphere of Mars: Observations from High Resolution Stereo Camera/Mars

892 Express (HRSC/MEX) and Mars Orbiter Camera/Mars Global Surveyor

893 (MOC/MGS) data. J. Geophys. Res., 111, E05001, doi:10.1029/2005JE002607.

894 Bart, G. D., 2007. Comparison of small lunar landslides and Martian gullies. Icarus, 187, 895 417-421, doi:10.1016/j.icarus.2006.11.004.

896 Bierson, C. J., Phillips, R. J., Smith, I. B., Wood, S. E., Putzig, N. E., Nunes, D., Byrne,

897 S., 2016. Stratigraphy and evolution of the buried $\mathrm{CO}_{2}$ deposit in the Martian south

898 polar cap. Geophys. Res. Lett., 43, doi:10.1002/2016GL068457.

899 Branney, M. J., Kokelaar, P., 2002. Pyroclastic density currents and the sedimentation of

900 ignimbrites. Geol. Soc. Memoir No. 27, Geological Society, London, 152 pp.

901 Bridges, N.T., Lackner, C.N., 2006. Northern hemisphere Martian gullies and mantled

902 terrain: Implications for near-surface water migration in Mars' recent past. J.

903 Geophys. Res., 111, E09014, doi:10.1029/2006JE002702.

904 Bridges, N.T., Herkenhoff, K.E., Titus, T.N., Kieffer, H.H., 2001. Ephemeral dark spots

905 associated with Martian gullies. Lunar Planet. Sci. Conf. 32, abstract \#2126.

906 Carr, M. H., 2006. The Surface of Mars. Cambridge University Press, Cambridge, 307 p. 
907 Cedillo-Flores, Y., Treiman, A. H., Lasue, J., Clifford, S. M., 2011. $\mathrm{CO}_{2}$ gas fluidization

908 in the initiation and formation of Martian polar gullies. Geophys. Res. Lett., 38,

909 L21202, doi:10.1029/2011GL049403.

910 Chamberlain, M. A., Boynton, W. V., 2007. Response of Martian ground ice to orbit-

911 induced climate change. J. Geophys. Res., 112, E06009, doi:10.1029/2006JE002801.

912 Christensen, P.R., 2003. Formation of recent Martian gullies through melting of extensive

913 water-rich snow deposits. Nature, 422, 45-48, doi:10.1038/nature01436.

914 Clancy, R.T., Sandor, B.J., Wolff, M.J., Christensen, P.R., Smith, M.D., Pearl, J.C.,

915 Conrath, B.J., Wilson, R.J., 2000. An intercomparison of groundbased millimeter,

916 MGS TES, and Viking atmospheric temperature measurements: Seasonal and

917 interannual variability of temperatures and dust loading in the global Mars

918 atmosphere. J. Geophys. Res., 105, 9553-9572, doi:10.1029/1999JE001089.

919 Conway, S. J., Balme, M. R., 2014. Decameter thick remnant glacial ice deposits on

920 Mars. Geophys. Res. Lett., 41, 5402-5409, doi:10.1002/2014GL060314.

921 Conway, S. J., Balme, M. R., 2016. A novel topographic parameterization scheme

922 indicates that Martian gullies display the signature of liquid water. Earth Planet. Sci.

923 Lett., 454, 36-45, doi:10.1016/j.eps1.2016.08.031.

924 Conway, S. J., Balme, M. R., Kreslavsky, M. A., Murray, J. B., Towner, M. C., 2015.

925 The comparison of topographic long profiles of gullies on Earth to gullies on Mars: A

926 signal of water on Mars. Icarus, 253, 189-204, doi:10.1016/j.icarus.2015.03.009.

927 Conway, S. J., Harrison, T. N., Lewis, S. R., Soare, R. J., Balme, M. R., Britton, A.,

928 2016. Martian gully orientation and slope used to test meltwater and carbon dioxide

929 hypotheses. Lunar Planet. Sci. Conf. 47, abstract \#1973. 
930 Costard, F., Forget, F., Mangold, N., Peulvast, J.P., 2002. Formation of recent Martian

931 debris flows by melting of near-surface ground ice at high obliquity. Science, 295,

$932 \quad 110-113$, doi:10.1126/science.1066698.

933 de Haas, T., Hauber, E., Kleinhans, M. G., 2013. Local late Amazonian boulder

934 breakdown and denudation rate on Mars. Geophys. Res. Lett., 40, 3527-3531,

935 doi:10.1002/grl.50726.

936 de Haas, T., Conway, S. J., Krautblatter, M., 2015a. Recent (Late Amazonian) enhanced

937 backweathering rates on Mars: Paracratering evidence from gully alcoves. J.

938 Geophys. Res. Planets, 120, doi:10.1002/2015JE004915.

939 de Haas, T., Hauber, E., Conway, S. J., van Steijn, H., Johnsson, A., Kleinhans, M. G.,

940 2015b. Earth-like aqueous debris-flow activity on Mars at high orbital obliquity in the

941 last million years. Nature Commun., 6:7543, doi:10.1038/ncomms8543.

942 de Haas, T., Ventra, D., Hauber, E., Conway, S. J., Kleinhans, M. G., 2015c.

943 Sedimentological analyses of Martian gullies: The subsurface as the key to the

$944 \quad$ surface. Icarus, 258, 92-108, doi:10.1016/j.icarus.2015.06.017.

945 Delamere, W. A., et al., 2010. Color imaging of Mars by the High Resolution Imaging

946 Science Experiment (HiRISE). Icarus, 205, 38-52, doi:10.1016/j.icarus.2009.03.012.

947 Dickson, J. L. Head, J.W., 2009. The formation and evolution of youthful gullies on

948 Mars: Gullies as the late-stage phase of Mars' most recent ice age. Icarus, 204, 63-86,

949 doi:10.1016/j.icarus.2009.06.018.

950 Dickson, J. L., Head, J.W., Kreslavsky, M., 2007. Martian gullies in the southern mid-

951 latitudes of Mars: Evidence for climate-controlled formation of young fluvial features 
952 based upon local and global topography. Icarus, 188, 315-323,

953 doi:10.1016/j.icarus.2006.11.020.

954 Dickson, J. L., Head, J. W., Goudge, T. A., Barbieri, L., 2015a. Recent climate cycles on

955 Mars: Stratigraphic relationships between multiple generations of gullies and the

956 latitude-dependent mantle. Icarus, 252, 83-94, doi:10.1016/j.icarus.2014.12.035.

957 Dickson, J. L., Kerber, L., Fassett, C. I., Head, J. W., Forget, F., Madeleine, J.-B., $2015 b$.

958 Formation of gullies on Mars by water at high obliquity: Quantitative integration of

959 Global Climate Models and gully distribution. Lunar Planet. Sci. Conf. 46, abstract

$960 \quad \# 1035$.

961 Diniega, S., Byrne, S., Bridges, N.T., Dundas, C.M., McEwen, A.S., 2010. Seasonality of

962 present-day Martian dune-gully activity. Geology, 38, 1047-1050,

963 doi:10.1130/G31287.1.

964 Diniega, S., Hansen, C.J., McElwaine, J.N., Hugenholtz, C.H., Dundas, C.M., McEwen, 965 A.S., Bourke, M.C., 2013. A new dry hypothesis for the formation of Martian linear 966 gullies. Icarus, 225, 526-537, doi:10.1016/j.icarus.2013.04.006.

967 Dundas, C. M., Byrne, S., 2010. Modeling sublimation of ice exposed by new impacts in 968 the Martian mid-latitudes. Icarus, 206, 716-728, doi:10.1016/j.icarus.2009.09.007.

969 Dundas, C.M., McEwen, A.S., Diniega, S., Byrne, S., Martinez-Alonso, S., 2010. New

970 and recent gully activity on Mars as seen by HiRISE. Geophys. Res. Lett., 37,

$971 \quad$ L07202, doi:10.1029/2009GL041351.

972 Dundas, C.M., Diniega, S., Hansen, C.J., Byrne, S., McEwen, A.S., 2012. Seasonal

973 activity and morphological changes in Martian gullies. Icarus, 220, 124-143, 974 doi:10.1016/j.icarus.2012.04.005. 
975 Dundas, C. M., Byrne, S., McEwen, A. S., 2015a. Modeling the development of Martian

976 sublimation thermokarst landforms. Icarus, 262, 154-169,

977 doi:10.1016/j.icarus.2015.07.033.

978 Dundas, C.M., Diniega, S., McEwen, A.S., 2015b. Long-term monitoring of Martian

979 gully formation and evolution with MRO/HiRISE. Icarus, 251, 244-263,

980 doi:10.1016/j.icarus.2014.05.013.

981 Dundas, C. M., McEwen, A. S., Chojnacki, M., Milazzo, M. P., Byrne, S., 2017. A 982 granular flow model for Recurring Slope Lineae on Mars. Lunar Planet. Sci. Conf. $983 \quad 48$, abstract \#2399.

984 Forget, F., Haberle, R. M., Montmessin, F., Levrard, B., Head, J. W., 2006. Formation of 985 glaciers on Mars by atmospheric precipitation at high obliquity. Science, 311, 368$986 \quad 371$, doi:10.1126/science.1120335.

987 Forget, F., Wordsworth, R., Millour, E., Madeleine, J.-B., Kerber, L., Leconte, J., Marcq, 988 E., Haberle, R. M., 2013. 3D modelling of the early Martian climate under a denser $989 \mathrm{CO}_{2}$ atmosphere: Temperatures and $\mathrm{CO}_{2}$ ice clouds. Icarus, 222, 81-99, 990 doi:10.1016/j.icarus.2012.10.019.

991 Forget, F., Pilorget, C., Pottier, A., Meslin, P.-Y., 2016. Deep incision of the Latitude

992 Dependent Mantle in Martian gullies formed by $\mathrm{CO}_{2}$ sublimation processes.

993 Unnumbered abstract presented at the Workshop on Martian Gullies and their Earth 994 Analogs, June 20, 2016, London, UK.

995 Gaidos, E.J., 2001. Cryovolcanism and the recent flow of liquid water on Mars. Icarus, $996 \quad 153,218-223$, doi:10.1006/icar.2001.6649. 
997 Gallagher, C., Balme, M. R., Conway, S. J., Grindrod, P. M., 2011. Sorted clastic stripes, 998 lobes and associated gullies in high-latitude craters on Mars: Landforms indicative of 999 very recent, polycyclic ground-ice thaw and liquid flows. Icarus, 211, 458-471, 1000 doi:10.1016/j.icarus.2010.09.010.

1001 Gilmore, M. S., Phillips, E. L., 2002. Role of aquicludes in formation of Martian gullies. 1002 Geology, 30, 1107-1110, doi:10.1130/0091$1003 \quad 7613(2002) 030<1107:$ ROAIFO $>2.0 . C O ; 2$.

1004 Goldspiel, J. M., Squyres, S. W., 2011. Groundwater discharge and gully formation on 1005 Martian slopes. Icarus, 211, 238-258, doi:10.1016/j.icarus.2010.10.008.

1006 Gough, R. V., Chevrier, V. F., Baustian, K. J., Wise, M. E., Tolbert, M. A., 2011.

1007 Laboratory studies of perchlorate phase transitions: Support for metastable aqueous 1008 perchlorate solutions on Mars. Earth Planet. Sci. Lett., 312, 371-377, 1009 doi:10.1016/j.eps1.2011.10.026.

1010 Hansen, C. J., Okubo, C., McEwen, A., Byrne, S., DeJong, E., Herkenhoff, K., Mellon, 1011 M., Russell, P., Thomas, N., 2007. HiRISE views of the sublimation of Mars' 1012 southern seasonal cap. $7^{\text {th }}$ Int. Conf. Mars, abstract \#3364.

1013 Hansen, C. J., Thomas, N., Portyankina, G., McEwen, A., Becker, T., Byrne, S., 1014 Herkenhoff, K., Kieffer, H., Mellon, M., 2010. HiRISE observations of gas 1015 sublimation-driven activity in Mars' southern polar regions: I. Erosion of the surface. 1016 Icarus, 205, 283-295, doi:10.1016/j.icarus.2009.07.021.

1017 Hansen, C. J., Diniega, S., Bridges, N., Byrne, S., Dundas, C., McEwen, A., Portyankina, 1018 G., 2015. Agents of change on Mars' northern dunes: $\mathrm{CO}_{2}$ ice and wind. Icarus, 251, 1019 264-274, doi:10.1016/j.icarus.2014.11.015. 
1020 Harrison, T.N., 2016. Martian gully formation and evolution: Studies from the local to 1021 global scale. Ph.D. Dissertation, Western University.

1022 Harrison, T.N., Malin, M.C., Edgett, K.S., 2009. Liquid water on the surface of Mars 1023 today: Present gully activity observed by the Mars Reconnaissance Orbiter (MRO) 1024 and Mars Global Surveyor (MGS) and direction for future missions. AGU Fall 1025 Meeting, abstract \#P43D-1454.

1026 Harrison, T. N., Osinski, G. R., Tornabene, L. L., Jones, E., 2015. Global documentation 1027 of gullies with the Mars Reconnaissance Orbiter Context Camera and implications for 1028 their formation. Icarus, 252, 236-254, doi:10.1016/j.icarus.2015.01.022.

1029 Hartmann, W.K., 2001. Martian seeps and their relation to youthful geothermal activity. $1030 \quad$ Space Sci. Rev., 96, 405-410.

1031 Hartmann, W. K., Thorsteinsson, T., Sigurdsson, F., 2003. Martian hillside gullies and 1032 Icelandic analogs. Icarus, 162, 259-277, doi:10.1016/S0019-1035(02)00065-9.

1033 Hayne, P. O., Paige, D. A., Heavens, N. G., and the Mars Climate Sounder Science

1034 Team, 2014. The role of snowfall in forming the seasonal ice caps of Mars: Models 1035 and constraints from the Mars Climate Sounder. Icarus, 231, 122-130, 1036 doi:10.1016/j.icarus.2013.10.020.

1037 Hecht, M.H., 2002. Metastability of liquid water on Mars. Icarus, 156, 373-386, 1038 doi:10.1006/icar.2001.6794.

1039 Heldmann, J. L., Mellon, M. T., 2004. Observations of Martian gullies and constraints on 1040 potential formation mechanisms. Icarus, 168, 285-304, 1041 doi:10.1016/j.icarus.2003.11.024. 
1042 Heldmann, J.L., Carlsson, E., Johansson, H., Mellon, M.T., Toon, O.B., 2007.

1043 Observations of Martian gullies and constraints on potential formation mechanisms:

1044 II. The northern hemisphere. Icarus, 188, 324-344, doi:10.1016/j.icarus.2006.12.010.

1045 Hoffman, N., 2002. Active polar gullies on Mars and the role of carbon dioxide.

1046 Astrobiology, 2, 313-323, doi:10.1089/153110702762027899.

1047 Hugenholtz, C.H., 2008. Frosted granular flow: A new hypothesis for mass wasting in

1048 Martian gullies. Icarus 197, 65-72, doi:10.1016/j.icarus.2008.04.010.

1049 Ingersoll, A., 1970. Mars: Occurrence of liquid water. Science, 168, 972-973,

1050 doi:10.1126/science.168.3934.972.

1051 Ishii, T., Sasaki, S., 2004. Formation of recent Martian gullies by avalanches of $\mathrm{CO}_{2}$

1052 Frost. Lunar Planet. Sci. Conf. 35, abstract \#1556.

1053 Ishii, T., Miyamoto, H., Sasaki, S., Tajika, E., 2006. Constraints on the formation of

1054 gullies on Mars: A possibility of the formation of gullies by avalanches of granular

$1055 \quad \mathrm{CO}_{2}$ ice particles. Lunar Planet. Sci. Conf. 37, abstract \#1646.

1056 Iverson, R. M., 1997. The physics of debris flows. Rev. Geophys., 35, 245-296,

1057 doi:10.1029/97RG00426.

1058 Johnsson, A., Reiss, D., Hauber, E., Hiesinger, H., Zanetti, M., 2014. Evidence for very

1059 recent melt-water and debris flow activity in gullies in a young mid-latitude crater on

1060 Mars. Icarus, 235, 37-54, doi:10.1016/j.icarus.2014.03.005.

1061 Kieffer, H. H., 2000. Annual punctuated $\mathrm{CO}_{2}$ slab-ice and jets on Mars. Mars Polar Sci.

1062 Conf., abstract \#4095.

1063 Kieffer, H. H., 2007. Cold jets in the Martian polar caps. J. Geophys. Res., 112, E08005, 1064 doi:10.1029/2006JE002816. 
1065 Knauth, L. P., Burt, D. M., 2002. Eutectic brines on Mars: Origin and possible relation to 1066 young surface features. Icarus, 158, 267-271, doi:10.1006/icar.2002.6866.

1067 Kneissl, T., Reiss, D., van Gasselt, S., Neukum, G., 2010. Distribution and orientation of 1068 northern-hemisphere gullies on Mars from the evaluation of HRSC and MOC-NA 1069 data. Earth Planet. Sci. Lett., 294, 357-367, doi:10.1016/j.eps1.2009.05.018.

1070 Kolb, K.J., Pelletier, J.D., McEwen, A.S., 2010a. Modeling the formation of bright slope 1071 deposits associated with gullies in Hale crater, Mars: Implications for recent liquid 1072 water. Icarus, 205, 113-137, doi:10.1016/j.icarus.2009.09.009.

1073 Kolb, K.J., Pelletier, J.D., McEwen, A.S., 2010b. Investigating gully flow emplacement 1074 mechanisms using apex slopes. Icarus, 208, 132-142, 1075 doi:10.1016/j.icarus.2010.01.007.

1076 Kossacki, K.J., Markiewicz, W.J., 2004. Seasonal melting of surface water ice 1077 condensing in Martian gullies. Icarus, 171, 272-283, 1078 doi:10.1016/j.icarus.2004.05.018.

1079 Kumar, P. S., Keerthi, V., Kumar, A. S., Mustard, J., Krishna, B. G., Amitabh, Ostrach, 1080 L. R., Kring, D. A., Kumar, A. S. K., Goswami, J. N., 2013. Gullies and landslides on 1081 the Moon: Evidence for dry-granular flows. J. Geophys. Res., 118, 1082 doi:10.1002/jgre.20043.

1083 Lammer, H., Chassefiére, E., Karatekin, O., Morschhauser, A., Niles, P. B., Mousis, O., 1084 Odert, P., Möstl, U. V., Breuer, D., Dehant, V., Grott, M., Gröller, H., Hauber, E., 1085 Pham, L. B. S., 2013. Outgassing history and escape of the Martian atmosphere and 1086 water inventory. Space Sci. Rev., 174, 113-154, doi:10.1007/s11214-012-9943-8. 
1087 Lanza, N. L., Meyer, G. A., Okubo, C. H., Newsom, H. E., Wiens, R. C., 2010. Evidence 1088 for debris flow gully formation initiated by shallow subsurface water on Mars. Icarus, $1089205,103-112$, doi:10.1016/j.icarus.2009.04.014.

1090 Laskar, J., Correia, A.C.M., Gastineau, M., Joutel, F., Levrard, B., Robutel, P., 2004.

1091 Long term evolution and chaotic diffusion of the insolation quantities of Mars. Icarus, $1092 \quad$ 170, 343-364, doi:10.1016/j.icarus.2004.04.005.

1093 Lee, P., Cockell, C. S., Marinova, M. M., McKay, C. P., Rice, J. W., 2001. Snow and ice 1094 melt flow features on Devon Island, Nunavut, Arctic Canada as possible analogs for 1095 recent slope flow features on Mars. Lunar Planet. Sci. Conf. 32, abstract \#1809.

1096 Leighton, R. B., Murray, B. C., 1966. Behavior of carbon dioxide and other volatiles on 1097 Mars. Science, 153, 136-144, doi:10.1126/science.153.3732.136.

1098 Levrard, B., Forget, F., Montmessin, F., Laskar, J., 2004. Recent ice-rich deposits formed 1099 at high latitudes on Mars by sublimation of unstable equatorial ice during low 1100 obliquity. Nature, 431, 1072-1075, doi:10.1038/nature03055.

1101 Levrard, B., Forget, F., Montmessin, F., Laskar, J., 2007. Recent formation and evolution 1102 of northern Martian polar layered deposits as inferred from a Global Climate Model.

1103 J. Geophys. Res., 112, E06012, doi:10.1029/2006JE002772.

1104 Levy, J. S., Head, J. W., Dickson, J. L., Fassett, C. I., Morgan, G. A., Schon, S. C., 2010. 1105 Identification of gully debris flow deposits in Protonilus Mensae, Mars:

1106 Characterization of a water-bearing, energetic gully-forming process. Earth Planet.

1107 Sci. Lett., 294, 368-377, doi:10.1016/j.epsl.2009.08.002. 
1108 Madeleine, J.-B., Forget, F., Head, J. W., Levrard, B., Montmessin, F., Millour, E., 2009.

1109 Amazonian northern mid-latitude glaciation on Mars: A proposed climate scenario.

1110 Icarus, 203, 390-405, doi:10.1016/j.icarus.2009.04.037.

1111 Madeleine, J.-B., Head, J. W., Forget, F., Navarro, T., Millour, E., Spiga, A., Colaïtis, A.,

1112 Määttänen, A., Montmessin, F., Dickson, J. L., 2014. Recent Ice Ages on Mars: The

1113 role of radiatively active clouds and cloud microphysics. Geophys. Res. Lett., 41,

1114 4873-4879, doi:10.1002/2014GL059861.

1115 Malin, M.C., Edgett, K.S., 2000. Evidence for recent groundwater seepage and surface

1116 runoff on Mars. Science, 288, 2330-2335, doi:10.1126/science.288.5475.2330.

1117 Malin, M. C., Edgett, K. S., 2005. 8 years at Mars \#1: New dune gullies, Malin Space

1118 Science Systems captioned image release, MOC2-1220, NASA/JPL Planetary

1119 Photojournal, http://photojournal.jpl.nasa.gov/, catalog number PIA04290.

1120 Malin, M.C., Edgett, K.S., Posiolova, L.V., McColley, S.M., Dobrea, E.Z.N., 2006.

1121 Present-day impact cratering rate and contemporary gully activity on Mars. Science,

$1122 \quad 314,1573-1577$, doi:10.1126/science. 1135156.

1123 Mangold, N., Costard, F., 2003. Debris flows over sand dunes on Mars: Evidence for

1124 liquid water. J. Geophys. Res., 108, 5027, doi:10.1029/2002JE001958.

1125 Mangold, N., Baratoux, D., Costard, F., Forget, F., 2008. Current gullies activity: Dry

1126 avalanches observed over seasonal frost as seen on HiRISE images. Workshop on

1127 Martian gullies: Theories and Tests, abstract \#8005.

1128 Mangold, N., Mangeney, A., Migeon, V., Ansan, V., Lucas, A., Baratoux, D., Bouchut,

1129 F., 2010. Sinuous gullies on Mars: Frequency, distribution, and implications for flow

1130 properties. J. Geophys. Res., 115, E11001, doi:10.1029/2009JE003540. 
1131 Massé, M., Conway, S. J., Gargani, J., Patel, M. R., Pasquon, K., McEwen, A., Carpy, S.,

1132 Chevrier, V., Balme, M. R., Ojha, L., Vincendon, M., Poulet, F., Costard, F.,

1133 Jouannic, G., 2016. Transport processes induced by metastable boiling water under

1134 Martian surface conditions. Nature Geosci., 9, 425-428, doi:10.1038/NGEO2706.

1135 McEwen, A.S., Eliason, E.M., Bergstrom, J.W., Bridges, N.T., Hansen, C.J., Delamere,

1136 W.A., Grant, J.A., Gulick, V.C., Herkenhoff, K.E., Keszthelyi, L., Kirk, R.L., Mellon,

1137 M.T., Squyres, S.W., Thomas, N., Weitz, C.M., 2007a. Mars Reconnaissance

1138 Orbiter's High Resolution Imaging Science Experiment (HiRISE). J. Geophys. Res.,

1139 112, E05S02, doi:10.1029/2005JE002605.

1140 McEwen, A. S., Ojha, L., Dundas, C. M., Mattson, S. S., Byrne, S., Wray, J. J., Cull, S.

1141 C., Murchie, S. L., Thomas, N., Gulick, V. C., 2011. Seasonal flows on warm Martian

1142 slopes. Science, 333, 740-743, doi:10.1126/science.1204816.

1143 McEwen, A. S., Dundas, C. M., Mattson, S. S., Toigo, A. D., Ojha, L., Wray, J. J.,

1144 Chojnacki, M., Byrne, S., Murchie, S. L., Thomas, N., 2014. Recurring slope lineae

1145 in equatorial regions of Mars. Nat. Geosci., 7, 53-58, doi:10.1038/ngeo2014.

1146 McEwen, A. S., Dundas, C. M., Chojnacki, M., Massé, M., 2016. Small Martian gullies

1147 associated with Recurring Slope Lineae. Unnumbered abstract presented at the

1148 Workshop on Martian Gullies and their Earth Analogs, June 20, 2016, London, UK.

1149 Mellon, M. T., Jakosky, B. A., 1995. The distribution and behavior of Martian ground ice

1150 during past and present epochs. J. Geophys. Res., 100, 11781-11799,

1151 doi:10.1029/95JE01027.

1152 Mellon, M.T., Phillips, R.J., 2001. Recent gullies on Mars and the source of liquid water.

1153 J. Geophys. Res., 106, 23,165-23,180, doi:10.1029/2000JE001424. 
1154 Morgan, G. A., Head, J. W., Forget, F., Madeleine, J.-B., Spiga, A., 2010. Gully

1155 formation on Mars: Two recent phases of formation suggested by links between

1156 morphology, slope orientation and insolation history. Icarus, 208, 658-666,

1157 doi:10.1016/j.icarus.2010.02.019.

1158 Musselwhite, D.S., Swindle, T.D., Lunine, J.I., 2001. Liquid $\mathrm{CO}_{2}$ breakout and the

1159 formation of recent small gullies on Mars. Geophys. Res. Lett., 28, 1283-1285,

1160 doi:10.1029/2000GL012496.

1161 Neuendorf, K.K.E., Mehl, J.P., Jackson, J.A. (eds.), 2005. Glossary of Geology, $5^{\text {th }}$

1162 Edition, American Geological Institute, 779 pp.

1163 Núñez, J. I., Barnouin, O. S., Murchie, S. L., Seelos, F. P., McGovern, J. A., Seelos, K.

1164 D., Buczkowski, D. L., 2016. New insights into gully formation on Mars: Constraints

1165 from composition as seen by MRO/CRISM. Geophys. Res. Lett., 43, 8893-8902,

1166 doi:10.1002/2016GL068956

1167 Okubo, C. H., Tornabene, L. L., Lanza, N. L., 2011. Constraints on mechanisms for the

1168 growth of gully alcoves in Gasa crater, Mars, from two-dimensional stability

1169 assessments of rock slopes. Icarus, 211, 207-221, doi:10.1016/j.icarus.2010.09.025.

1170 Parker, T. J., Golombek, M. P., Lamb, M., Palucis, M. C., Athena Science Team, 2017.

1171 An opportunity to inspect a Martian gully up close. Lunar Planet. Sci. Conf. 48, 1172 abstract \#2468.

1173 Pasquon, K., Gargani, J., Massé, M., Conway, S. J., 2016. Present-day formation and 1174 seasonal evolution of linear dune gullies on Mars. Icarus, 274, 195-210, 1175 doi:10.1016/j.icarus.2016.03.024. 
1176 Pelletier, J.D., Kolb, K.J., Kirk, R.L., 2008. Recent bright gully deposits on Mars: Wet or 1177 dry flow? Geology, 36, 211-214, doi:10.1130/G24346A.1.

1178 Phillips, R.J., Davis, B.J., Tanaka, K.L., Byrne, S., Mellon, M.T., Putzig, N.E., Haberle, 1179 R.M., Kahre, M.A., Campbell, B.C., Carter, L.M., Smith, I.B., Holt, J.W., Smrekar, 1180 S.E., Nunes, D.C., Plaut, J.J., Egan, A.F., Titus, T.N., Seu, R., 2011. Massive $\mathrm{CO}_{2}$ ice 1181 deposits sequestered in the South Polar Layered Deposits of Mars. Science, 332, 838$1182 \quad$ 841, doi:10.1126/science.1203091.

1183 Pilorget, C., Forget, F., 2016. Formation of gullies on Mars by debris flows triggered by $1184 \quad \mathrm{CO}_{2}$ sublimation. Nature Geosci., 9, 65-69, doi:10.1038/ngeo2619.

1185 Piqueux, S., Byrne, S., Richardson, M. I., 2003. Sublimation of Mars's southern seasonal $1186 \quad \mathrm{CO}_{2}$ ice cap and the formation of spiders. J. Geophys. Res., 108, 1187 doi:10.1029/2002JE002007.

1188 Piqueux, S., Kleinböhl, A., Hayne, P. O., Kass, D. M., Schofield, J. T., McCleese, D. J., 1189 2015. Variability of the Martian seasonal $\mathrm{CO}_{2}$ cap extent over eight Mars Years.

$1190 \quad$ Icarus, 251, 164-180, doi:10.1016/j.icarus.2014.10.045.

1191 Piqueux, S., Kleinböhl, A., Hayne, P. O., Heavens, N. G., Kass, D. M., McCleese, D. J., 1192 Schofield, J. T., Shirley, J. H., 2016. Discovery of a widespread low-latitude diurnal $1193 \mathrm{CO}_{2}$ frost cycle on Mars. J. Geophys. Res. Planets, 121, doi:10.1002/2016JE005034. 1194 Raack, J., Reiss, D., Hiesinger, H., 2012. Gullies and their relationships to the dust-ice 1195 mantle in the northwestern Argyre Basin, Mars. Icarus, 219, 129-141, 1196 doi:10.1016/j.icarus.2012.02.025. 
1197 Raack, J., Reiss, D., Appéré, T., Vincendon, M., Ruesch, O., Hiesinger, H., 2015.

1198 Present-day seasonal gully activity in a south polar pit (Sisyphi Cavi) on Mars. Icarus, 1199 251, 226-243, doi:10.1016/j.icarus.2014.03.040.

1200 Reiss, D., Jaumann, R., 2003. Recent debris flows on Mars: Seasonal observations of the 1201 Russell Crater dune field. Geophys. Res. Lett., 30, doi:10.1029/2002GL016704.

1202 Reiss, D., van Gasselt, S., Neukum, G., Jaumann, R., 2004. Absolute dune ages and 1203 implications for the time of formation of gullies in Nirgal Vallis, Mars. J. Geophys. $1204 \quad$ Res., 109, doi:10.1029/2004JE002251.

1205 Reiss, D., Erkeling, G., Bauch, K.E., Hiesinger, H., 2010. Evidence for present day gully 1206 activity on the Russell crater dune field, Mars. Geophys. Res. Lett., 37, L06203, 1207 doi:10.1029/2009GL042192.

1208 Richardson, M. I., Mischna, M. A., 2005. Long-term evolution of transient liquid water 1209 on Mars. J. Geophys. Res., 110, E03003, doi:10.1029/2004JE002367.

1210 Rummel, J. D., and 24 coauthors, 2014. A new analysis of Mars "Special Regions":

1211 Findings of the Second MEPAG Special Regions Science Analysis Group (SR$1212 \quad$ SAG2). Astrobiology, 14, 887-968, doi:10.1089/ast.2014.1227.

1213 Schon, S. C., Head, J. W., 2009. Terraced cutbanks and longitudinal bars in gully 1214 channels on Mars: Evidence for multiple episodes of fluvial transport. Lunar Planet. 1215 Sci. Conf. 40, abstract \#1691.

1216 Schon, S. C., Head, J. W., 2011. Keys to gully formation processes on Mars: Relation to 1217 climate cycles and sources of meltwater. Icarus, 213, 428-432, 1218 doi:10.1016/j.icarus.2011.02.020. 
1219 Schon, S. C., Head, J. W., 2012. Gasa impact crater, Mars: Very young gullies formed 1220 from impact into latitude-dependent mantle and debris-covered glacier deposits?

1221 Icarus, 218, 459-477, doi:10.1016/j.icarus.2012.01.002.

1222 Schon, S.C., Head, J.W., Fassett, C.I., 2009. Unique chronostratigraphic marker in 1223 depositional fan stratigraphy on Mars: Evidence for ca. 1.25 Ma gully activity and 1224 surficial meltwater origin. Geology, 37, 207-210, doi:10.1130/G25398A.1.

1225 Schorghofer, N., Edgett, K.S., 2006. Seasonal surface frost at low latitudes on Mars.

1226 Icarus, 180, 321-334, doi:10.1016/j.icarus.2005.08.022.

1227 Schorghofer, N., Forget, F., 2012. History and anatomy of subsurface ice on Mars. Icarus, $1228 \quad 220,1112-1120$, doi:10.1016/j.icarus.2012.07.003.

1229 Shinbrot, T., Duong, N.-H., Kwan, L., Alvarez, M.M., 2004. Dry granular flows can 1230 generate surface features resembling those seen in Martian gullies. Proc. Nat. Acad. 1231 Sci., 101, 8542-8546, doi:10.1073/pnas.0308251101.

1232 Sylvest, M. S., Conway, S. J., Patel, M. R., Dixon, J. C., Barnes, A., 2016. Mass wasting 1233 triggered by seasonal $\mathrm{CO}_{2}$ sublimation under Martian atmospheric conditions:

1234 Laboratory experiments. Geophys. Res. Lett., 43, 12,363-12,370, 1235 doi:10.1002/2016GL071022.

1236 Thomas, N., Hansen, C. J., Portyankina, G., Russell, P. S., 2010. HiRISE observations of 1237 gas sublimation-driven activity in Mars' southern polar regions: II. Surficial deposits 1238 and their origins. Icarus, 205, 296-310, doi:10.1016/j.icarus.2009.05.030.

1239 Treiman, A.H., 2003. Geologic settings of Martian gullies: Implications for their origins.

1240 J. Geophys. Res., 108, 8031-8042, doi:10.1029/2002JE001900. 
1241 Turnbull, B., Bowman, E. T., McElwaine, J. N., 2015. Debris flows: Experiments and 1242 modelling. Comp. Rend. Phys., 16, 86-96.

1243 Vincendon, M., 2015. Identification of Mars gully activity types associated with ice 1244 composition. J. Geophys. Res. Planets, 120, doi:10.1002/2015JE004909.

1245 Vincendon, M., Forget, F., Mustard, J., 2010a. Water ice at low to midlatitudes on Mars. 1246 J. Geophys. Res., 115, E10001, doi:10.1029/2010JE003584.

1247 Vincendon, M., Mustard, J., Forget, F., Kreslavsky, M., Spiga, A., Murchie, S., Bibring, 1248 J.-P., 2010b. Near-tropical subsurface ice on Mars. Geophys. Res. Lett., 37, L01202, 1249 doi:10.1029/2009GL041426.

1250 Williams, K. E., Toon, O. B., Heldmann, J. L., Mellon, M. T., 2009. Ancient melting of 1251 mid-latitude snowpacks on Mars as a water source for gullies. Icarus, 200, 418-425, 1252 doi:10.1026/j.icarus.2008.12.013.

1253 Wordsworth, R. D., 2016. The climate of early Mars. Annu. Rev. Earth Planet. Sci., 44, 1254 381-408, doi:10.1146/annurev-earth-060115-012355.

1255 Zurek, R.W., Smrekar, S.E., 2007. An overview of the Mars Reconnaissance Orbiter 1256 (MRO) science mission. J. Geophys. Res., 112, E05S01, doi:10.1029/2006JE002701. 1257 1258 
1260 Table 1. Comparison of Gully Observations and Dry Frost Model

\begin{tabular}{|c|c|}
\hline Observation & Frost Model Interpretation \\
\hline $\begin{array}{l}\text { Widespread gully activity, consistent with } \\
\text { all fresh gullies being active on timescales } \\
\text { of centuries. }\end{array}$ & Key observation supporting frost model. \\
\hline $\begin{array}{l}\text { Current activity associated with seasonal } \\
\text { frost, primarily } \mathrm{CO}_{2} \text {. }\end{array}$ & Key observation supporting frost model. \\
\hline $\begin{array}{l}\text { Diverse aqueous-like (fluviatile or debris } \\
\text { flow-like) morphologies in gullies. }\end{array}$ & $\begin{array}{l}\text { Observed to form by current processes (see } \\
\text { main text for further discussion). }\end{array}$ \\
\hline $\begin{array}{l}\text { Gullies concentrated in mid-latitudes, } \\
\text { occasionally high latitude, and are } \\
\text { relatively uncommon in Hellas basin and } \\
\text { northern plains.* }\end{array}$ & $\begin{array}{l}\text { Distribution represents overlap of frost } \\
\text { abundance (minimal near equator) and } \\
\text { topographic roughness/steep slopes (rare at } \\
\text { high latitude and on plains). }\end{array}$ \\
\hline Mid-latitude gullies face the pole.* & Consistent with observed frost distribution. \\
\hline $\begin{array}{l}\text { High-latitude gullies face equator or have } \\
\text { no preference.* }\end{array}$ & Consistent with observed frost distribution. \\
\hline $\begin{array}{l}\text { Equatorial gullies exist, but are less } \\
\text { developed (McEwen et al., 2016). }\end{array}$ & $\begin{array}{l}\text { Due to minor frost and/or RSL; should } \\
\text { show minimal fluidization beyond typical } \\
\text { dry mass movements. }\end{array}$ \\
\hline Gullies initiate on steep slopes.* & $\begin{array}{l}\text { Steep slopes are less stable, more easily } \\
\text { eroded; may also be required to permit } \\
\text { frost accumulation at lower latitudes. }\end{array}$ \\
\hline $\begin{array}{l}\text { Gullies found at a wide range of } \\
\text { elevations.* }\end{array}$ & $\begin{array}{l}\mathrm{CO}_{2} \text { frost found at all elevations; frost } \\
\text { point varies }<10 \mathrm{~K} \text { over typical gully } \\
\text { elevations. }\end{array}$ \\
\hline $\begin{array}{l}\text { Gullies found on sand dunes and isolated } \\
\text { peaks.* }\end{array}$ & $\begin{array}{l}\text { Consistent with frost deposited from } \\
\text { atmosphere. }\end{array}$ \\
\hline $\begin{array}{l}\text { Gullies associated with low dust cover, low } \\
\text { albedo, intermediate grain size at coarse } \\
\text { scales (Harrison et al., 2015). }\end{array}$ & $\begin{array}{l}\text { May be proxy for other favorable } \\
\text { conditions; thermophysical classes } \\
\text { correlate with latitude. }\end{array}$ \\
\hline $\begin{array}{l}\text { Gullies are not routinely associated with } \\
\text { hydrated minerals (Núñez et al., 2016). }\end{array}$ & $\begin{array}{l}\text { Consistent with no frequent or long-lived } \\
\text { water-rock interactions. }\end{array}$ \\
\hline $\begin{array}{l}\text { Apparent reduction in gully fluidization in } \\
\text { recent events (Kolb et al., 2010b). }\end{array}$ & $\begin{array}{l}\text { Frost process intensity varies over time; } \\
\text { alternatively, may represent local effects at } \\
\text { the small number of sites. }\end{array}$ \\
\hline $\begin{array}{l}\text { Episodic formation by many events, with } \\
\text { channel abandonment (Dickson and Head, } \\
\text { 2009). }\end{array}$ & $\begin{array}{l}\text { Current activity is the most recent } \\
\text { generation of ongoing formative events. } \\
\text { Channel abandonment observed. }\end{array}$ \\
\hline $\begin{array}{l}\text { Age } \leq \sim 1 \text { Ma (e.g., Reiss et al., 2004; } \\
\text { Schon et al., 2009; Raack et al., 2012). }\end{array}$ & $\begin{array}{l}\text { Consistent with ongoing formation. Most } \\
\text { gullies are un-cratered. }\end{array}$ \\
\hline $\begin{array}{l}\text { Northern hemisphere gullies appear more } \\
\text { degraded/eroded than those in the south } \\
\text { (Heldmann et al., 2007). }\end{array}$ & $\begin{array}{l}\text { Lower current activity rate in northern } \\
\text { gullies, due to occurrence of perihelion in } \\
\text { northern fall. }\end{array}$ \\
\hline Buried and/or inactive gullies exist (e.g., & Due to variations in the distribution of \\
\hline
\end{tabular}




\begin{tabular}{|l|l|}
\hline $\begin{array}{l}\text { Morgan et al., 2010; Raack et al., 2012; } \\
\text { Dickson et al., 2015a). }\end{array}$ & $\begin{array}{l}\text { seasonal frost processes over time (cf. } \\
\text { Pilorget and Forget, 2016). }\end{array}$ \\
\hline $\begin{array}{l}\text { Gullies commonly incised into mid-latitude } \\
\text { mantle (e.g., Christensen, 2003). }\end{array}$ & $\begin{array}{l}\text { Mantle readily eroded by frost processes } \\
\text { when not ice-cemented. Bedrock is more } \\
\text { resistant to erosion and mobilization. }\end{array}$ \\
\hline $\begin{array}{l}\text { Occasional association with bedrock layers } \\
\text { (e.g., Malin and Edgett, 2000; Gilmore and } \\
\text { Phillips, 2002). }\end{array}$ & $\begin{array}{l}\text { Consistent with erosion of material up to } \\
\text { resistant layers. }\end{array}$ \\
\hline $\begin{array}{l}\text { Gully fan outcrops expose boulders (de } \\
\text { Haas et al., 2015c). }\end{array}$ & $\begin{array}{l}\text { Current processes observed to transport and } \\
\text { bury boulders within channels and on fans. }\end{array}$ \\
\hline $\begin{array}{l}\text { Small lunar mass-wasting features } \\
\text { resemble poorly developed gullies with } \\
\text { straight channels (Bart, 2007; Kumar et al., } \\
\text { 2013). }\end{array}$ & $\begin{array}{l}\text { Demonstrates that simple forms can } \\
\text { develop with no volatile; larger, well- } \\
\text { developed features require frost processes. }\end{array}$ \\
\hline
\end{tabular}

1261 *Major surveys of the distribution and properties of gullies include Malin and Edgett 1262 (2000), Heldmann and Mellon (2004), Heldmann et al. (2007), Balme et al. (2006), 1263 Bridges and Lackner (2006), Dickson et al. (2007), Dickson and Head (2009), Kneissl et 1264 al. (2010), and Harrison et al. (2015).

1265

1266

\section{Figure Captions}




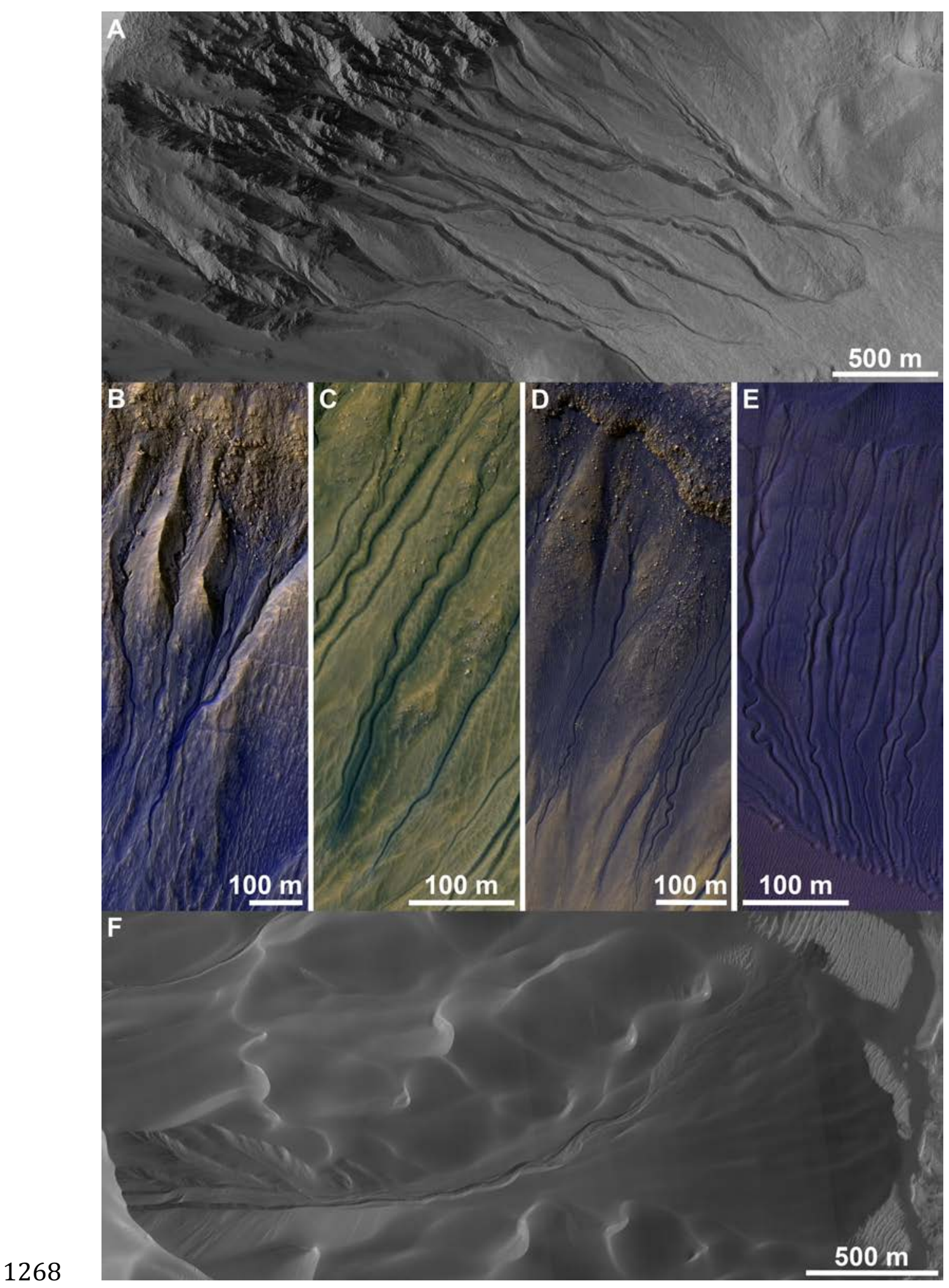

1269 Figure 1. Examples of gully morphologies. A) Examples of classic alcove-channel-apron

1270 gullies cut into the wall of Triolet crater $\left(37.1^{\circ} \mathrm{S}, 191.9^{\circ} \mathrm{E}\right)$. B-E show a gradation from 
1271 classic crater-wall gullies towards linear dune gullies. B) Alcove-channel-apron gullies

1272 cut into mid-latitude mantle material, but with minor sand coloration/infill. C) Gullies

1273 with distinct channels but minor alcoves and depositional aprons, cut into a substrate with

1274 some large ripples but without the coloration of sand. D) Gullies in crater-wall material

1275 that appears to be a mix of sand and other material. E) Linear dune gullies (channels with

1276 minimal alcoves or deposits, and common terminal pits) in sand, including sinuous

1277 examples. F) Large dune gully in Matara crater $\left(49.5^{\circ} \mathrm{S}, 34.9^{\circ} \mathrm{E}\right)$ with classic alcove-

1278 channel-apron morphology. (A: HiRISE image PSP_003583_1425. B:

1279 ESP_046309_1425. C: ESP_040402_1410. D: ESP_024344_1325. E:

1280 ESP_029701_1295. F: ESP_038387_1300. Downhill is to the right in A and F and to the

1281 bottom in B-E. All image figures herein are sub-frames of HiRISE images (credit:

1282 NASA/JPL/University of Arizona) with north up and light from the left, and have been

1283 stretched to maximize local contrast. All original data are available via the Planetary Data

1284 System.)
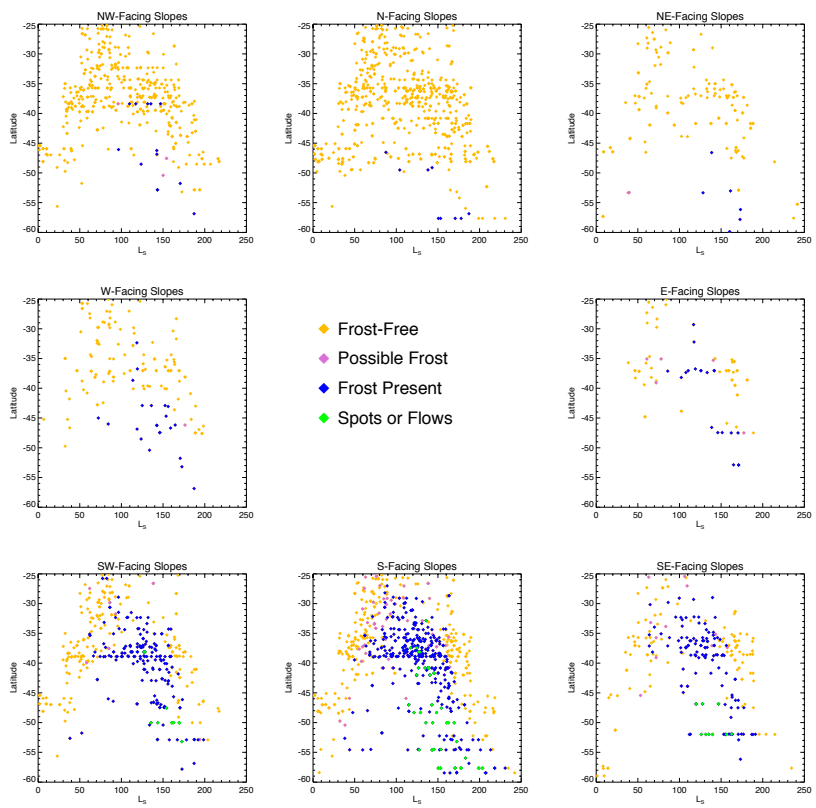
1286 Figure 2. Seasonal frost (outside gully alcoves) in the southern hemisphere, as a function

1287 of season and slope orientation.

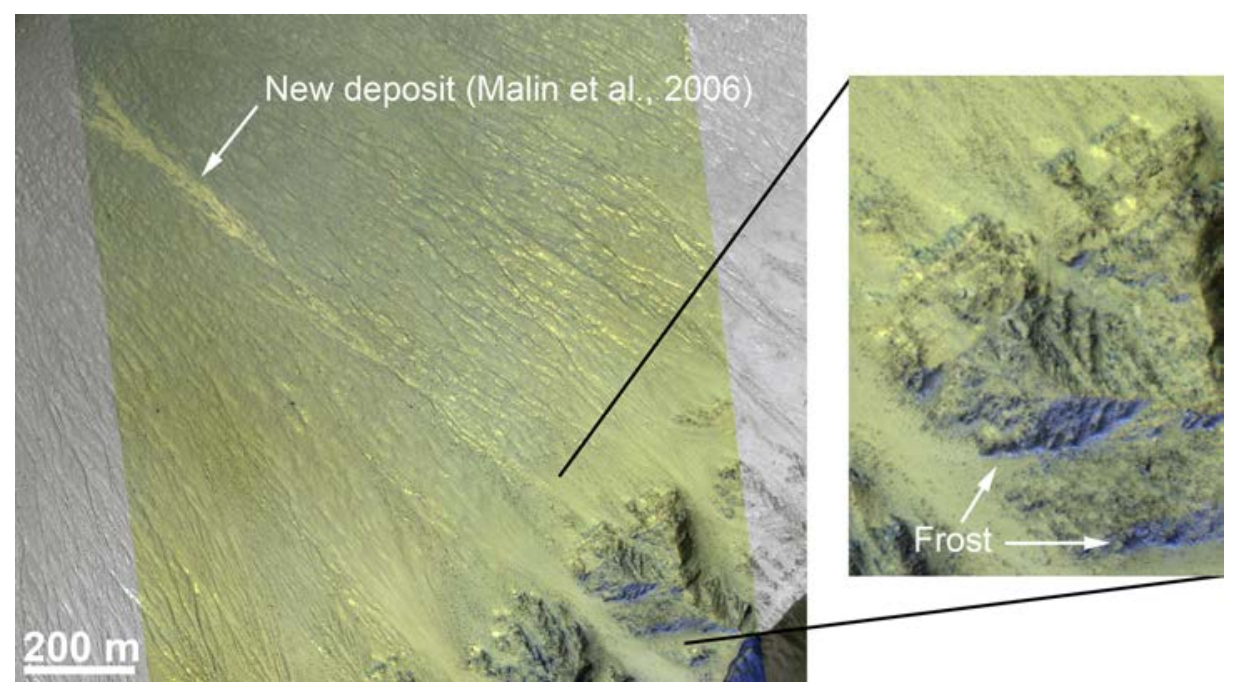

1289 Figure 3. One of the few equator-facing mid-latitude gully flows correlates with an

1290 unusual small patch of frost. Local frost (blue-tinted material) occurred in hollows on a

1291 broadly equator-facing slope uphill (lower right) from a new gully deposit in Penticton

1292 crater $\left(38.4^{\circ} \mathrm{S}, 96.8^{\circ} \mathrm{E}\right)$ at $\mathrm{L}_{\mathrm{S}}=132^{\circ}$. (HiRISE image ESP_036578_1415.)

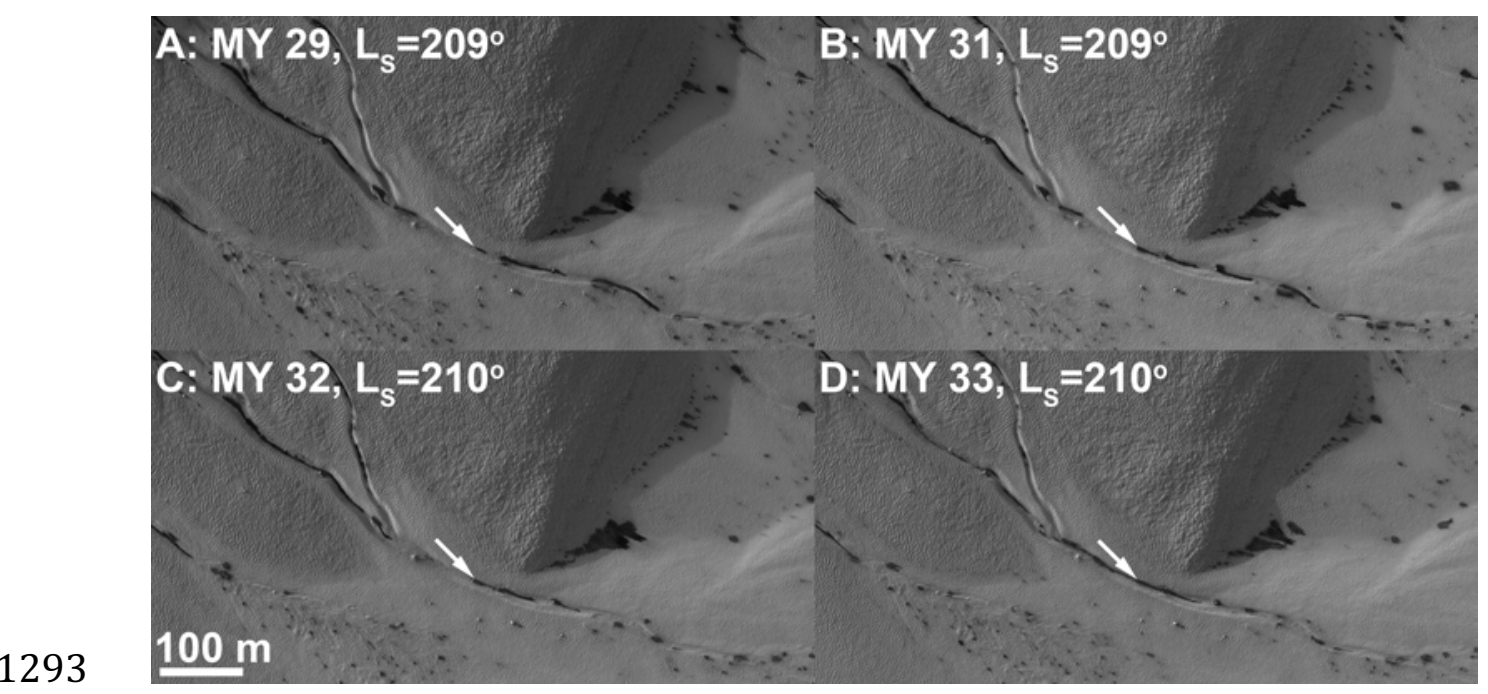

1294 Figure 4. Example of defrosting flows in a polar pit gully $\left(68.5^{\circ} \mathrm{S}, 1.3^{\circ} \mathrm{E}\right)$. Flows

1295 concentrate in channels, gradually advance, and approximately repeat from year to year.

1296 The flows are dark in contrast with the widespread frost and leave no resolvable sign in 
1297 albedo or topography once the frost is gone. Arrows indicate the source point of a flow

1298 for comparison between years. In (D), the flow is being overtaken by another flow

1299 initiating higher in the channel. (A: HiRISE image ESP_011963_1115. B:

1300 ESP_029580_1115. C: ESP_038428_1115. D: ESP_047250_1115. Downhill is to the 1301 lower right.)

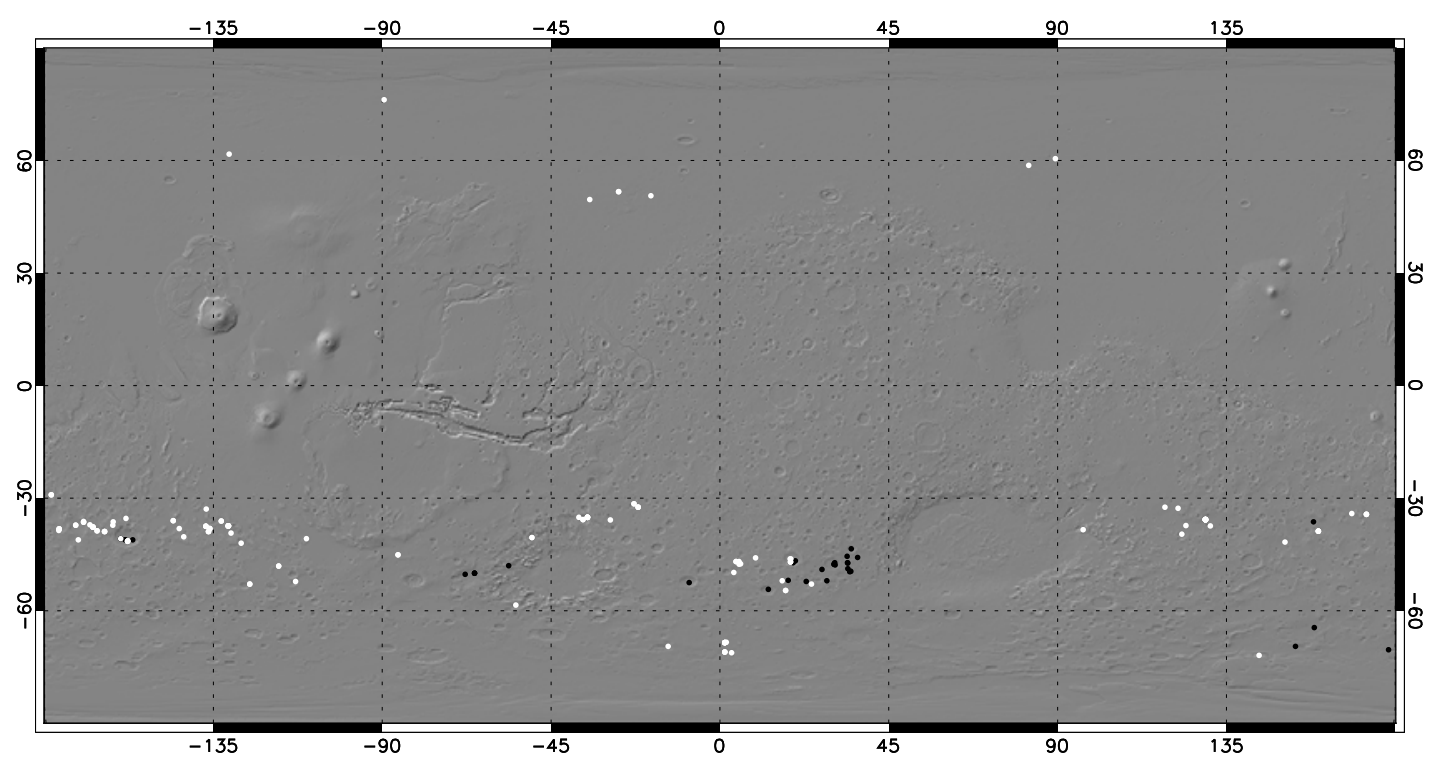

1303 Figure 5. Map of observed active gullies (white symbols) and active dune or sandy-slope 1304 gullies (black). North polar dune alcoves (Hansen et al. 2015) and similar minor alcoves 1305 on other dunes are not included here. 


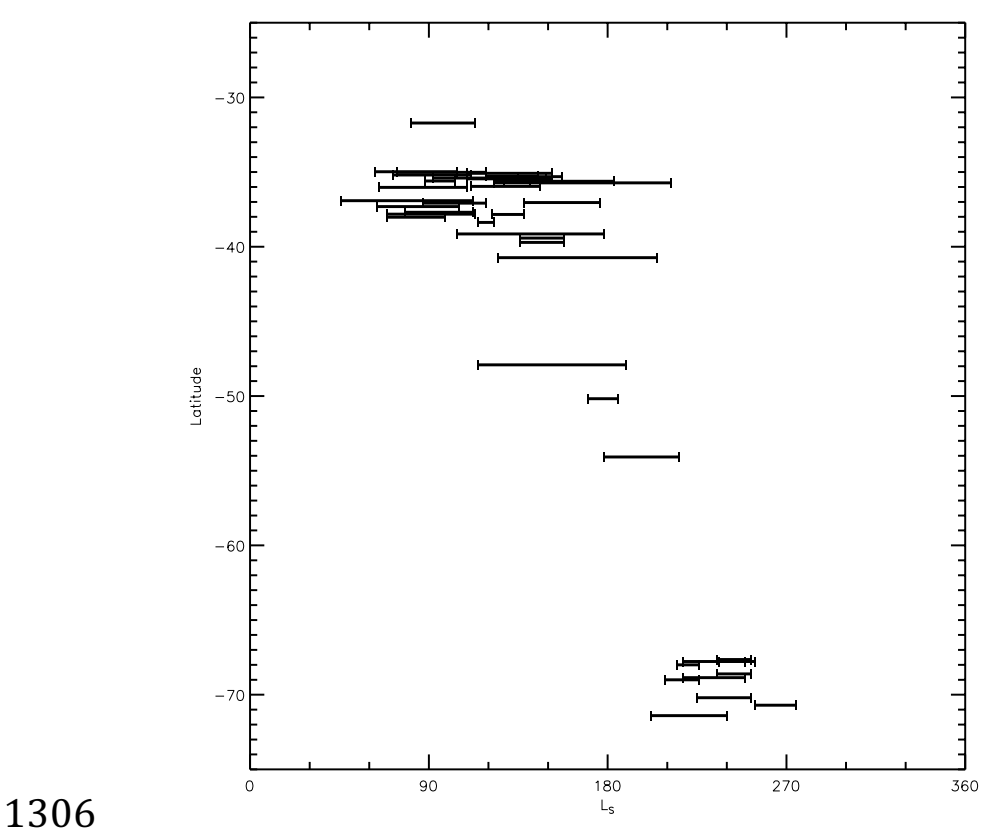

1307 Figure 6. Timing of well-constrained gully changes in the southern hemisphere as a

1308 function of latitude. Only changes constrained to an interval $<90^{\circ}$ of $\mathrm{L}_{\mathrm{S}}$ are shown. (Note 1309 that this is not quite a constant unit of time due to Mars' elliptical orbit.) Lines are offset 1310 in latitude by small amounts in order to separate overlapping intervals. 


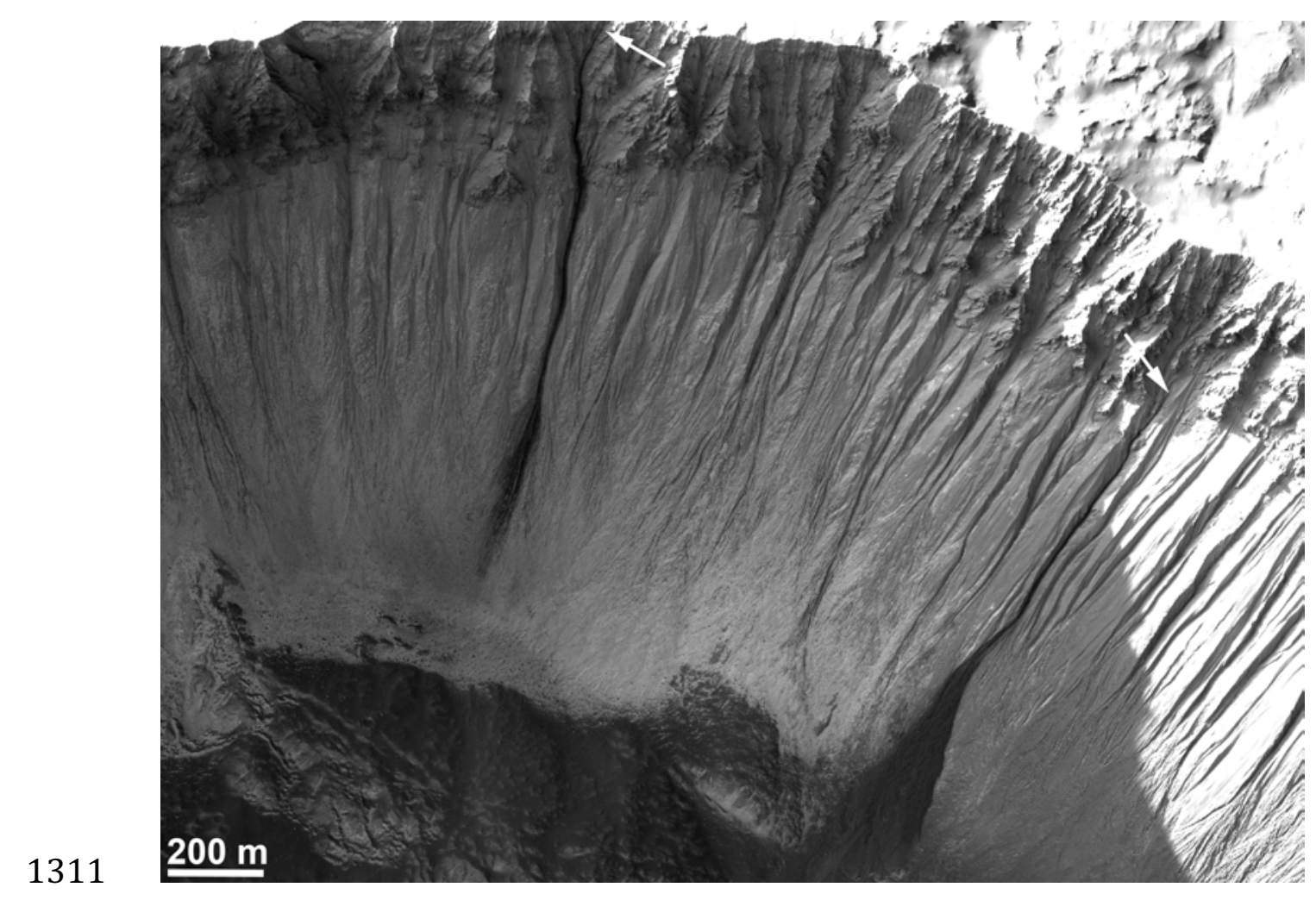

1312 Figure 7. Gully flows in Selevac crater $\left(37.4^{\circ} \mathrm{S}, 228.9^{\circ} \mathrm{E}\right)$. The flows bury or disrupt

1313 seasonal frost, allowing the shape of the entire mass movement to be seen. They begin at

1314 point sources (arrows), descend along channels, and terminate in extensive deposits. The

1315 image is in shadow and has been stretched to show detail, saturating the illuminated

1316 areas; original data available via the Planetary Data System. (HiRISE image

1317 ESP_045158_1425.) 

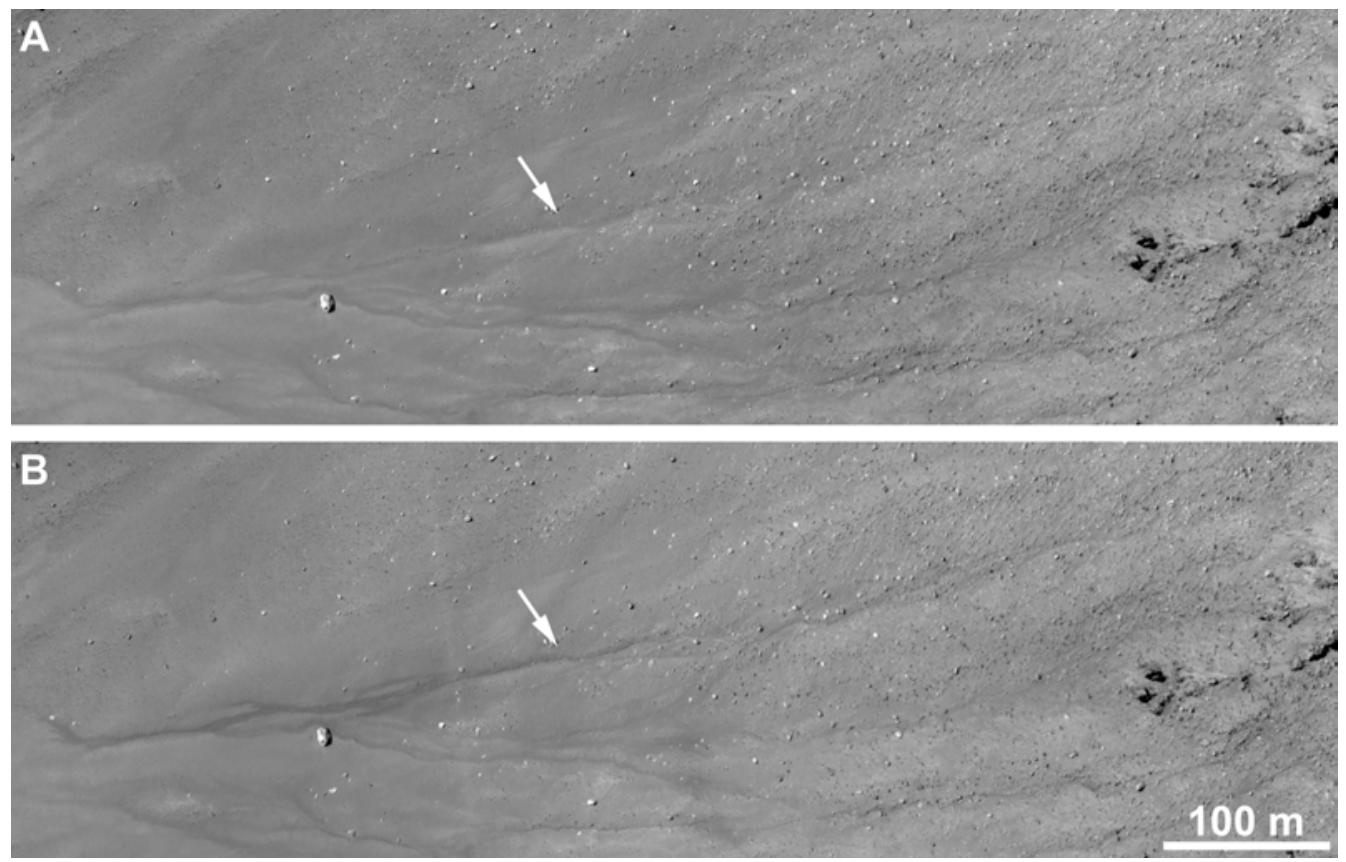

1319 Figure 8. Activity in Raga crater $\left(48.1^{\circ} \mathrm{S}, 242.4^{\circ} \mathrm{E}\right)$ showing gully formation. An ill-

1320 defined shallow trough or degraded gully seen in MY 29 (A) subsequently became active.

1321 Two flow events occurred, resulting in a much more sharply-defined channel system (B).

1322 (A: HiRISE image ESP_014011_1315. B: ESP_040239_1315. Downhill is to the left.) 


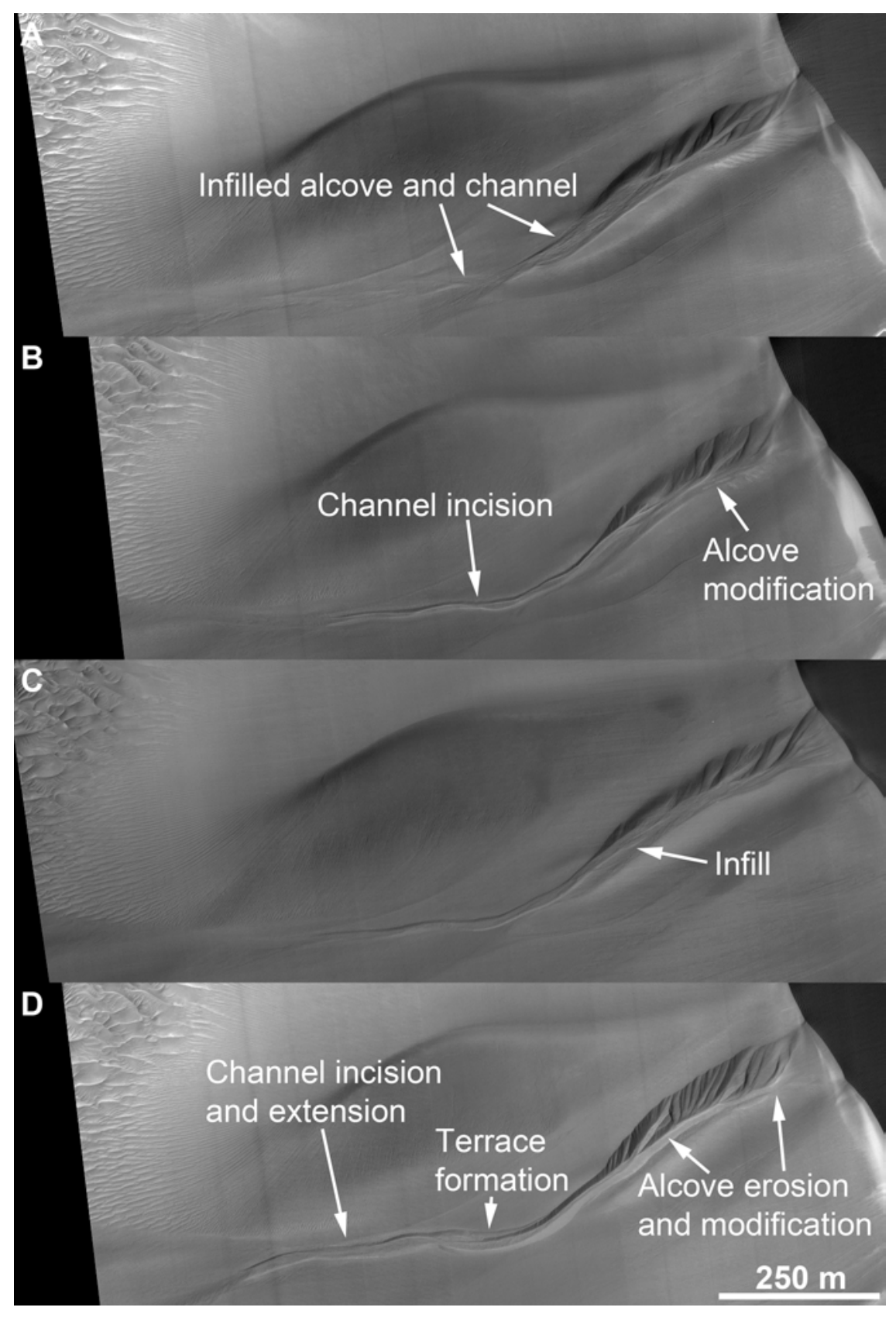

1324 Figure 9. Major changes in a dune gully west of the Argyre basin $\left(48^{\circ} \mathrm{S}, 303.7^{\circ} \mathrm{E}\right)$,

1325 progressing from a degraded alcove and obliterated apron (A) to a sharply defined system

1326 with a large, terraced channel (D). Panels B-C show incremental annual changes, which

1327 can each be dated to Martian winter. (A: HiRISE image ESP_023582_1315. B:

1328 ESP_030584_1315. C: ESP_038087_1315. D: ESP_047331_1315. Downhill is to the 1329 left.) 


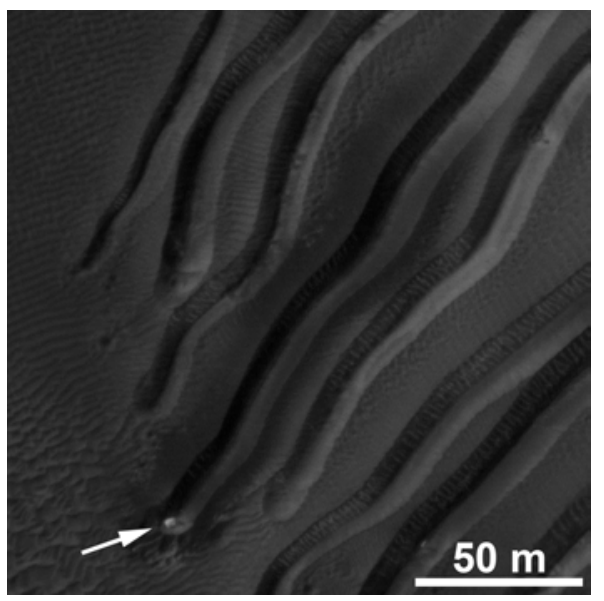

1331 Figure 10. Ice slab and dark halo at the toe of a large linear dune gully in Russell crater

$1332\left(54.3^{\circ} \mathrm{S}, 12.9^{\circ} \mathrm{E}\right)$. The halo is interpreted to form via sand thrown out by the sliding ice

1333 block, maintaining and incising the channel (Diniega et al., 2013). (HiRISE image

1334 ESP_047078_1255. Downhill is to the lower left.)

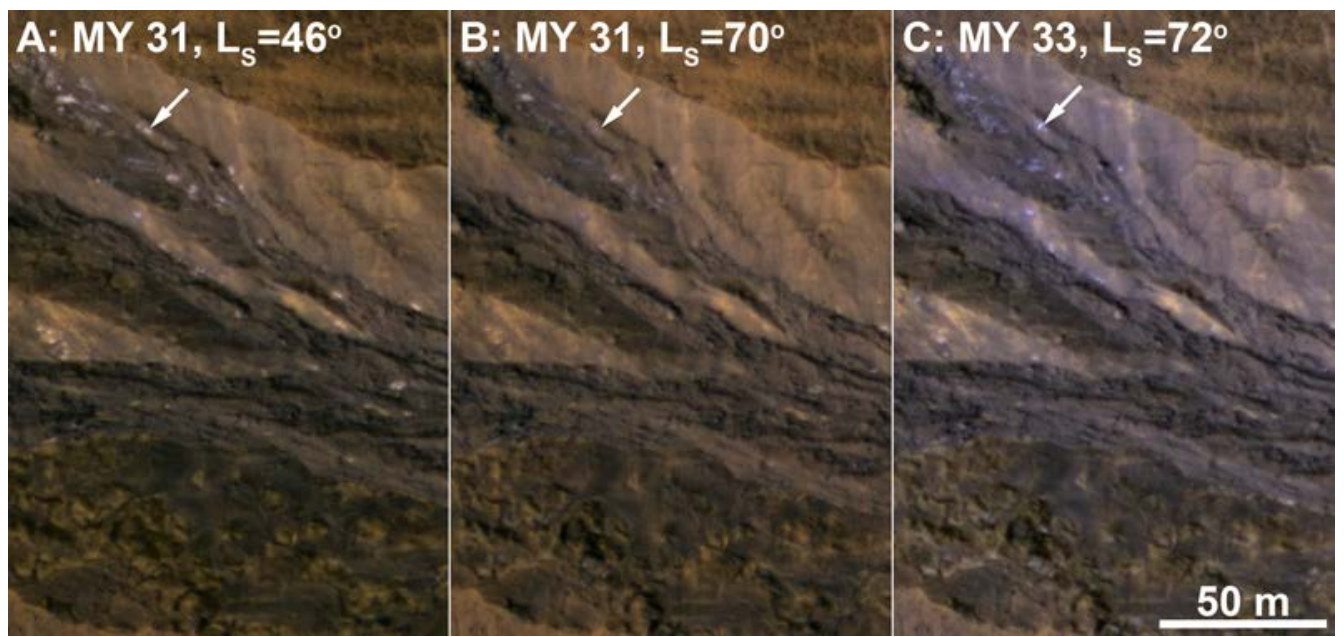

1336 Figure 11. Likely ice exposure in mid-latitude mantle materials in a gully alcove

$1337\left(59.5^{\circ} \mathrm{N}, 302.2^{\circ} \mathrm{E}\right)$. Bright spots appeared prominent in mid-spring of MY 31 but faded

1338 over several months. They were again prominent, but with a different pattern, in MY 33.

1339 Arrow indicates an example of one of the spots. (A: HiRISE image ESP_025322_2400.

1340 B: ESP_026021_2400.C: ESP_043691_2400. Downhill is to the right.) 

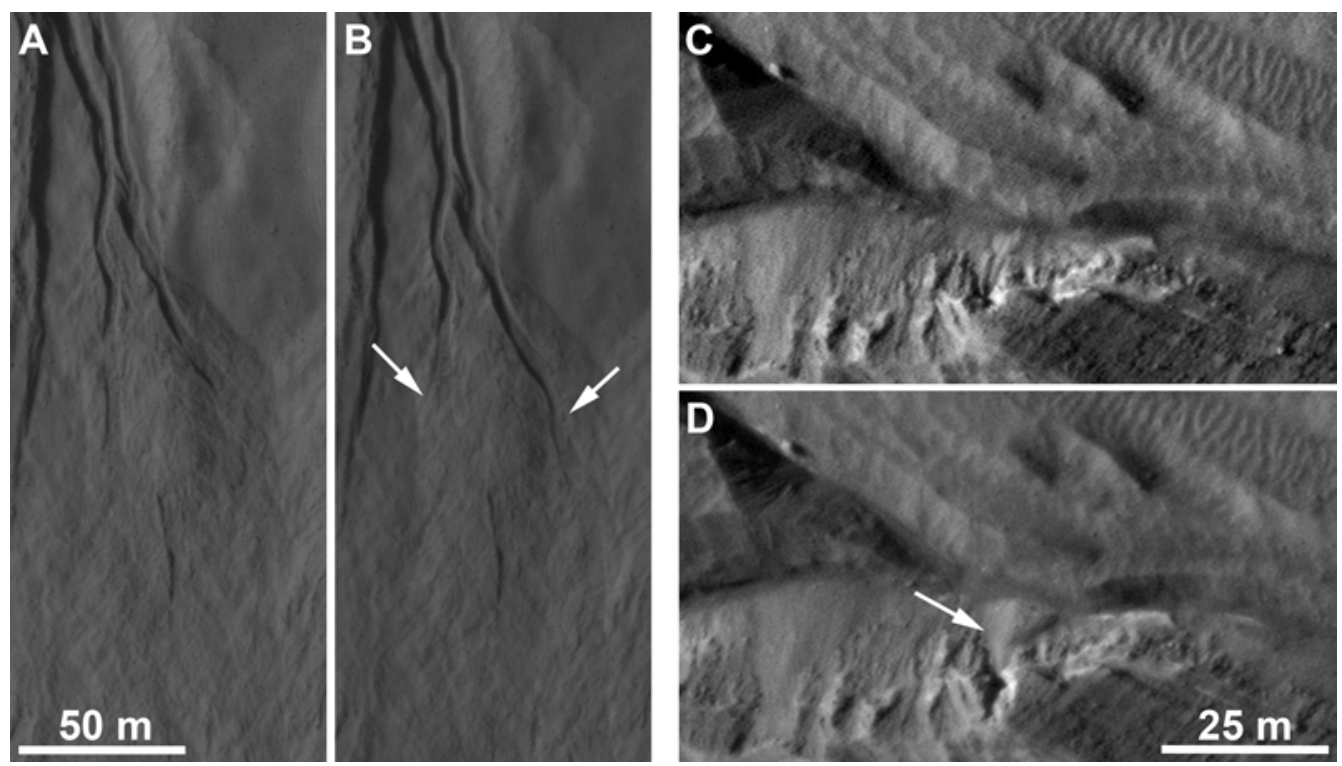

1342 Figure 12. Examples of channel changes in gullies. A-B) A flow event in this gully in

1343 eastern Hale crater $\left(35.1^{\circ} \mathrm{S}, 324.7^{\circ} \mathrm{E}\right)$ divided between two channels. The arrows indicate

1344 that in one (left), deposition obliterated part of the channel system, while in the other

1345 (right), the channel was extended. Distributed changes due to deposition occur

1346 throughout the bottom of the frames. C-D) A flow in Triolet crater $\left(37.1^{\circ} \mathrm{S}, 191.9^{\circ} \mathrm{E}\right)$

1347 disturbed material along the edge of the channel, causing a small hollow to collapse and

1348 form a small debris cone within the channel. (A: HiRISE image ESP_011819_1445. B:

1349 ESP_038218_1445. C: ESP_020751_1425. D: ESP_047190_1425. Downhill is to the

1350 bottom in $\mathrm{A}-\mathrm{B}$ and to the right in $\mathrm{C}-\mathrm{D}$.) 

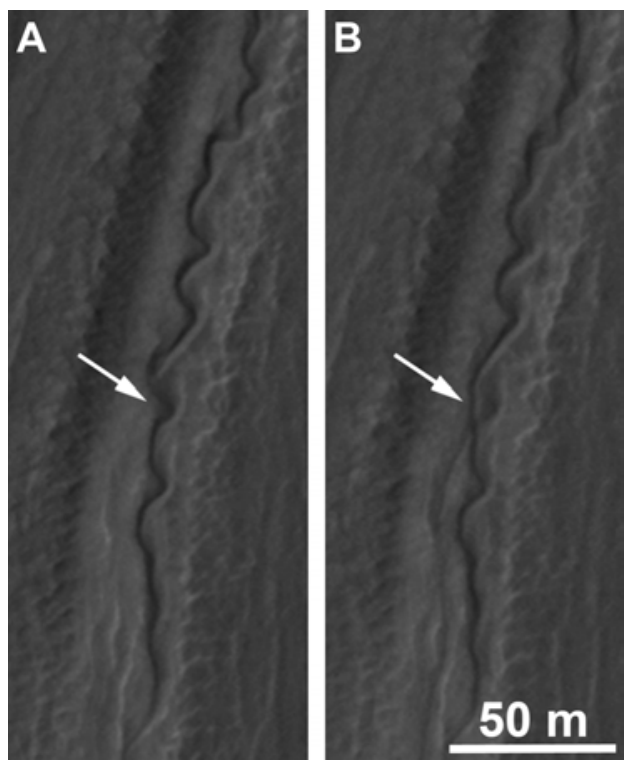

1352 Figure 13. Cutoff of a sinuous curve (arrow) by a new incised segment in a gully channel

1353 within sandy fill in a crater-wall gully $\left(38.9^{\circ} \mathrm{S}, 196^{\circ} \mathrm{E}\right)$. (A: HiRISE image

1354 ESP_029032_1410. B: ESP_046702_1410. Downhill is to the bottom.)
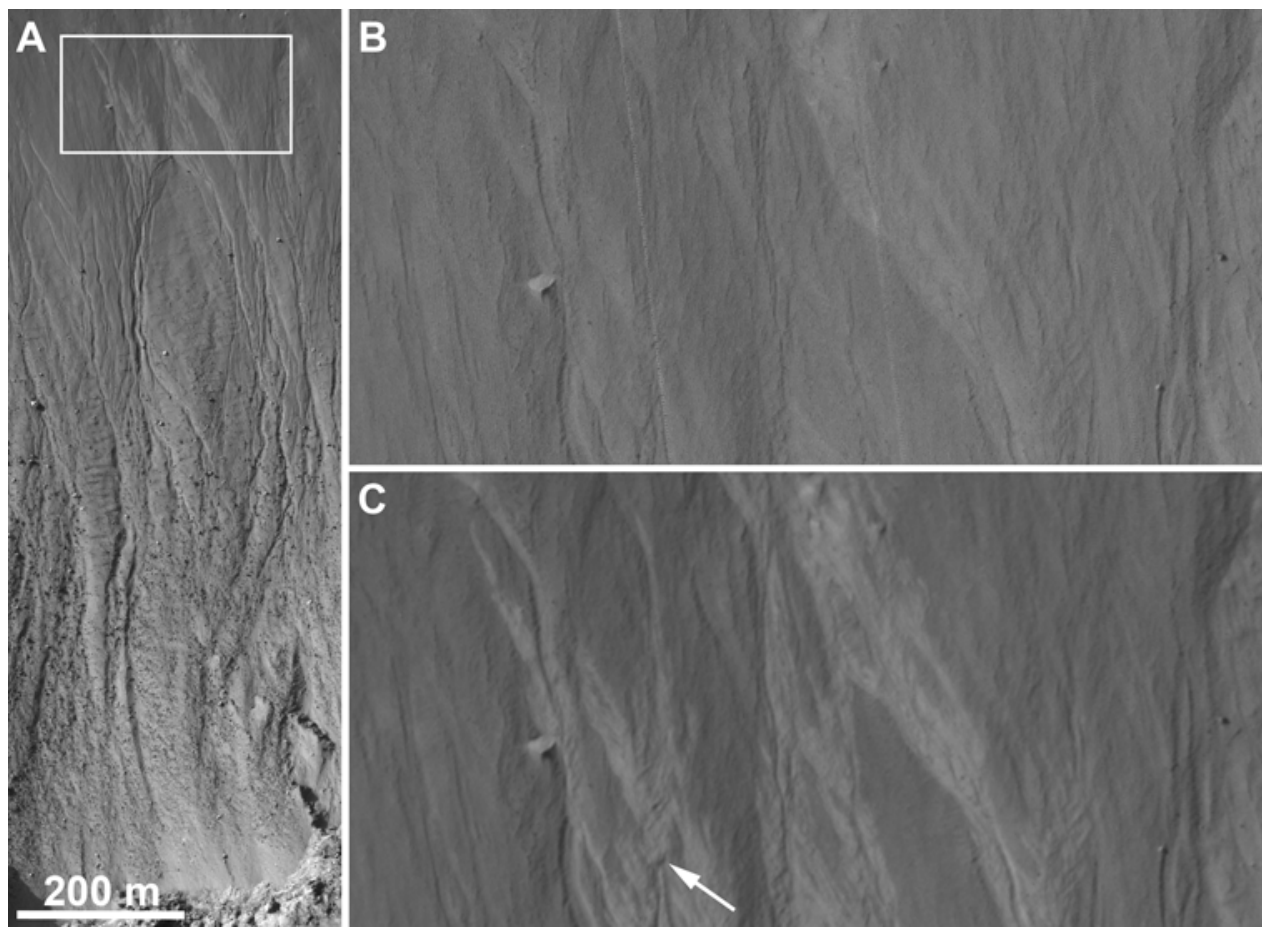

C

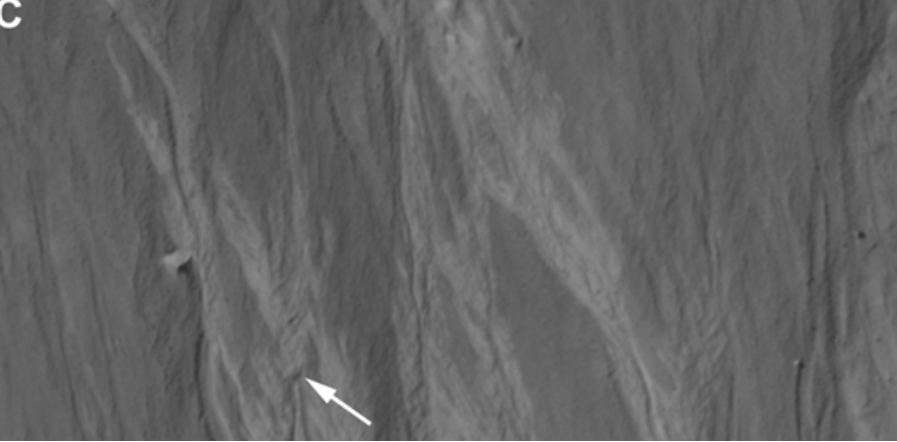

1356 Figure 14. Example of branching flow producing activity in multiple channels, located in

1357 Asimov crater $\left(46.8^{\circ} \mathrm{S}, 4.3^{\circ} \mathrm{E}\right)$. A) Overview of gully system, with complex channel 
1358 network. Box indicates location of panels B-C. B) "Before" image showing faint light

1359 material associated with some channels. C) "After" image with distinct bright deposits

1360 branching and occupying different channels, breaking out in some cases. Deposition

1361 producing a topographic change (arrow) demonstrates that this is real activity and not a

1362 photometric effect. (A, C: HiRISE image ESP_036977_1330. B: PSP_002179_1330.

1363 Downhill is to the top.)
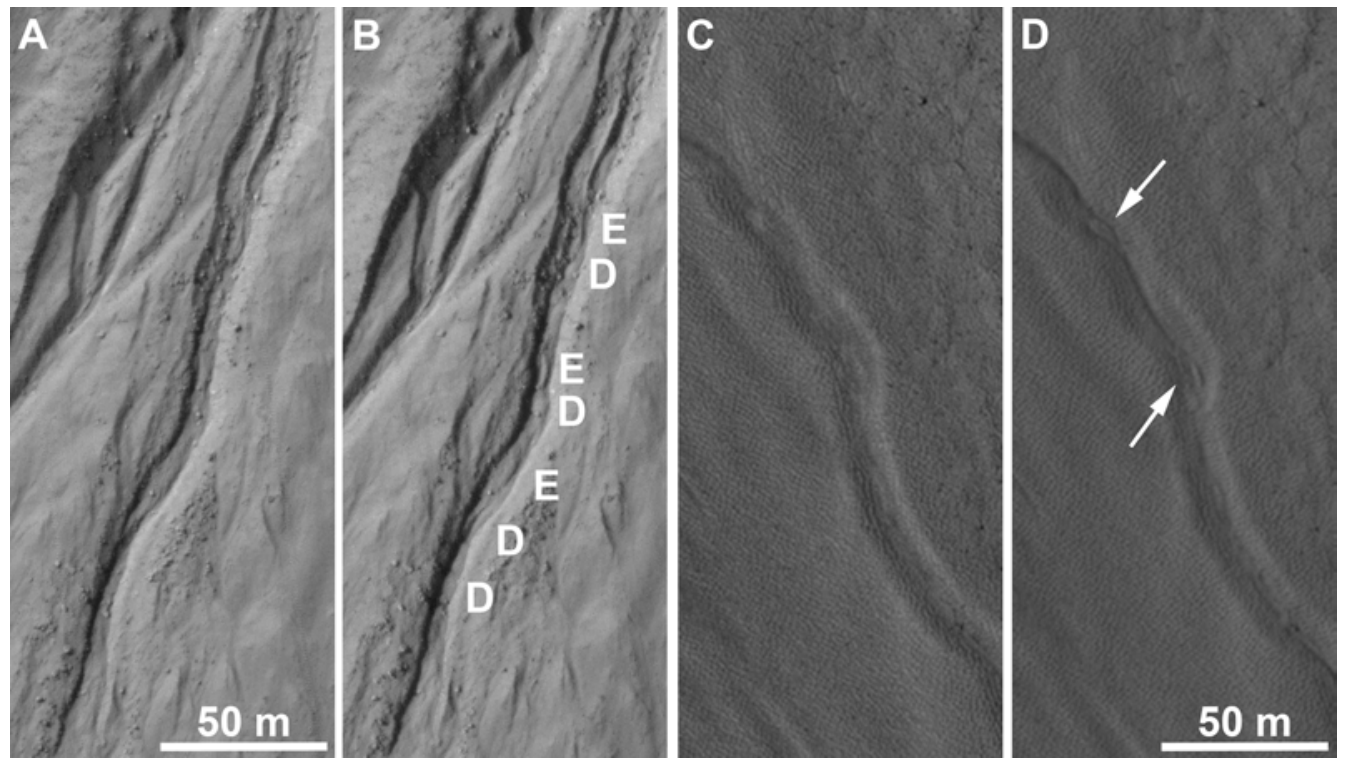

1365 Figure 15. Examples of changes in channels. A-B) Alternating erosion and deposition

1366 ("E" and "D" annotations) produced by local conditions, resulting in small-scale bar-like

1367 landforms within the channel $\left(38.1^{\circ} \mathrm{S}, 224^{\circ} \mathrm{E}\right)$. C-D) Incision within an older, larger

1368 channel $\left(47.5^{\circ} \mathrm{S}, 5.5^{\circ} \mathrm{E}\right)$, resulting in formation or enhancement of an "island" (upper

1369 arrow) and a lobate bar-like feature (lower arrow). (A: HiRISE image

1370 ESP_023809_1415. B: ESP_047057_1415. C: ESP_013334_1320. D:

1371 ESP_047276_1320. Downhill is to the bottom in all panels.) 


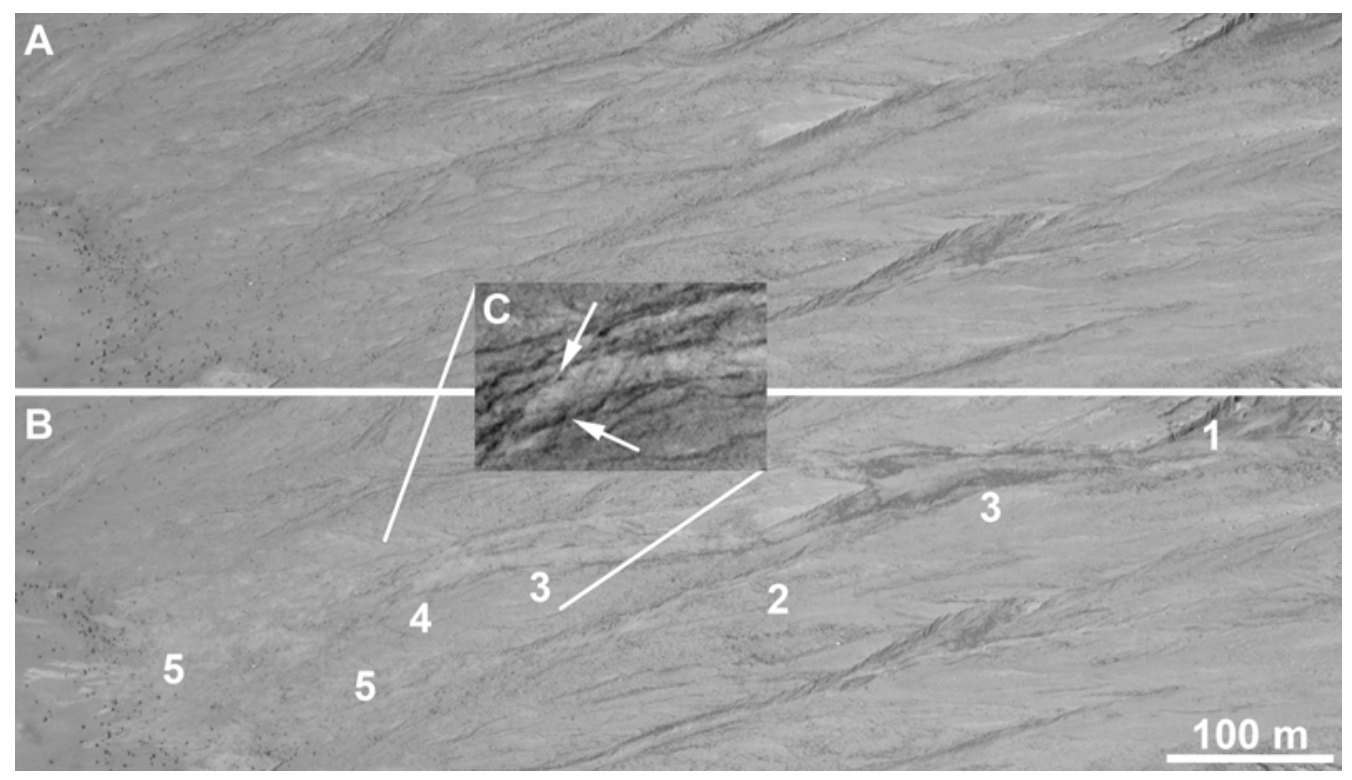

1373 Figure 16. Changes within a gully system in Istok crater $\left(45.1^{\circ} \mathrm{S}, 274.2^{\circ} \mathrm{E}\right)$, which either

1374 divided between two gullies or encompassed multiple events closely spaced in time.

1375 Numbers indicate source alcove (1), local scour of a channel segment (2), deposition of

1376 dark boulder-rich levees (3), formation of a lobate deposit snout (4), and distributed

1377 topographic changes (sufficient to move and/or bury rocks) (5). Note that the most distal

1378 deposits are small, relatively-bright toes, although the deposit mostly matches the tone of

1379 the upper slope and thus lacks contrast. Inset C) shows an enlarged view of the lobate

1380 snout (4) from a low-Sun image to emphasize topography with arrows indicating

1381 margins. (A: HiRISE image ESP_040251_1345. B: ESP_048255_1345. C:

1382 ESP_045842_1345. Downhill is to the left.) 


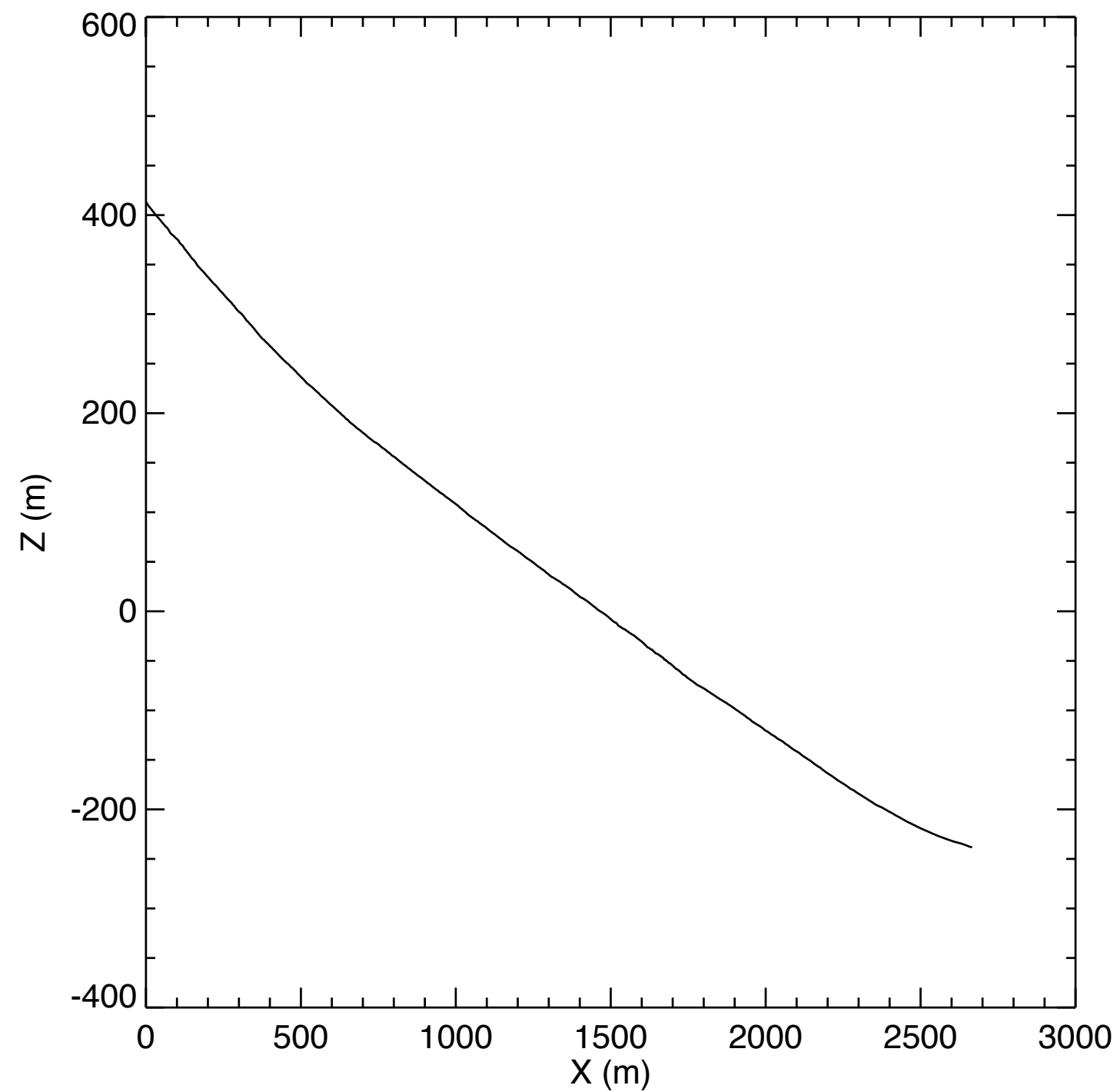

1383

Figure 17. Longitudinal profile of the large alcove-channel-apron dune gully in Matara

1385 crater (Fig. 1f) derived from a HiRISE Digital Terrain Model

1386 (DTEEC_022115_1300_22392_1300_U01). Using definitions from Conway et al.

1387 (2015), this profile has concavity measures $A_{\text {ero }}=0.14$ (Mars gully range $0.02-0.77$ from

1388 Conway et al. (2015), $E q=0.28$ (Mars range 0.11-0.63), $C I=0.07$ (Mars range $-0.16-0.3$ ),

1389 and $\theta=-0.23$ (Mars range $-0.86-0.02$ ). The slope is over $20^{\circ}$ near the head of the gully 
1390 (and may be higher on alcove slopes above the thalweg) and below $10^{\circ}$ near the flow 1391 termination.

1392 


\section{Supplementary Materials for "The Formation of Gullies on Mars Today"}

The supplementary information for this report includes figures, animations, and a summary table describing details of known gully activity. Original HiRISE images are available via the Planetary Data System, including both raw spacecraft data and the Reduced Data Records used for these figures. Some images have been stretched to improve contrast.

\section{Supplementary Figures}

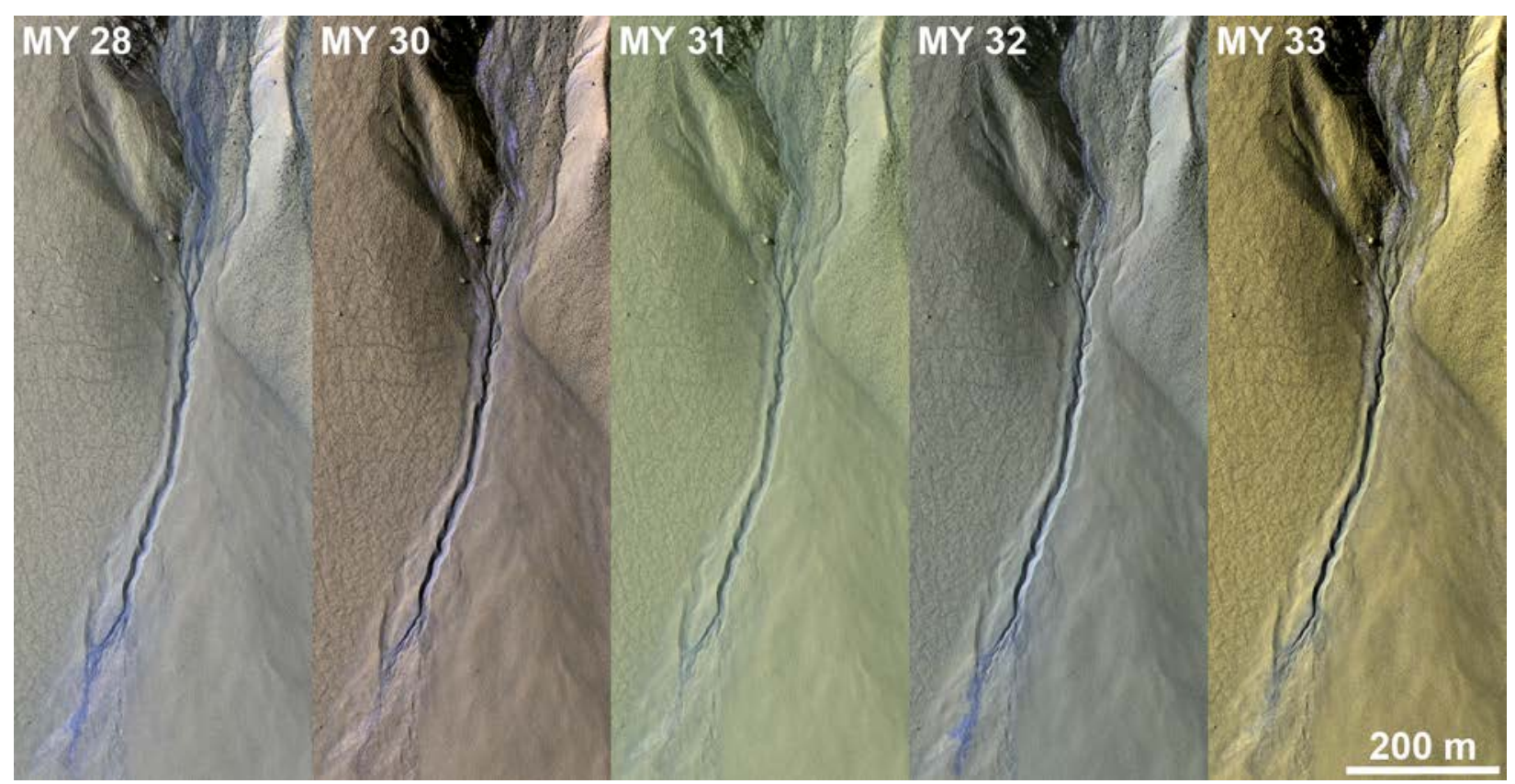

Supplementary Figure 1. Rapid changes in the appearance of deposits associated with a gully at $54.5^{\circ}$ S. The deposit appeared fresh in MY 28 , but was largely faded in MY 30 31. In MY 32, a new dark deposit formed, with accompanying morphologic changes including minor channel incision. This deposit had mostly faded by MY 33. This demonstrates that distinct deposits can fade on short timescales, and also that frequent activity can occur in individual gullies. (HiRISE color images PSP_003695_1250, ESP_020863_1250, ESP_030344_1250, ESP_038546_1250, and ESP_047302_1250. Images have relative stretch to maximize contrast despite variable frost, illumination, and atmospheric dust, so absolute color is not directly comparable across images.) 


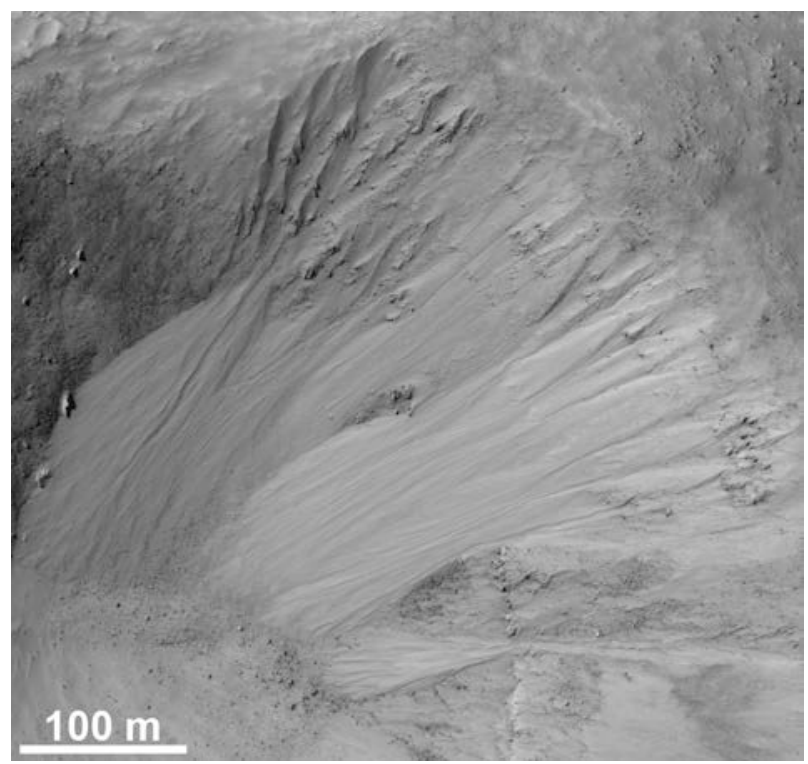

1416 Supplementary Figure 2. Equatorial gully-like landforms (McEwen et al., 2016) in an 1417 unnamed crater at $2.6^{\circ} \mathrm{N}$ latitude. Water frost is observed at low latitudes in the southern hemisphere (Vincendon et al., 2010a) and perhaps traces are enough to occasionally trigger mass movements and gully formation. Nighttime $\mathrm{CO}_{2}$ frost also occurs in lowthermal inertia regions at the equator (Piqueux et al., 2016), and $\mathrm{H}_{2} \mathrm{O}$ frost has been observed on the Opportunity rover in the early morning (Landis et al., 2007). However, equatorial gullies have not been studied in sufficient detail to understand how they relate to the more prominent mid-latitude features. (HiRISE image ESP_034864_1825.)

\section{A}

$100 \mathrm{~m}$

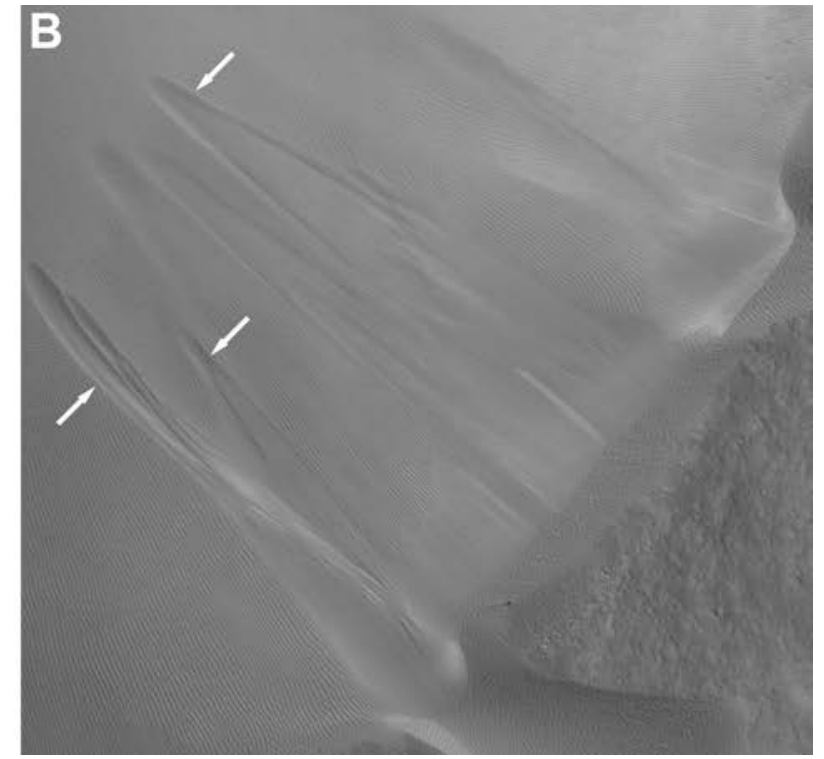

Supplementary Figure 3. Large-scale, leveed, lobate flows formed in sand covering an equatorial crater wall in Meroe Patera $\left(7.2^{\circ} \mathrm{N}, 67.8^{\circ} \mathrm{E}\right)$, demonstrating that these morphologies can form with little or no volatiles (HiRISE images ESP_039388_1875 and ESP_040588_1875.) 

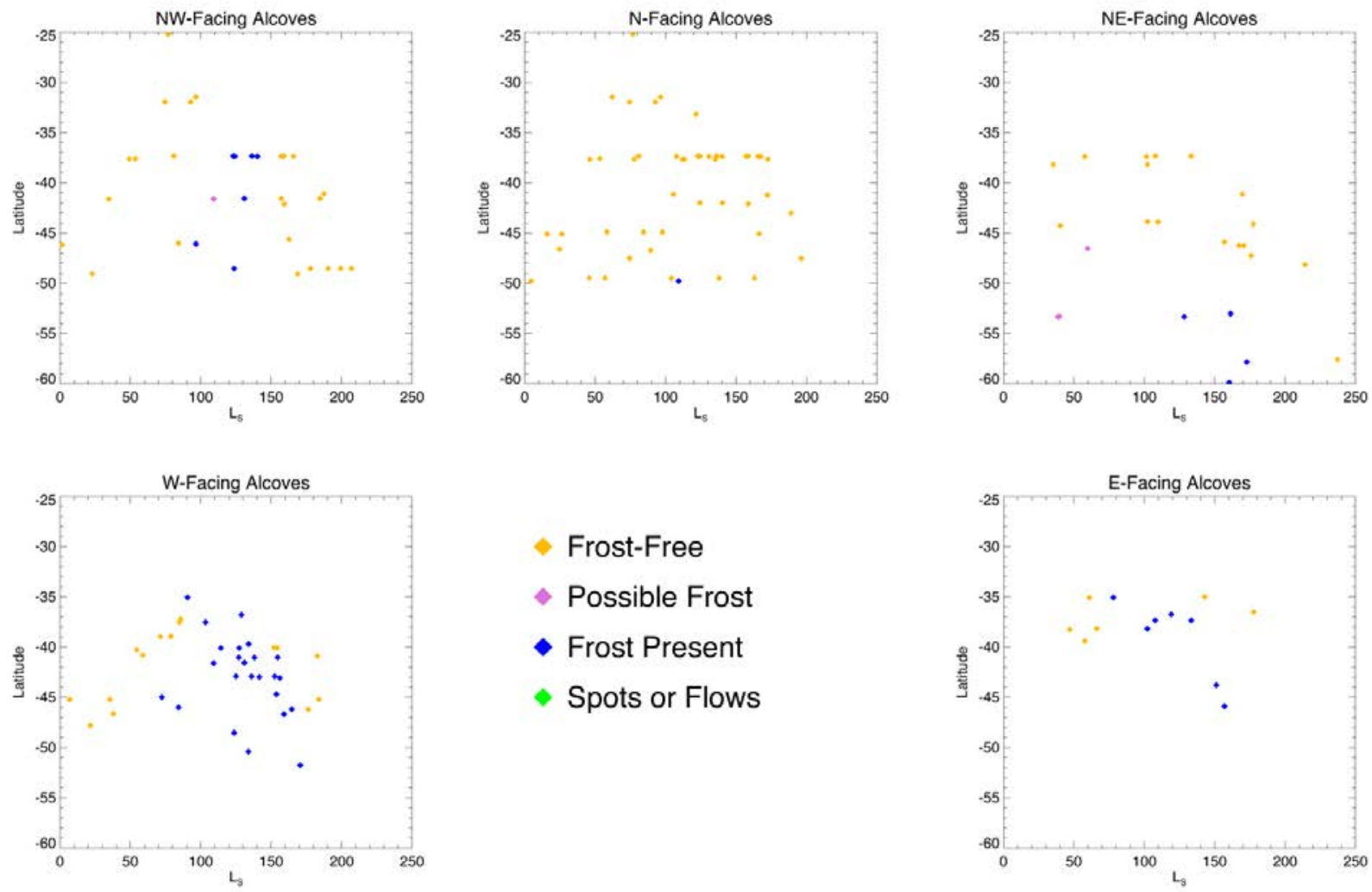

- Frost-Free

- Possible Frost

- Frost Present

Spots or Flows
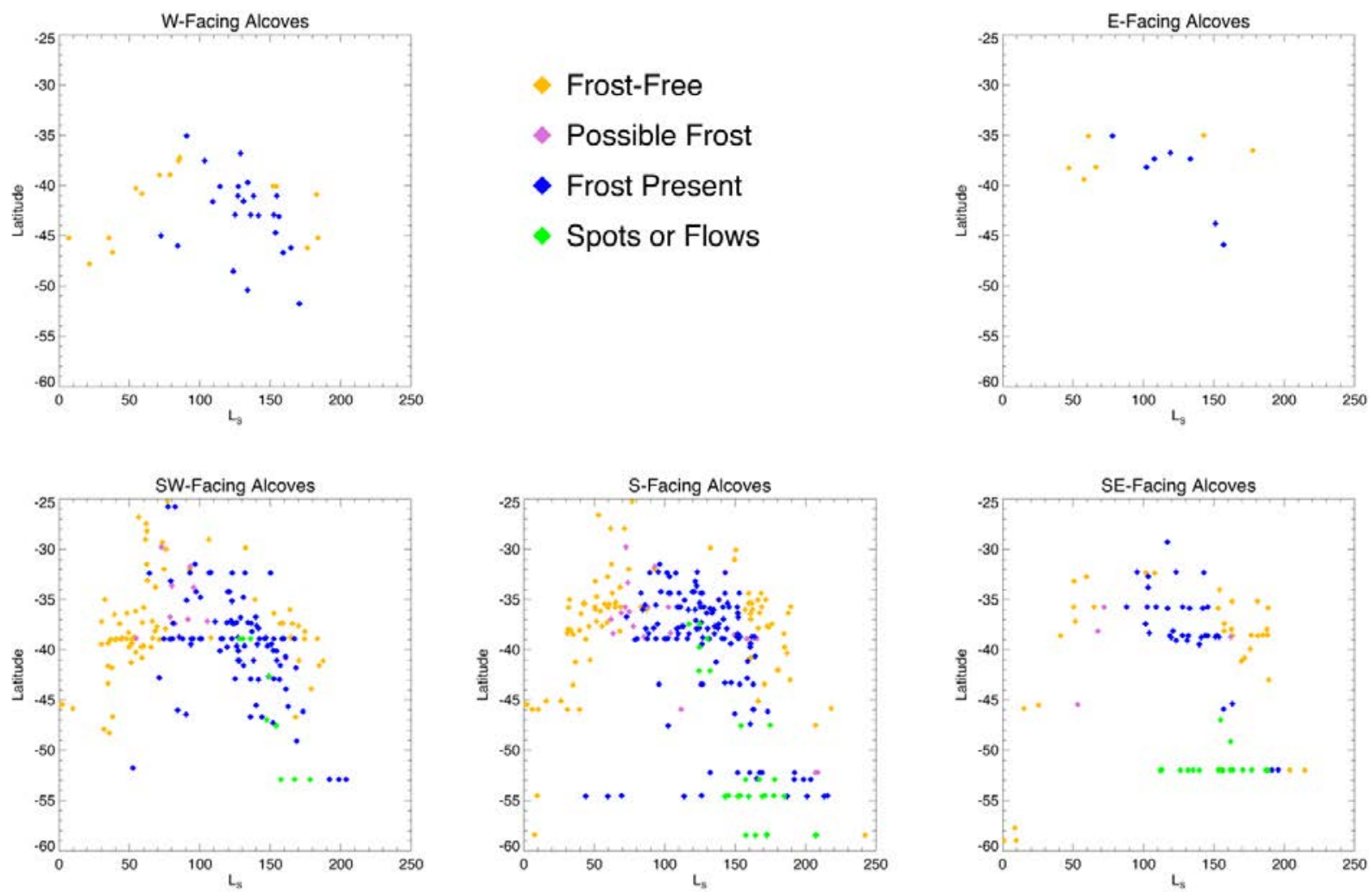

Supplementary Figure 4. Observations of frost within moderately to well-developed gully alcoves in the southern hemisphere (compare with main text Fig. 2, which shows non-gullied slopes and poorly developed, shallow alcoves). 

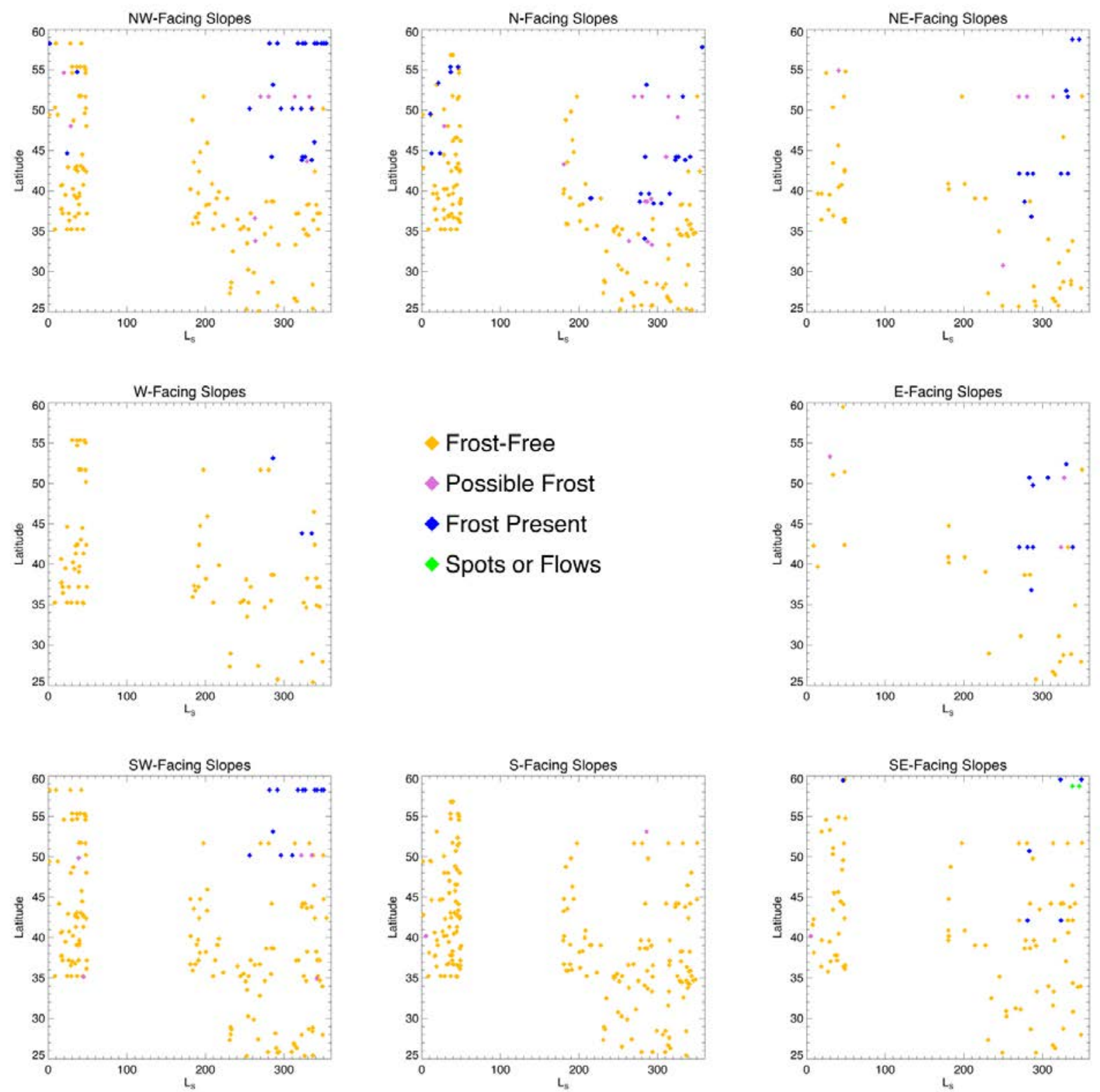

Supplementary Figure 5. Observations of frost on non-gully slopes or in poorly 1438 developed alcoves in the northern hemisphere. 

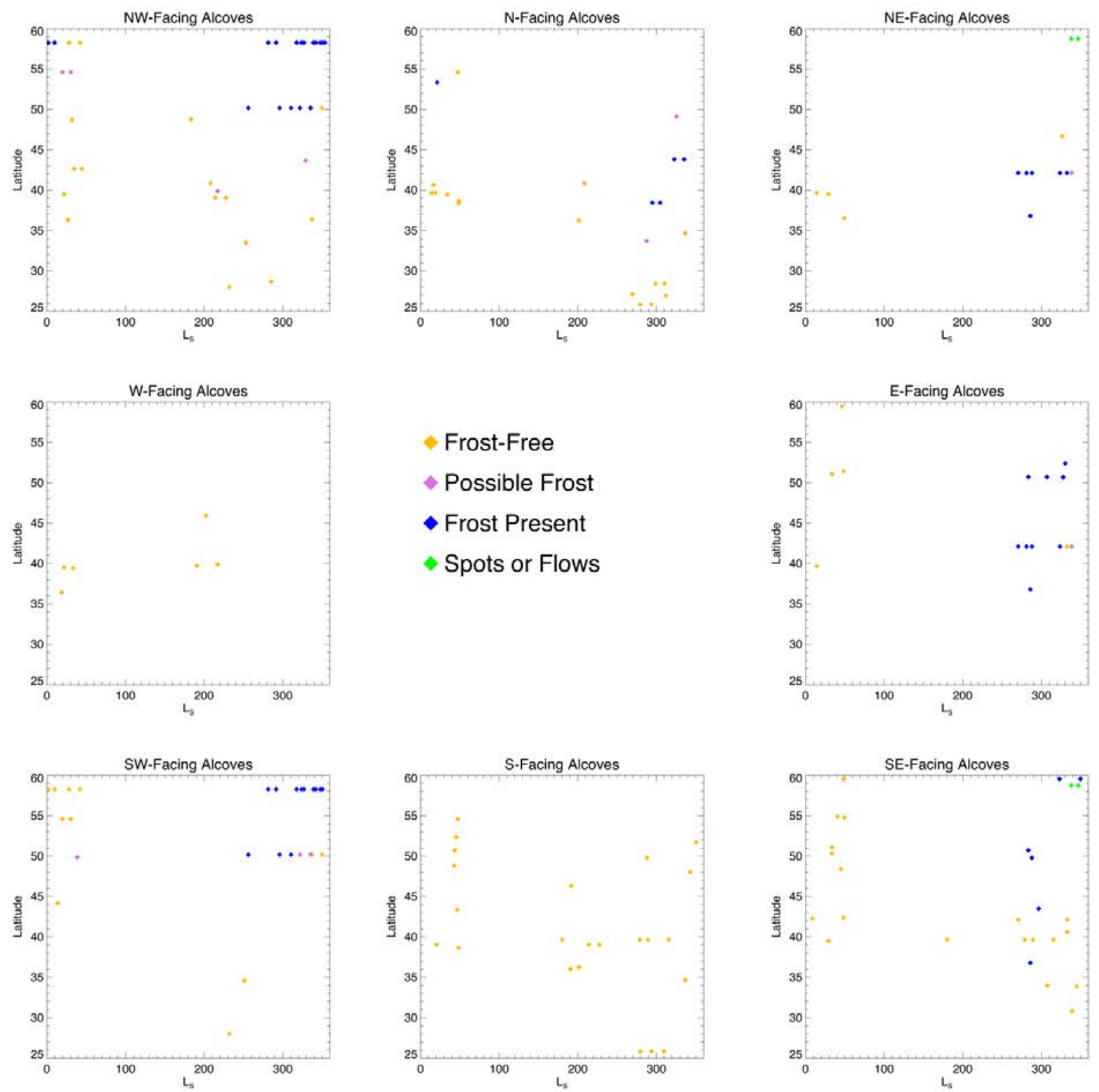

Supplementary Figure 6. Observations of frost within moderately to well-developed 1442 gully alcoves in the northern hemisphere. 
1443 1444 1445 1446 1447 1448 1449 1450 1451 1452 1453 1454

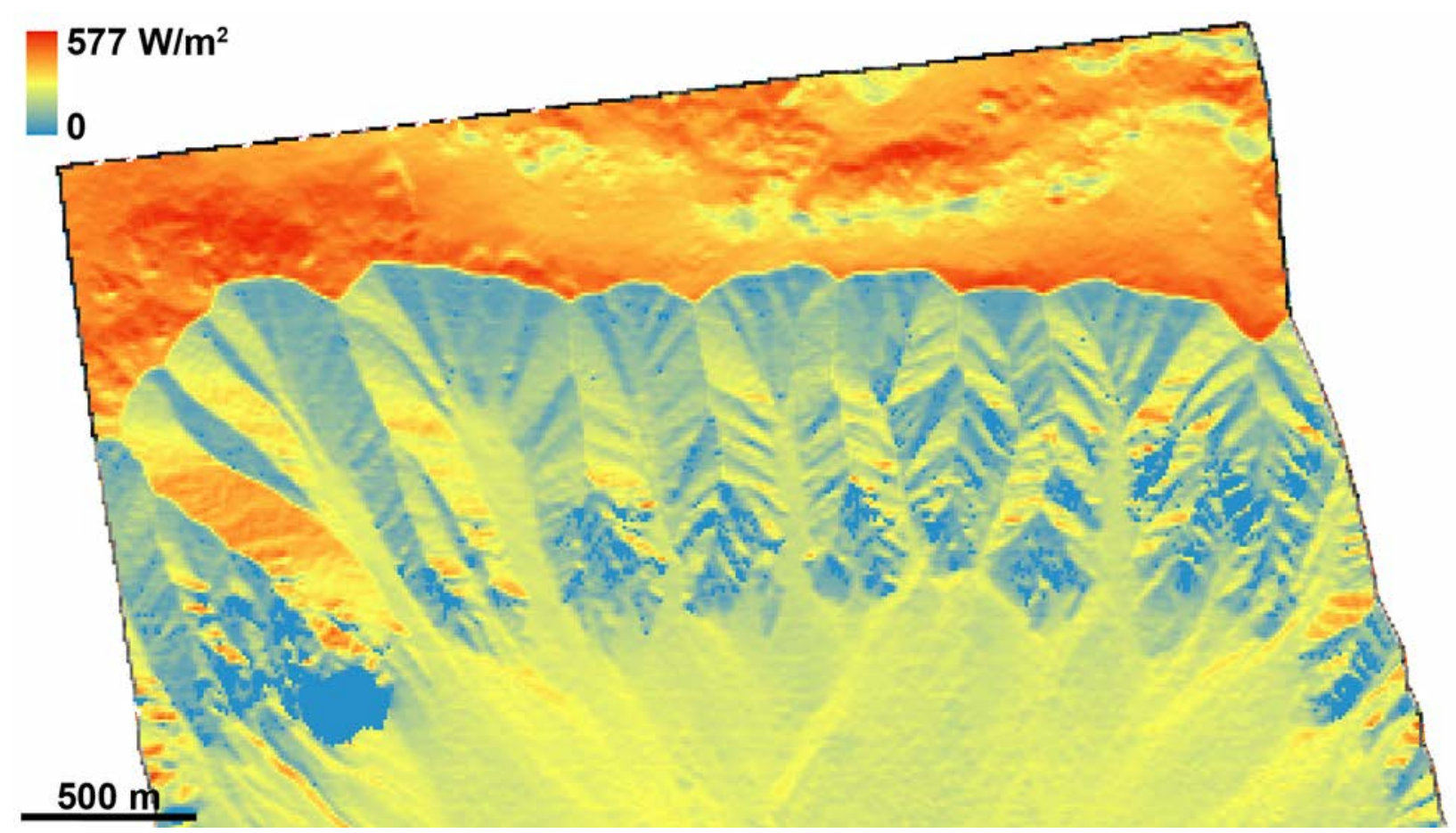

Supplementary Figure 7: Modeled insolation in Gasa crater at noon at $\mathrm{L}_{\mathrm{S}}=150^{\circ}$ (late winter, after most activity has concluded), assuming a clear atmosphere. Insolation was modeled based on the slopes and aspects of a DTM resampled to $10 \mathrm{~m} / \mathrm{pix}$. The insolation in even the best-illuminated parts of the gully alcoves is just over $400 \mathrm{~W} / \mathrm{m}^{2}$. This heat input is far below the heat loss for $\mathrm{H}_{2} \mathrm{O}$ ice approaching the melting temperature, so frost or ice cannot melt at the times and places of gully activity. For pure water frost, latent heat loss to sublimation alone exceeds this insolation at temperatures below the melting point (Ingersoll, 1970; Hecht, 2002). Additionally, radiative heat loss at $273 \mathrm{~K}$ is 315 $\mathrm{W} / \mathrm{m}^{2}$, which could be reduced by a factor of $\sim 2$ in these alcoves since roughly half of the sky is blocked by warmer ground, and conductive and convective heat losses also occur. 
1455

1456

1457

1458

1459

1460

1461

1462

1463

1464

1465

1466

1467

1468

1469

1470

1471

1472

1473

1474

1475

1476

1477

1478

1479

1480

1481

1482

1483

1484

1485

1486

1487

1488

1489

1490

\section{Supplementary Animations}

The supplementary animations are time comparisons of selected changes which highlight important morphological effects. Images used in the animations are selected for similar illumination and viewing geometry, but are not orthorectified. (Orthorectified images are not always available, and entail some loss of detail due to resampling.) There is thus typically some distortion between the frames which appears as a stretch or twist of the surface, but the comparisons have been selected to minimize distortion and maximize visibility of the changes.

The animations are provided as separate animated gif files. Descriptions of each animation are below.

Supplementary Animation 1: Gully initiation in Raga crater $\left(48.1^{\circ} \mathrm{S}, 242.5^{\circ} \mathrm{E}\right)$; compare with main text Fig. 8. Two separate events between the images resulted in formation of a well-defined channel following a pre-existing crease in the topography, possibly a degraded or infilled old channel. The images have near-identical illumination (ESP_014011_1315: incidence angle $41.9^{\circ}$, phase angle $43.4^{\circ}$, subsolar azimuth $208.1^{\circ}$; ESP_040239_1315: incidence angle $41.1^{\circ}$, phase angle $40.8^{\circ}$, subsolar azimuth $203.8^{\circ}$ ).

Supplementary Animation 2: Gully changes in Dunkassa crater (37.5 $\left.{ }^{\circ} \mathrm{S}, 222.9^{\circ} \mathrm{E}\right)$. Two separate events between the images resulted in channel abandonment and breakout, forming a new 50-meter channel and terminal deposit. Sinuous curves in the upper channel migrated downhill (arrows indicate outermost point of the bends). The images have near-identical illumination (ESP_013115_1420: incidence angle $41.2^{\circ}$, phase angle $47.1^{\circ}$, subsolar azimuth $183.6^{\circ}$; ESP_039488_1420: incidence angle $42.2^{\circ}$, phase angle $47.6^{\circ}$, subsolar azimuth $183.1^{\circ}$ ).

Supplementary Animation 3: Channel changes in an unnamed crater (compare main text Fig. 13). Note migration of curves by erosion of the outer, downhill part of the curve, and cutoff of one meander by formation of a new channel reach. Substrate is likely sandy, but gullies are largely cut into mantle material. The images have near-identical

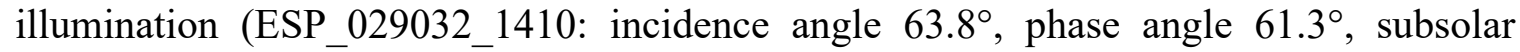
azimuth $200.1^{\circ}$; ESP_046702_1410: incidence angle $61.2^{\circ}$, phase angle $58.6^{\circ}$, subsolar azimuth $201.8^{\circ}$ ). 
1491

1492

1493

1494

1495

1496

1497

1498

1499

1500

1501

1502

1503

1504

1505

1506

1507

1508

1509

1510

1511

1512

1513

1514

1515

1516

1517

1518

1519

\section{Supplementary Tables}

Supplementary Table 1 summarizes information about known gully changes on Mars. As noted in the main text, some changes are likely missed because of poor image conditions or poor match in lighting and/or geometry; therefore, this is a lower bound on gully activity in existing data. Only definite changes are reported here; additional possible and probable changes have been observed but are considered unconfirmed for various reasons. Typically, this is because either the quality of the comparison data is poor (e.g., shadows over the gullies), the comparison images are a poor match (very different illumination or spacecraft geometry), or because the effects of the change are subtle. These factors can trade off against each other-subtle changes may be considered confirmed if there is an extremely good match in lighting and viewing angles. It is likely that these candidate changes will eventually be tested, and some confirmed, by acquisition of additional data. In some cases where multiple changes occurred, only the most prominent are enumerated, as it is not practical to give all the details of assorted minor changes.

Most of the changes recorded here were first observed in this project or predecessor work (Dundas et al., 2010; 2012; 2015; Diniega et al., 2010). To our knowledge, the first definite observation of gully changes on Mars was in a Mars Orbiter Camera captioned image release by Malin and Edgett (2005; http://www.msss.com/mars_images/moc/2005/09/20/dunegullies/), showing a new dune gully in Matara crater. Some additional detections were reported in refereed publications by Malin et al. (2006). A few candidate changes were suggested for HiRISE imaging by the Mars Reconnaissance Orbiter Context Camera team after being observed in their data; we thank them for calling them to our attention. Sara Martinez-Alonso and Virginia Gulick noted individual sites. Raack et al. (2015) discussed the activity in gullies at one south polar pit site in more detail than possible here.

Supplementary Tables 1 and 2 are provided as separate CSV files. Supplementary Table 1 summarizes the following information for non-dune gullies (note that this includes gullies found in sandy material on non-dune steep slopes):

\section{Field Comment/Explanation}

\begin{tabular}{|l|l|}
\hline Site name & $\begin{array}{l}\text { Geographic location and identifier number. Numbers index } \\
\text { monitoring sites and therefore are non-sequential in this listing of } \\
\text { active sites. }\end{array}$ \\
\hline Latitude & Planetocentric \\
\hline Longitude & East \\
\hline Gully type & $\begin{array}{l}\text { ACA indicates gullies with the classic alcove-channel-apron } \\
\text { morphology. "Linear" gullies are generally sand-substrate gullies } \\
\text { with small alcoves and long channels with little or no terminal } \\
\text { deposit. "Channels" indicates gullies with minimal alcoves and } \\
\text { aprons, but morphologically distinct from linear gullies. }\end{array}$ \\
\hline Substrate & $\begin{array}{l}\text { Non-sand, sand, light/rippled, or mixed. "Sand" refers to dark sand. } \\
\text { "Light/rippled" refers to light-toned materials with ripples, } \\
\text { suggesting aeolian modification, but lacking the dark blue color of } \\
\text { active sand dunes on Mars (cf. Bridges et al., 2013). "Mixed" is } \\
\text { used for cases where there is some component of dark sand within } \\
\text { a gully that is mostly in non-sand material. }\end{array}$ \\
\hline
\end{tabular}




\begin{tabular}{|c|c|}
\hline Orientation & $\begin{array}{l}\text { Apparent downhill direction of the main slope. If flows of multiple } \\
\text { orientations are summarized, the orientations are separated by } \\
\text { semicolons. }\end{array}$ \\
\hline Number of flows & $\begin{array}{l}\text { Number of flows described by a given line. In some cases, } \\
\text { individual events at a site have separate lines. In other cases, } \\
\text { multiple similar events are reported together. }\end{array}$ \\
\hline MY - before & Mars year of the last image before the change.* \\
\hline $\mathrm{L}_{\mathrm{S}}$ - before & LS $_{\mathrm{S}}$ of the last image before the change.* \\
\hline MY - after & Mars year of the last image before the change.* \\
\hline $\mathrm{L}_{\mathrm{S}}-\mathrm{after}$ & Ls $_{\mathrm{S}}$ of the last image before the change. ${ }^{*}$ \\
\hline Bright? & $\begin{array}{l}Y \text { if deposit is notably brighter than adjacent material in HiRISE } \\
\text { red CCD, } N \text { otherwise. }\end{array}$ \\
\hline Dark? & $\begin{array}{l}\text { Y if deposit is notably darker than adjacent material in HiRISE red } \\
\text { CCD, N otherwise. }\end{array}$ \\
\hline Color? & $\begin{array}{l}\text { States color if deposit is distinct in HiRISE color relative to } \\
\text { adjacent material, } N \text { otherwise. } U \text { if there is no HiRISE color } \\
\text { coverage. Colors are relative and based on color products with the } \\
\text { near-IR/Red/Blue-green (IRB) filters assigned to red/green/blue } \\
\text { channels, not true color. }\end{array}$ \\
\hline Shadow-only? & $\begin{array}{l}\text { Used for flows that appear distinct in a shadowed winter image, but } \\
\text { are not visible when well-illuminated. Requires an "after" image } \\
\text { with comparable shadows that does not show the flow in question. }\end{array}$ \\
\hline Channel changes? & $\begin{array}{l}Y \text { if there are visible changes in morphology along the channel for } \\
\text { any of the flows, including brightness changes, deposition, and/or } \\
\text { topographic changes of uncertain character. Includes cases of } \\
\text { definite channel incision (next field). } \dagger\end{array}$ \\
\hline Channel incision? & $\begin{array}{l}\text { Y if there is channel widening, deepening, extension, or formation } \\
\text { of new channel segments, } \mathrm{N} \text { otherwise. } \dagger\end{array}$ \\
\hline Thick deposit? & $\begin{array}{l}Y \text { if there is a (near-)terminal deposit with visible thickness and } \\
\text { topographic effects, } N \text { otherwise. } \dagger\end{array}$ \\
\hline Notes & $\begin{array}{l}\text { Description of the changes, as needed. Coordinates of the form } \\
\text { IMAGE_ID: X; Y give approximate locations of features of interest } \\
\text { in HiRISE images. (These are from the red-filter RDR data product } \\
\text { unless otherwise noted. They are typically chosen for good } \\
\text { visibility of one of the more obvious parts of the change and are } \\
\text { not necessarily the images that provide time constraints.) X and Y } \\
\text { are pixel coordinates with the origin at upper left, with X } \\
\text { increasing to the right and Y increasing downwards, as output by } \\
\text { the HiView image viewer (http://www.uahirise.org/hiview/). }\end{array}$ \\
\hline
\end{tabular}

1520

1521

1522

1523

1524

1525

1526
*Image intervals are conservative. In some cases there are intervening images, but we were not confident that it was possible to determine whether or not the change had occurred in the image, typically because of poor lighting or seasonal frost cover.

$\dagger$ Fields relating to topographic changes are $\mathrm{U}$ (uncertain) if there is no HiRISE image before the event or an observation is marginal. They are L (Likely) if the images suggest changes but the resolution/lighting match/scale of the changes is such that they are not considered definite. Flows with no evidence for topographic change are marked N, but 
1527 some of these may have changes that are not detectable in existing data. (For instance, 1528 topography is difficult to see in high-Sun images.)

1529

1530

1531

1532

1533

1534

1535

1536

1537
Supplementary Table 2 provides locations and brief descriptions of known active dune gullies. Reiss et al. (2010) reported activity in the Russell crater linear gullies, and Pasquon et al. (2016) documented activity at several linear gully sites. Due to the large number of changes found in many dune gullies, the individual events are not listed separately. Changes in minor alcove-apron features without defined channels occur on many dunes but are not included here. 

Current results and future plans. Aeolian Research, 9, 133-151, doi:10.1016/j.aeolia.2013.02.004. .

Diniega, S., Byrne, S., Bridges, N.T., Dundas, C.M., McEwen, A.S., 2010. Seasonality of present-day Martian dune-gully activity. Geology, 38, 1047-1050, doi: 10.1130/G31287.1.

Dundas, C.M., McEwen, A.S., Diniega, S., Byrne, S., Martinez-Alonso, S., 2010. New and recent gully activity on Mars as seen by HiRISE. Geophys. Res. Lett., 37, L07202, doi: 10.1029/2009GL041351.

Dundas, C.M., Diniega, S., Hansen, C.J., Byrne, S., McEwen, A.S., 2012. Seasonal activity and morphological changes in Martian gullies. Icarus, 220, 124-143, doi:10.1016/j.icarus.2012.04.005.

Dundas, C.M., Diniega, S., McEwen, A.S., 2015. Long-term monitoring of Martian gully formation and evolution with MRO/HiRISE. Icarus, 251, 244-263, doi:10.1016/j.icarus.2014.05.013. .

Hecht, M. H., 2002. Metastability of liquid water on Mars. Icarus, 156, 373-386, doi:10.1006/icar.2001.6794.

Ingersoll, A. P., 1970. Mars: Occurrence of liquid water. Science, 168, 972-973.

Landis, G.A., and the MER Athena Science Team, 2007. Observation of frost at the equator of Mars by the Opportunity rover. Lunar Planet. Sci. Conf. XXXVIII, abstract \#2423.

Malin, M.C., Edgett, K.S., Posiolova, L.V., McColley, S.M., Dobrea, E.Z.N., 2006. Present-day impact cratering rate and contemporary gully activity on Mars. Science, 314, 1573-1577, doi: 10.1126/science.1135156.

Pasquon, K., Gargani, J., Massé, M., Conway, S. J., 2016. Present-day formation and seasonal evolution of linear dune gullies on Mars. Icarus, 274, 195-210, doi:10.1016/j.icarus.2016.03.024.

Piqueux, S., Kleinböhl, A., Hayne, P. O., Heavens, N. G., Kass, D. M., McCleese, D. J., Schofield, J. T., Shirley, J. H., 2016. Discovery of a widespread low-latitude diurnal $\mathrm{CO}_{2}$ frost cycle on Mars. J. Geophys. Res. Planets, 121, doi:10.1002/2016JE005034.

Raack, J., Reiss, D., Appéré, T., Vincendon, M., Ruesch, O., Hiesinger, H., 2015. Present-day seasonal gully activity in a south polar pit (Sisyphi Cavi) on Mars. Icarus, 251, doi:10.1016/j.icarus.2014.03.040.

Reiss, D., Erkeling, G., Bauch, K.E., Hiesinger, H., 2010. Evidence for present day gully activity on the Russell crater dune field, Mars. Geophys. Res. Lett., 37, L06203, doi: 10.1029/2009GL042192.

Vincendon, M., Forget, F., Mustard, J., 2010a. Water ice at low to midlatitudes on Mars. J. Geophys. Res. 115, E10001, doi: 10.1029/2010JE003584. 